\title{
THE SOUND PROPAGATION CONDITIONS IN THE BLACK SEA
}

YAVUZ ERGENGIL 


$$
\begin{aligned}
& \text { IIBRARI POSTERAUAT } 93940 \\
& \text { NONTERY. }
\end{aligned}
$$




$$
=4-46 x+7^{2}
$$






\section{United Stites \\ Nava! Postgraduate School

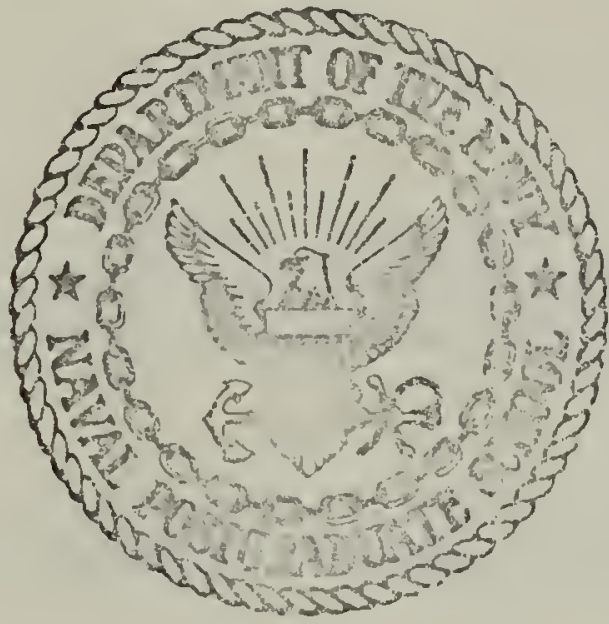 \\ LIBRARY STGRADUATE SCHOOL NAVAL POST CALIF. 93940 MONIEREY, CALII

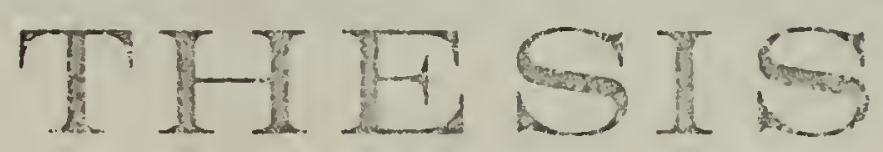

THE SOUND DROPAGATION CONDITIONS

IN THE BIACK SEA

by

Yavuz Ergengil

Thesis Advisor:

W. D. Denner

September 1971

This documert has been sporoved for public reiease and sale; its distribution is urilimited. 

The Sound Propagation Conditions in the Black sea

$$
\text { by }
$$

\author{
Yavuz Ergengi. I \\ Lieutenant," Turkish Navy \\ B.S., United States Naval Postgraduate School, 1970
}

Submitted in partial fulfillment of the requirements for the degree of

MASTER OF SCIENCE IN OCEANOGRAPHY

\author{
from the \\ NAVAI POSTGRADUATE SCHOCL \\ September 1971
}




$$
E=668
$$

c. 1 


\section{ABSTRACT}

The sound propagation conditions in the central part of the Black Sea were investigated. Profiles of temperature and salinity were generated by averaging data from the U.S. National Oceanographic Data Center over monthly periods. Wilson's equation was used to compute sound velocities and a digital computer program provided plots of sound velocity versus depth and selected ray trace diagrams.

Seasoral temperature, salinity and sound velocity variations are found only in the upper layer of the Black sea. Below $125 \mathrm{~m}$, seasonal variations are insignificant.

A well defined sound channcl exists in the Elack Sea that is caused by a cold intermediate layer. Therefore, a seasonal convergence zone is observed during the months of May, November and December.

Finally, bottom reflectivity was calculated by Rayleigh's formula and surface backscattering strength was calculated according to Schulkin and Shaffer. 
TABLE OF CONTENTS

I. INTRODUCTION -- 9

II. PHYSICAL GEOGRAPHY OF THE BLACK SEA -------- 11

III. HYDROLOGY OF THE BLACK SEA --------------- 15

A. VERTICAL STRUCTURE OF WATER MASSES ------- 15

1. Surface Water -- 15

2. Cold Intermediate Layer Water --_---- 16

3. Mixed Water -_- 17

4. Deep Water (-.- 18

5. Bottom Water -

B. TEMPERATURE DISTRIBUTION -

C. SALINITY DISTRIBUTION

IV. BОTTOM SEDIMENTS --_-

A. COASTAL SEDIMENTS --

1. Pebble Zone --_-n 54

2. Boulder Zone --

3. Gravel zone - 55

4. Sand Zone --_--- 55

B. SHALLCW WATER SEDIMENTS --------------- 56

C. DEEP WATER SEDIMENTS --

V. ACOUSTICAI CHARACTERISTICS -

A. SOUND VELOCITY STRUTTURE -.--

B. BOTTOM REFLECTION - 74

C. DUCT PROPAGATION - 82 
D. SURFACE BACKSCATTERING -

E. RAY DIAGRAMS

VI. CONCLUSION ----------------------------109

APPENDIX A: Computation of Sound Velocity

APPENDIX B: The Computer Program for Computation

of Sound Velocity -

IIST OF REFERENCES -

INITIAL DISTRIBUIION LIST

FORM DD 1473 

LIST OF TABLEE

Table

I. Area of the Black Sea for Sereral Depths _-_-_-- 12

II. Average Monthly Temperature Distribution in the Central Part of the Black Sea

III. Annual Minimum, Maximum and Average Temperature Distribution

IV. Average Monthly Salinity Distribution in the

Central Part of the Black Sea

V. Annual Minimum, Maximum and Average Salinity

Distribution

VI. Average Monthly Sound Velocity Distribution in the Central Part of the Black Sea

VII. Annual Minimum, Maximum and Average Sound

Velocity Distribution

Vi.II. Physical Eroperties of sea Water and Bottom

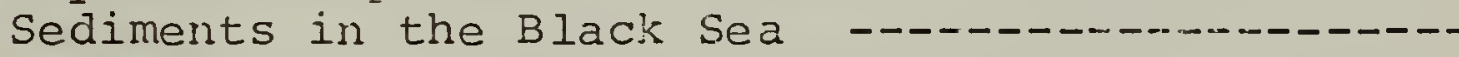

IX. Monthly Reflection Coefficients Distribution in the Central Part of the Black Sea -.---------

x. Monthly Surface Backscattering Parareters in the Central Part of the Black Sea

XI. Monthly Surface Backscattering Strength in the Central Part of tine Black Sea for Cutofi

Frequencies

XII. Monthly Surface Backscattering Strength in the Central Part of the Black Sea for $10 \mathrm{kiz}$

XIII. Monthly Surface Backscattering Strength in the Central Part of the 3 lack Sea for $15 \mathrm{kHz}$

XIV. Monthly Surface Backscattering Strength in the Central Part of the Black. Sea for $20 \mathrm{kHz}$ 


\section{LIST OF FIGURES}

Figure

1. Black Sea -

2. Hypsographic Curve of the Black Sea _-_...-.- 14

3-7. Temperature - Salinity Diagrams for June, July, August, November and December --_-_-_-_----19-23

8. Vertical Distribution of Oxygen and Hydrogen Sulfide at Three July Stations in the Black Sea

9-16. Average Temperature Profiles for February: March, May, June, July, August, November, and December -

17. Annual Minimum, Maximum and Average Temperature Profiles

18. Annual Minimum, Maximum and Average Temperature Profiles for Upper ijo $\mathrm{m}$

19. Salinity Distribution of the Sea surface in the Surnmer (July, August and September)

20-27. Average Salinity Profjles for February, March May, June, July, August, November and December

28. Annual Minimum, Maximum and Average Sainity Profiles

29. Annual Minimum, Maximum and Average Salinity Profiles for Upper $200 \mathrm{~m}$

30. Bottom sediment distribution in the Black Sea -- 58

31-38. Average Sound Velocity Profiles for February, March, May, June, July, August, November and Decemiber

39. Annual Minimum, Maximum and Average Sound Velocity Profiles

40. Annual Minimum, Maximum and Average Sound Velocity Profiles for Upper $200 \mathrm{~m}$ 
41-43. Reflectivity Versus Incident Angle Diagrams for

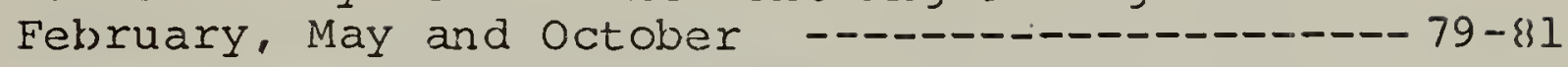

44-50. Surface Backscattering Strength Versus Grazing Angle Diagrams for May, June, July, August, October, November and December

51-58. Ray Diagrams in the Central Part of the Black Sea for February, March, May, June, July, August, November and December 



\section{ACKNOWLEDGENENTS}

The author wishes to express his appreciation for the guidance and assistance given by Professor Warren $W$. Denner and LCDR. Charles H. Bassett of the Naval Postgraduate Schocl. Appreciation is also expressed to LT. Margaret A. Frederick, and other personnel of the Naval Fleet Numerical Weather Central for their cooperation auring the preparation of this thesis. 


\section{INTRODUCTION}

The propagation of scund in the sea water of much of the world's ocean area has been studied for many years. However, until recently certain areas, particularly the smaller adjacent seas have received little attention. Increasing naval operational interest in sound propagation in these adjacent seas now demands that the ground work established by oceanographic investigations be built upon to achieve a level of understanding of sonic conditions in these regions.

The propagation of sound in the sea is dependent on several onvironmontal factors, the most important of witich are the depth and configuration of the bottom, the physical properties of the bottom rnaterial, the sound velocity structure, the distribution and character of sound scatterers and the roughness of the sea surface. The purpose of this thesis is to study sound propagation conditions in the Black Sea using available environmental information.

The temperature and salinity distributions were obtained from the U.S. National Oceanographic Data Center, Washington, D.C. (NODC). NODC has about 1000 hydrocasts from the Black Sea on file coliected between 1924 and 1965. In more recent years the data seasonally incomplete and insufficient to obtain yearly oceanographic features of the Black sea. For this reason, the data collected in 1924 to 1927 surveys was used in this thesis to obtain the sound relocity profiles. The 
temperature and salinity profiles were generated by averaging over monthly periods the data from NoDC. The corresponding sound velocity profiles were obtained using Wilson's equation [19].

The character of the bottom topography and the bottom sediments are the most important environmental fastors which bear on the problem of bottom reflected transmission. Little is known about the bathymetry, the distribution of bottom sediments, and the physical properties of bottom sediments for the Black Sea. However, the available information has been summarized and bottom reflectivity was calculated making several assumptions.

Finally, ray diagrams for several months in the central part of the Black Sea are presented and analyzed in this thesis. These were generated using advanced digital computer ray trace programs from Fleet Numerical Weather Centrai, Monterey, California (FNWW). 


\section{PHYSICAL GEOGRAPHY OF THE BLACK SEA}

The Black Sea (Figure 1) is an almost isolated body of water, bounded by U.S.S.R. on the north and east, by Rumania and Bulgaria on the west, and by Turkey on the south and southwest. It is connected with the Mediterranean Sea through the Bosporus and the Dardanelles, and is about $3000 \mathrm{~km}$ from Gibraltar, the nearest point on the A.tlantic Ocean.

The Black Sea is a relatively uriform deep marine basin, with long coasts, and few islands. In the north, the crimean Peninsula extend far into the basin, and the Peninsulas of Kerch and Taman, extending west-east, separate the sea of Azov, which is connected with the Black Sea only by the narrow Straight of Kerch.

The Black Sea extends between latitudes $46^{\circ} 32^{\prime}$ and $40^{\circ} 55^{\prime}$ North, and Iongitudes $27^{\circ} 27^{\prime}$ to $41^{\circ} 42^{\prime}$ East. T'he greatest length is $1149 \mathrm{~km}$, the width $610 \mathrm{~km} \mathrm{[1].} \mathrm{The} \mathrm{area} \mathrm{and} \mathrm{volume}$ of the Black Sea were calculated by the Institute of Oceanography of the U.S.S.R. in 1965 from the results of extensive bathymetric surveys of the Black Sea. From this data, the surface area of the Black Sea is $420,325 \mathrm{~km}^{2}$, the volume is $547,015 \mathrm{~km}^{3}$, and the average depth is $1301 \mathrm{~m}$ with a maximum depth of $2212 \mathrm{~m}[2]$.

The bathymetric areal averages for the Black Sea are summarized in Table $I$ and as a hypsographic curve in Figure 2. 
TABLE I

AREA OF THE BLACK SEA FOR SEVERAL DEPTHS

\begin{tabular}{r}
\hline Depth (m) \\
\hline $0-100$ \\
$100-200$ \\
$200-500$ \\
$500-1000$ \\
$1000-1500$ \\
$1500-2000$ \\
$2000-2200$ \\
2200 \\
TCTAL
\end{tabular}

\begin{tabular}{c}
\hline Area $\left(\mathrm{km}^{2}\right)$ \\
\hline 101,452 \\
11,400 \\
14,610 \\
21,220 \\
33,480 \\
86,571 \\
135,322 \\
16,270 \\
420,325
\end{tabular}

Area (\%)

24.1

2.7

3.5

5.0

8.0

20.6

32.2

3.9

100.0 



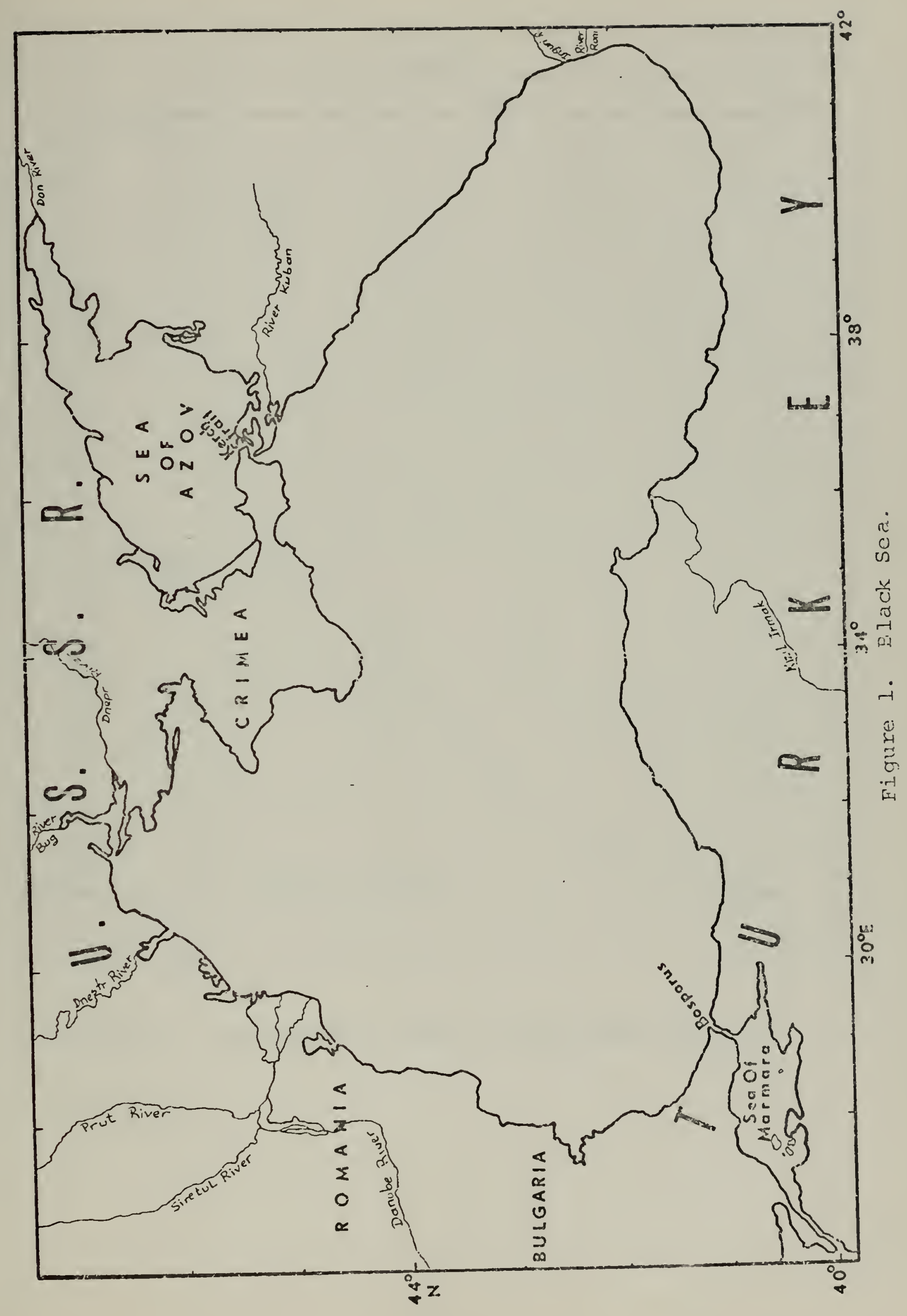





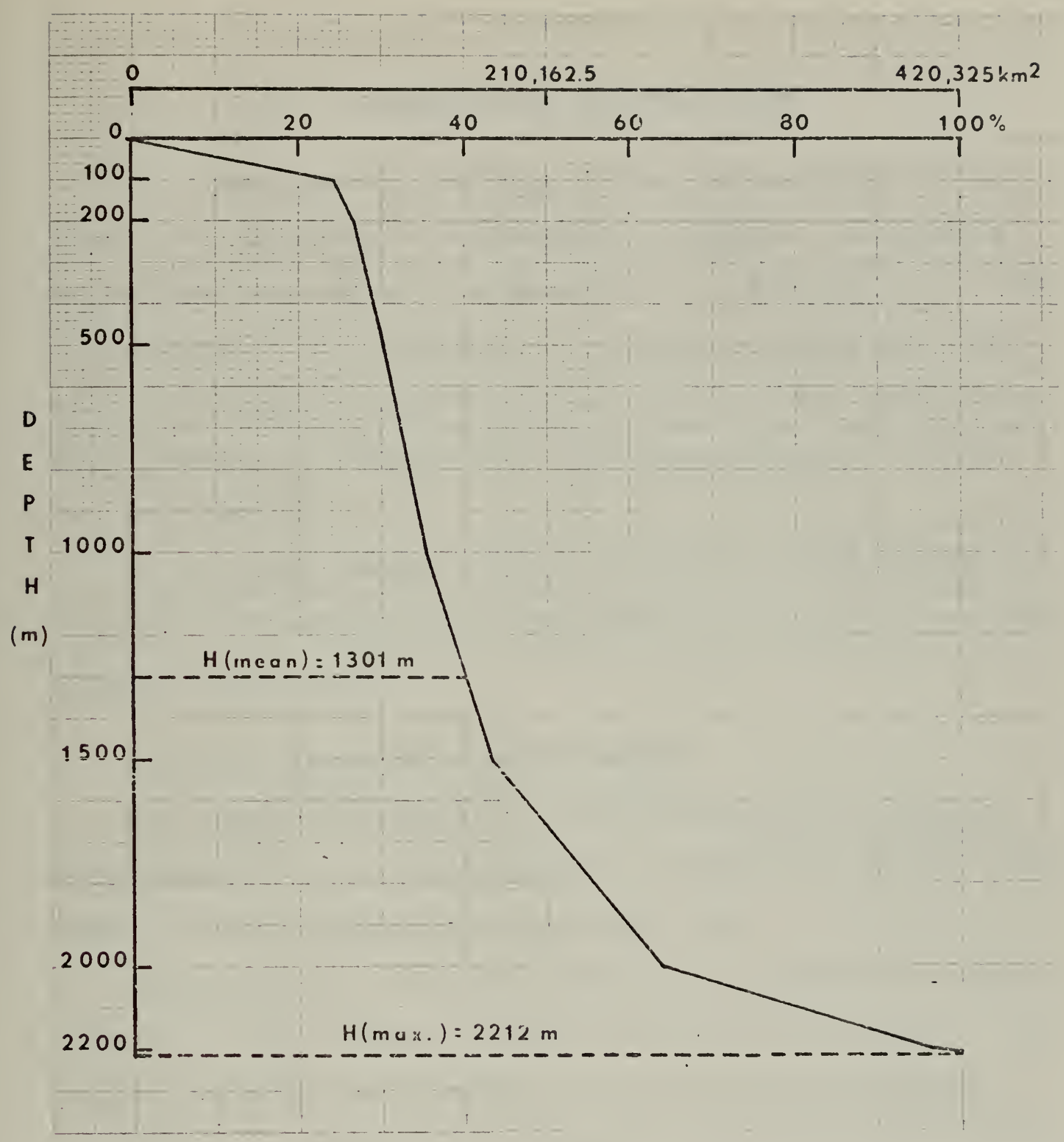

Figure 2. Hypsographic Curve of the Black Sea [2]. 



\section{HYDROLOGY OF RHE BLACK SEA}

The first general knowledge of the oceanographic structure of the Black Sea was obtained by Spindler and Wrangel during the first Black Sea Expediticn in 1890-1891 [3]. Fron the results of this expedition, it was recognized that the Black Sea occupied a special place among all the seas of the world because it was devoid of all higher forms of iife below about $200 \mathrm{~m}$.

In 1923, the Russians began to explore the Black sea in detail with measurements of the chemical, biological and physical characteristics.

\section{A. VERTICAL STRUCTURE OF WATER MASSES}

The temperature-salinity characteristics were analyzed by Novitskiy [4], and he suggested à scheme of vertical structure in the open portion of the Black Sea.

Figures $3,4,5,6$, and 7 are typical temperature-salinity diagrams in the central part of the Black Sea for June, July, August, November and December. The temperature-salinity diagrams were generated by averaging over monthly periods the data from NODC. According to Novitskiy scheme, five different water types exist for the open portion of the Black Sea.

The five water types are:

1. Surface Water

The surface water of the Black Sea extends to 25 to $35 \mathrm{~m}$ in summer season [4], and penetrates to 15 to $80 \mathrm{~m}$ in 

the winter months. From February to March this surface layer. is almost issothermal and its temperature is l.ower than that of the cold intermediate layer. In summer, a very strong thermocline exists, with a minimum temperature at $50 \mathrm{~m}$. Salinity increases slowly from the surface to the depth of the temperature minimum.

Along the coast this water type is often covered by $z$ layer of runoff, and near the Kerch Strait and crimea coast, it is covered with water from the Sea of Azov.

The mean monthly temperature of the Black Sea surface: water varies within a year from $7-8^{\circ} \mathrm{C}$ in winter to $24-25^{\circ} \mathrm{C}$ in summer but the mean monthly salinity varies only from 17.70 to $1.8 .50 \%$

\section{Cold Intermeatate Layer water}

The water of the cold intermediate layer iies under the Black Sea surface water. The lowest summer temperatures of the Black sea are observed in this layer. Generally, the temperature minimum has a value of 6 to $8^{\circ} \mathrm{C}$ at depths of $50-$ $75 \mathrm{~m}$. Taking the upper and lower limits in the summer as the $8^{\circ} \mathrm{C}$ isotherms, its mean thickness is $50-70 \mathrm{~m}$, being thicker along the edge of the sea than in the central regions [5]. During winter, surface temperatures decrease to below the minimum ternperature of the intermediate layer and the upper limit defined by the $8^{\circ} \mathrm{C}$ isotherm is located at $80-90 \mathrm{~m}$ in January. The cold intermediate layer reaches its maximum thickness (120-130 m) in March and minimum thickness during 

December and January months (around $25 \mathrm{~m}$ ). The salinity in this layer iies in the range from 18.5 to $20.0 \%$

According to Kolesnikov [5], the cola intermediate layer in the Black Sea is clearly produced by advection. Kolesnikov's advection hypothesis for the formation of the cold intermediate layer in the Black Sea is as Follows:

"In winter the largest layer of water affected by convection forms in the western half of the sea where there is free penetration of cold air masses from the north and northeast between Crimea and the western shores. The 50-75 $\mathrm{m}$ layer of water that forms here is carried to the south by the prevailing current and then to the east: along to the Anatolia Coast. As they move eastwards, these waters gradually warm from the surface downwards, and are slightly freshened in the uppermost layer as a result of interaction with coastal waters." I

\section{Mixed Water}

Midxed water of the Black sea is fourd between the

lower limit of cold intermediate layer and 300 or $400 \mathrm{~m}$. Among the dynamic factors that cause the formation of mixed water in the Black Sea, the most significant are the convergence of the surface and deep layers in the coastal belt and internal waves [4]. The mixed water is characterized by presence of both oxygen and hydrogen slifide (Figure 8). The temperature increases gradually in the mixed layer. And reaches to $8.8^{\circ} \mathrm{C}-8.9^{\circ} \mathrm{C}$ at a depth of $300 \mathrm{~m}$. Sainity increase in this layer from $21.10-21.50 \%$ in the eastern

1 Filippov, D. M., "The Cold Internediate Layer in the Black Sea," Oceanology, V. 5, No. 4, p. 47-51, 1965. 
Black sea and from $21.60-21.90 \%$ in the western part.

4. Deep Water

The deep water present between the mixed water and bottom water is found at depths of 500-1000 $\mathrm{m}$ in the western part of the sea, but is located at depths of 800-1400 $\mathrm{m}$ in the eastern part of the sea. Inflow of warm, saline water through the Bosporus produces a temperature and salinity increase with depth in the deep water. The temperature of the layer ranges from $8.65^{\circ} \mathrm{C}$ to $8.95^{\circ} \mathrm{C}$, the salinity is about $22.2-22.3^{\circ} / 00$.

\section{Bottom Water}

The bottom water fills all the remaining depressions below the depths of $1000 \mathrm{~m}$ in the west and $1400 \mathrm{~m}$ in the east. The bottom water differs from the overlying layers by virtue of having very small or zero vertical temperature and salinity gradient. At the bottom, the temperature and salinity values range from $8.90-9.10^{\circ} \mathrm{C}$ and $22.39-22.41 \%$ over the deep basin of the Black sea. 


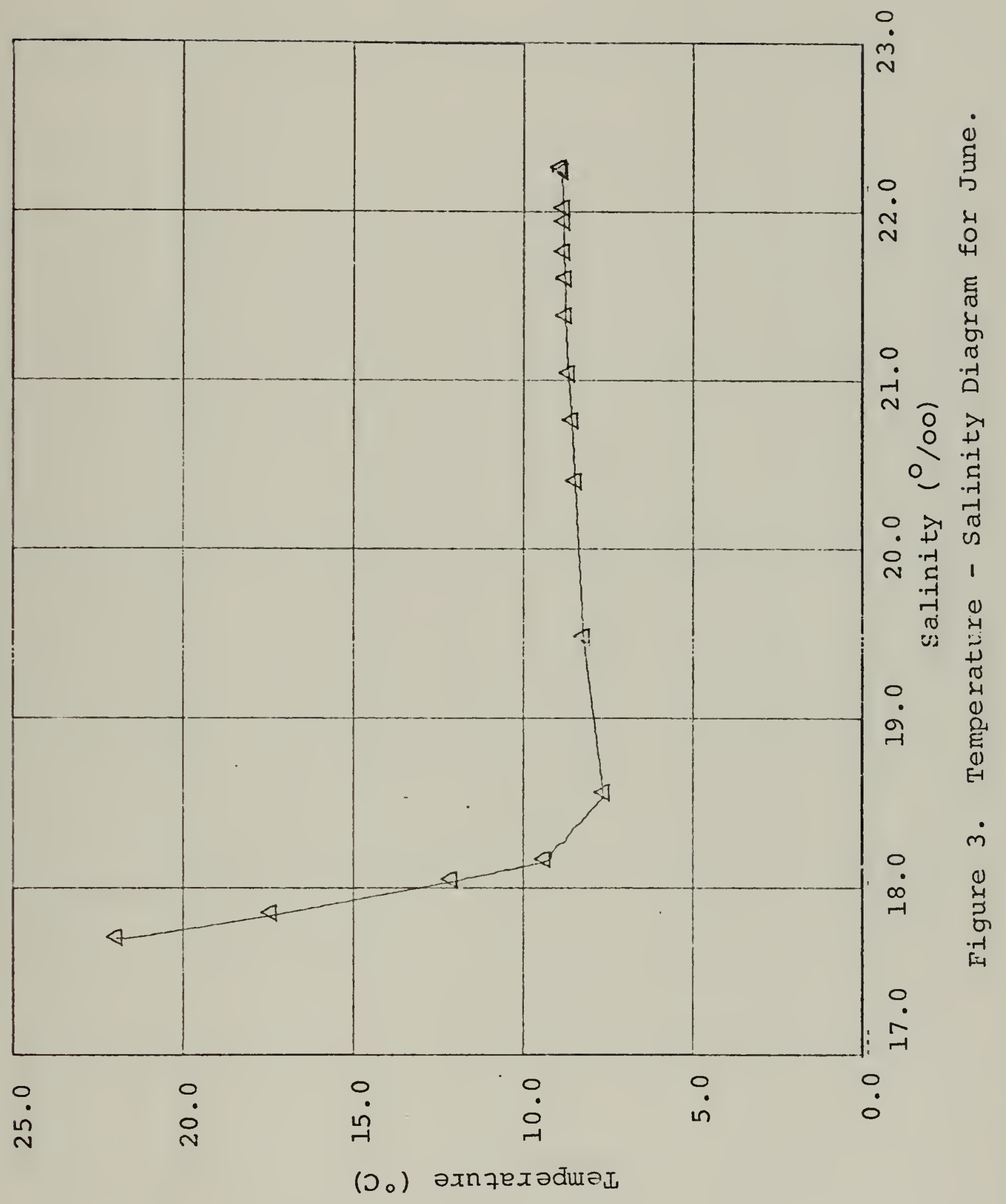





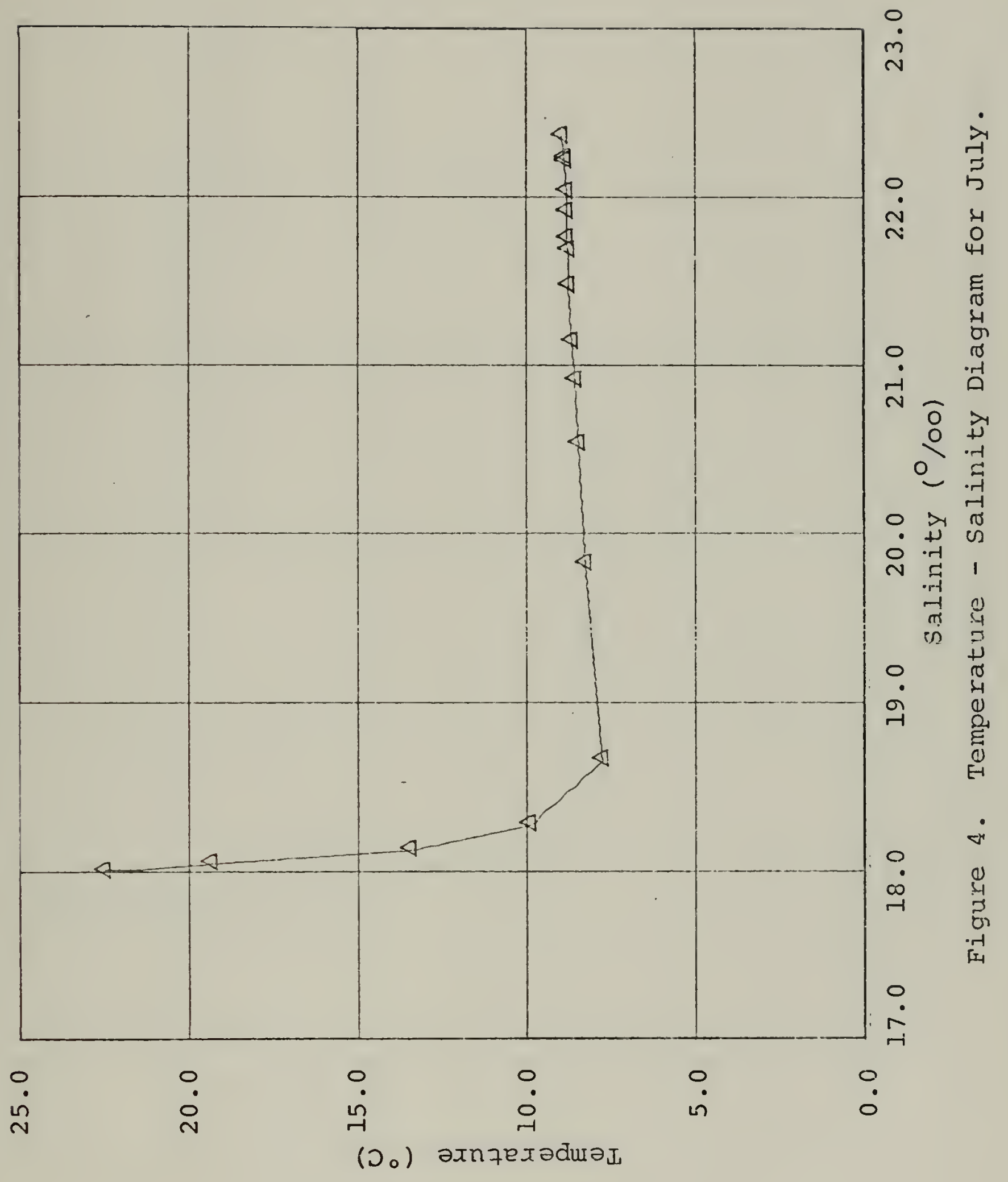





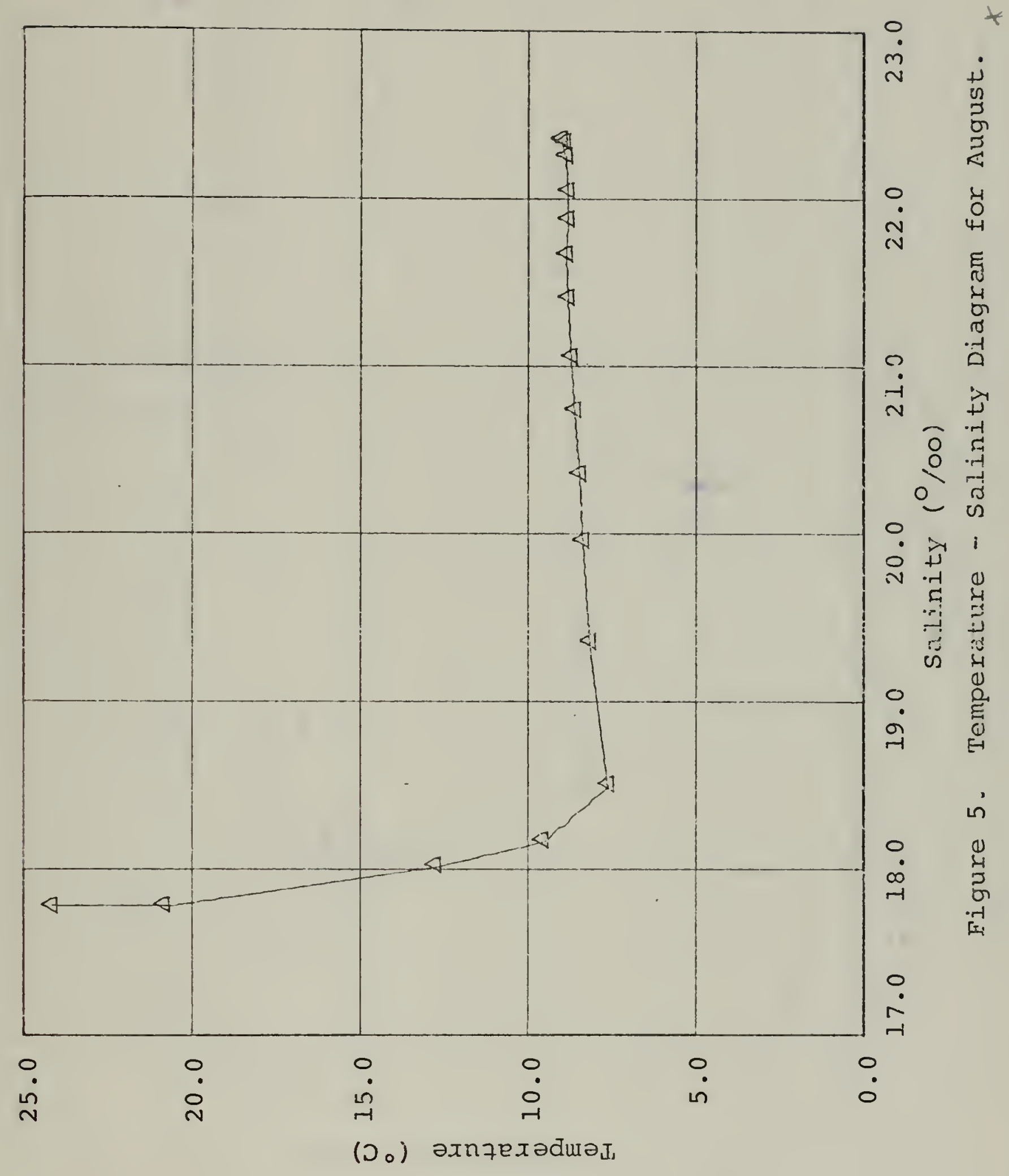




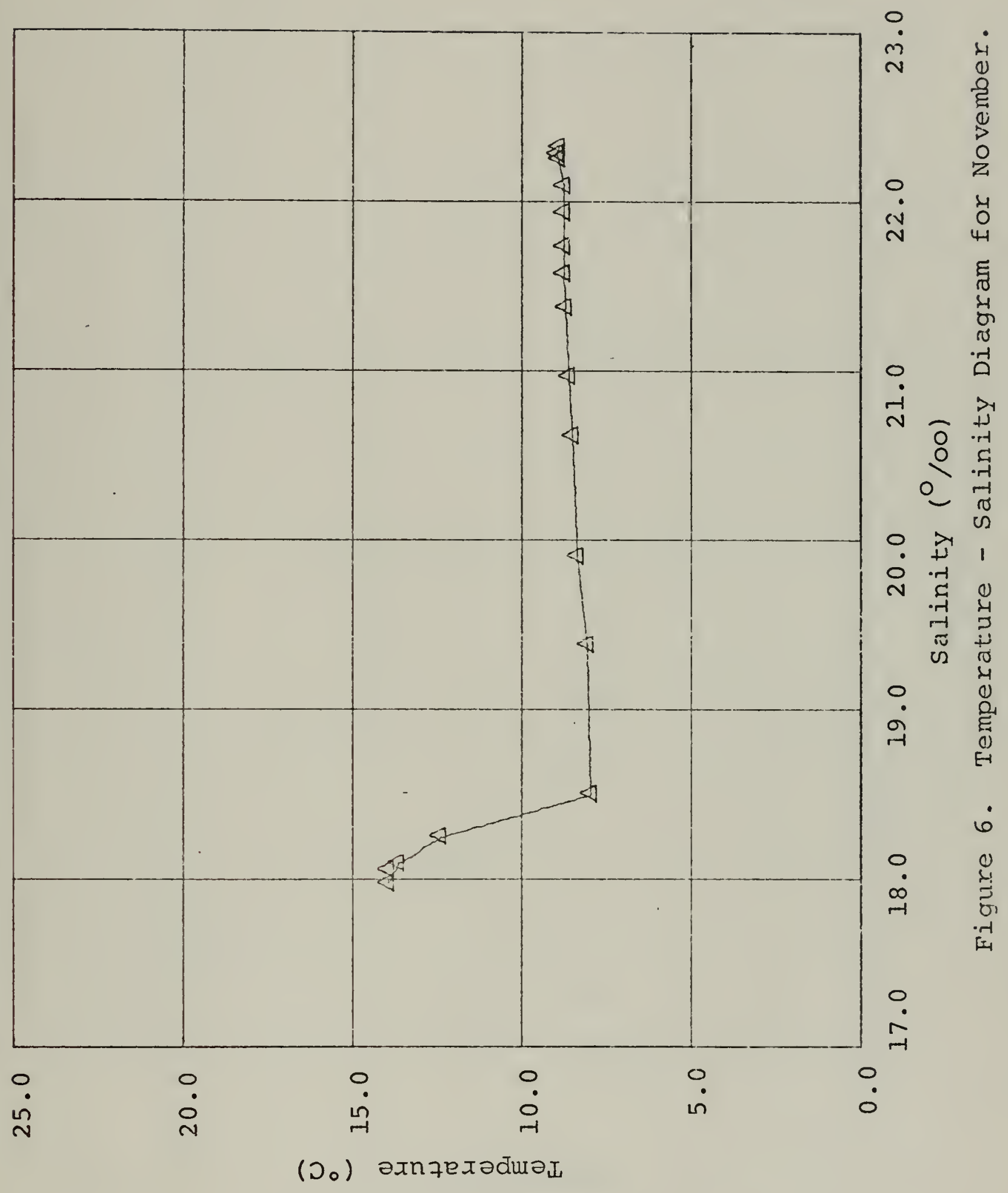




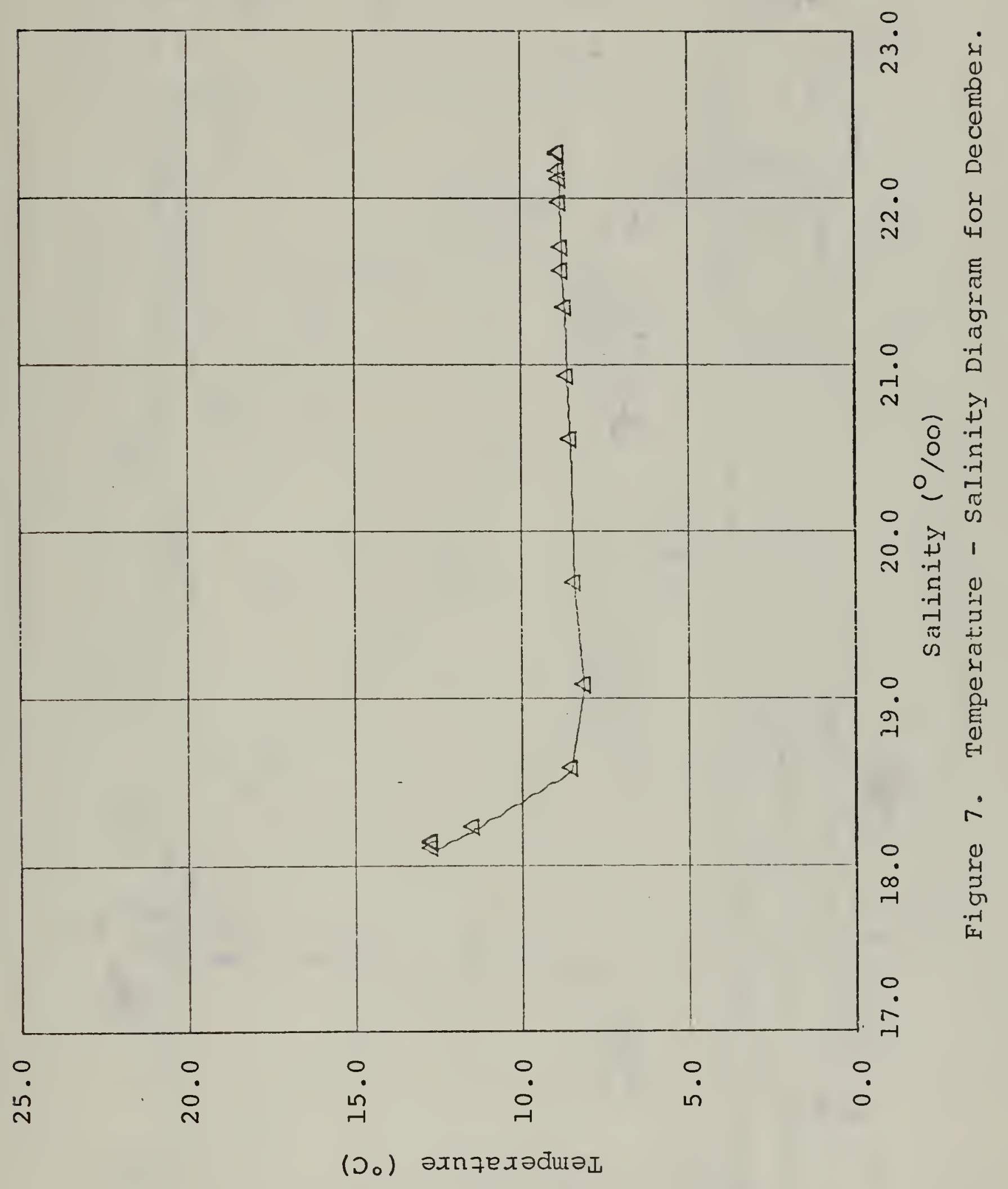





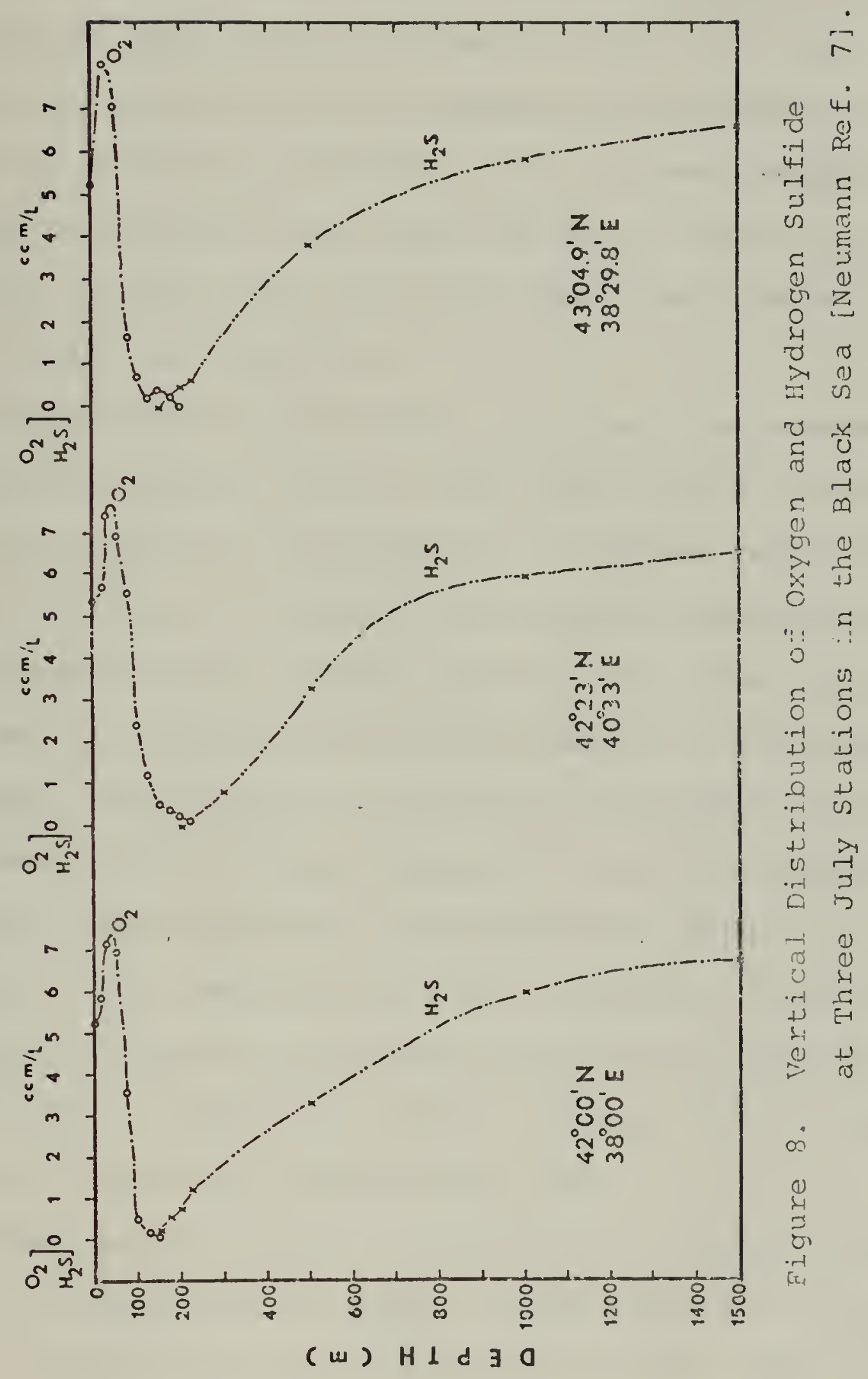


B. TEMPERATURE DISTRIBUTION

The average vertical temperature profiles ir, the central part of the Black Sea for several months are presented in Figures 9 to 16. These monthly average temperature distributions are summarized for selected depths in Table II, and Table III presents minimum, maximum and average temperatures. Figure 17 gives the profiles of the minimum, maximurn and average temperature drawn from the data in Table III. The profiles for the upper $100 \mathrm{~m}$ structure are presented with expanded scale in Figure 18.

In the central part of the Black sea, the average surface temperature changes within a year from $7.10^{\circ} \mathrm{C}$ in winter to $24.17^{\circ} \mathrm{C}$ in summer. The minimum and maximum temperatures always occurring in Fobruary and August respectively. During the period February through August, the surface temperature increases monotonically, and after August, it decreases.

Under the influence of wind and convective rixing which provides surface cooling during the vinter, ar iscthermal layer is formed with the mixed layer depth occurring at $50 \mathrm{~m}$ in February. The temperature of the isothermal layer decreases gradually during the first two months of the year to its minimum $\left(7.10^{\circ} \mathrm{C}\right)$ in February, which is lower than the temperature minimum of the cold intermediate layer.

After the end of the cooling season, surface heating causes a temperature increase to take place in the surface layer, resulting in the formation of a less dense layer. Consequently, a stable stratification and shallow t:ermocline is 


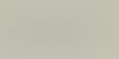


developed (Figure 11). However, this shallow thermocline can be destroyed within a day either by convective mixing or by wind mixing or both.

During the summer, a well defined thermocline occurs in the central part of the Black Sea (Figures 12, 13, and 14) where the temperature may decrease with depth as much as $14-16^{\circ} \mathrm{C}$ in 50 meters.

At the end of the heating season, the surface water cools from the annual maximum $\left(24.17^{\circ} \mathrm{C}\right)$ until it reaches its annual minimum $\left(7.10^{\circ} \mathrm{C}\right)$ in February. As the water cools, the surface isothermal layer thickens, from its annual minimum $(10 \mp 5 \mathrm{~m})$ in August to its maximum $(50 \mathrm{~m})$ in Fecruary. Below the minimum temperature zone $(50-75 \mathrm{~m})$, the temperature increases gradually with depth, reaching $8.90^{\circ} \mathrm{C}$ at a depth of $1000 \mathrm{~m}$, and finally about $9.00^{\circ} \mathrm{C}$ near the Biack sea bottorn. According to Vladimirtsev [6], the reason for the increase in water temperature with depth is related to the constant inflow of warm, saline water through the Bosporus which mixes and sinks to from the bcttom water. 



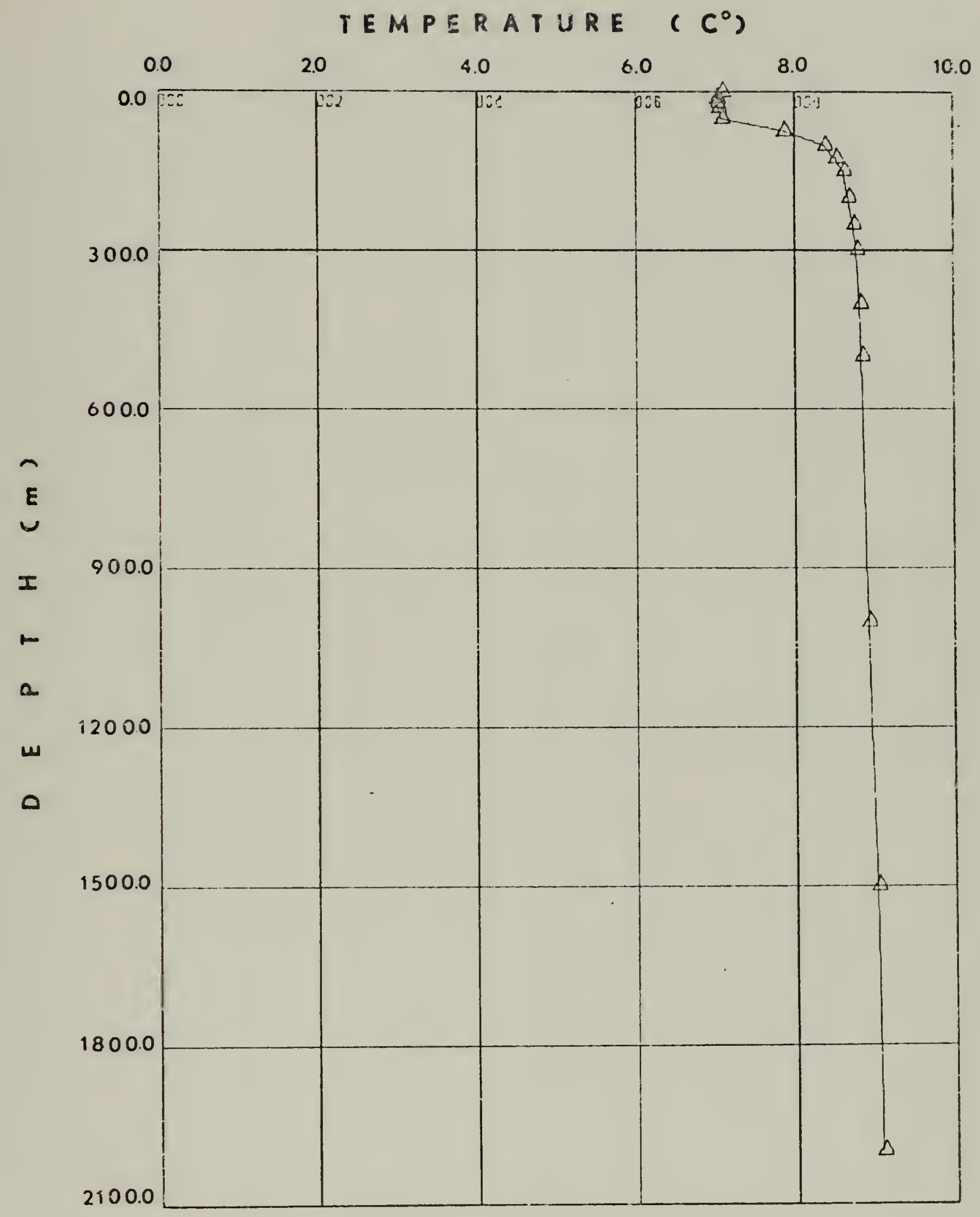

Figure 9. Average Temperature Profile for February. 


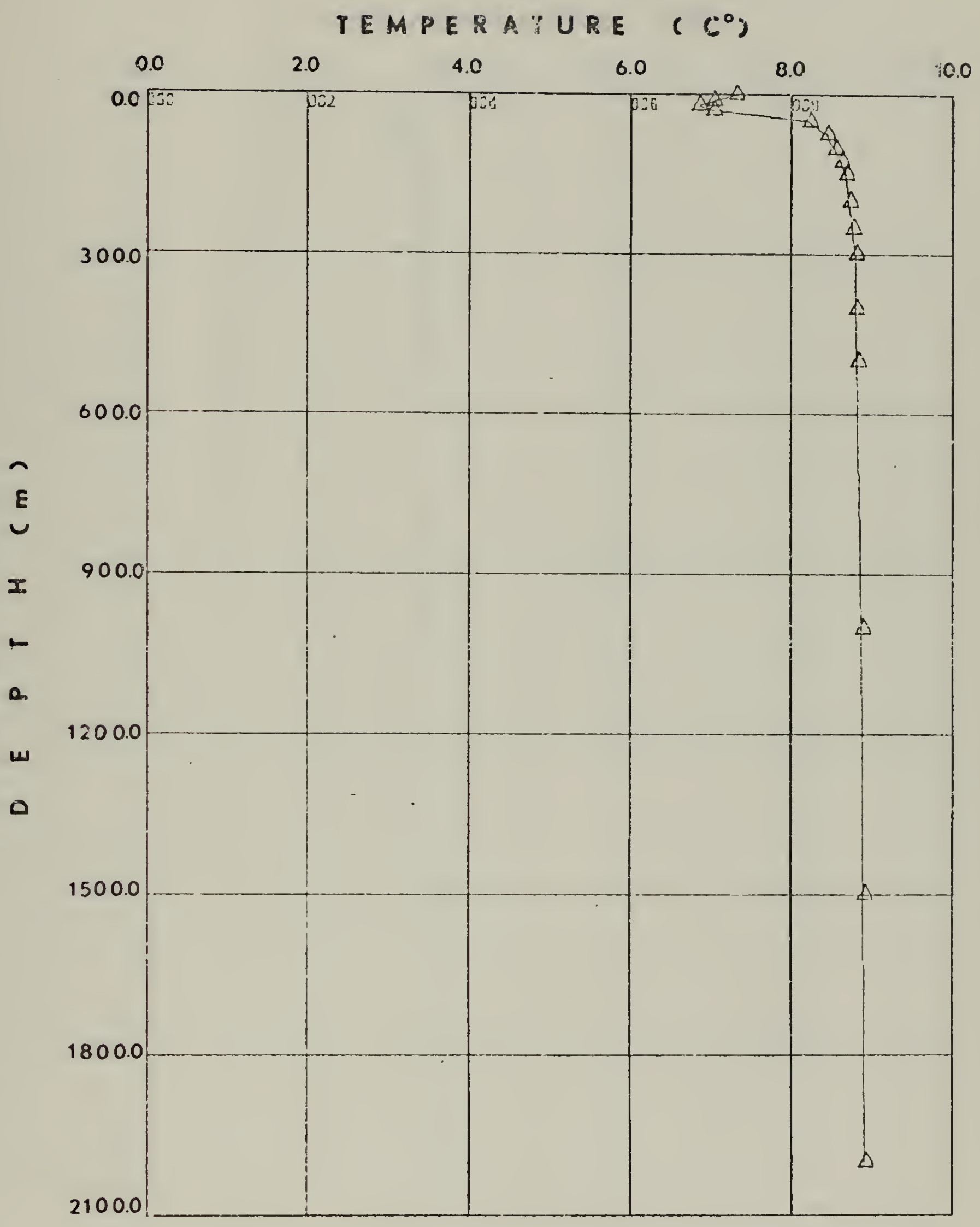

Figure 10. Average Temperature Profile for March 


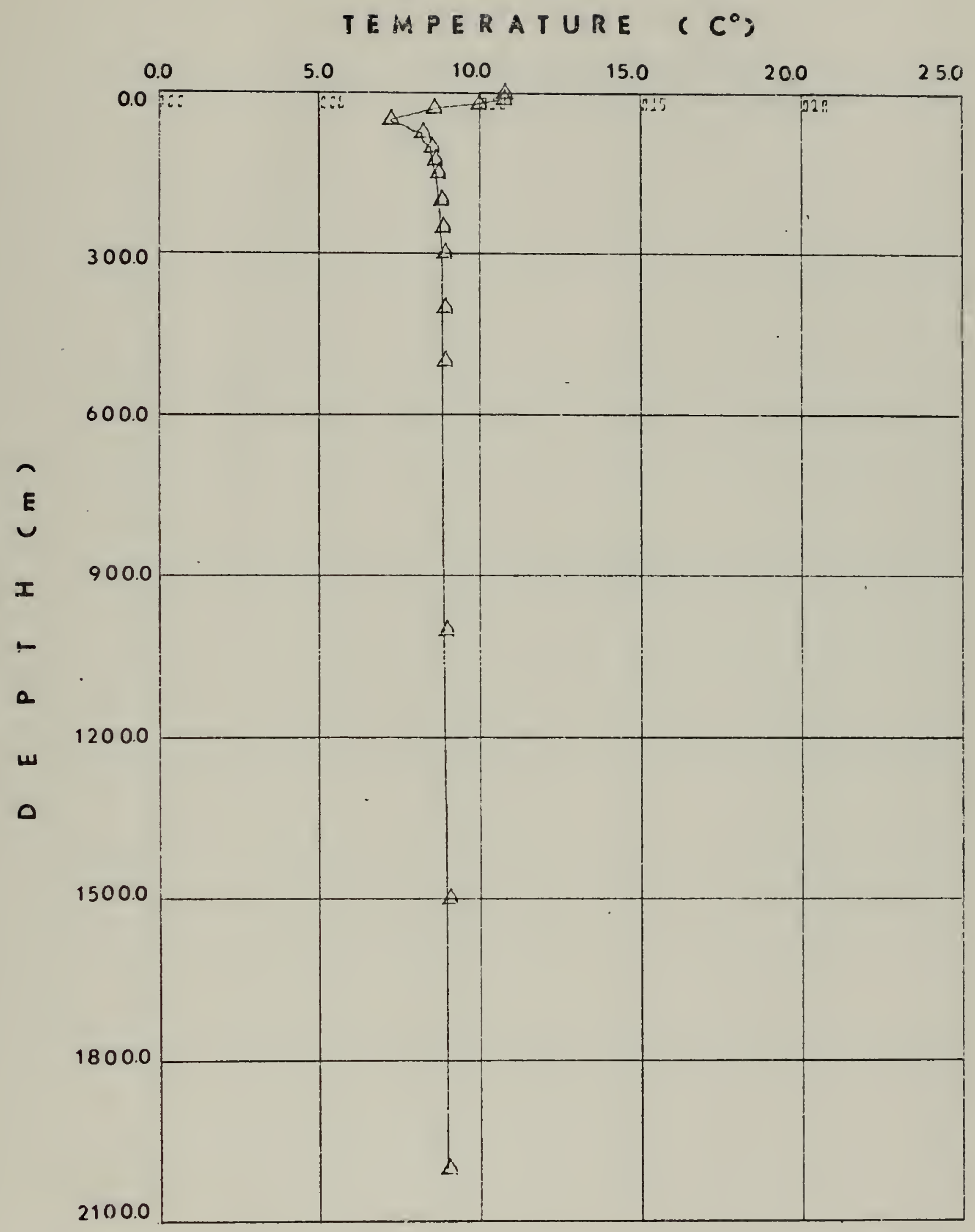

Figure 11. Average Temperature Profile for May. 


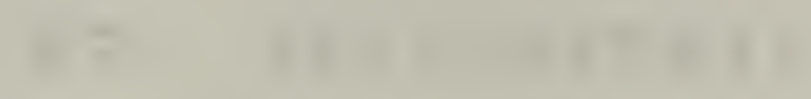




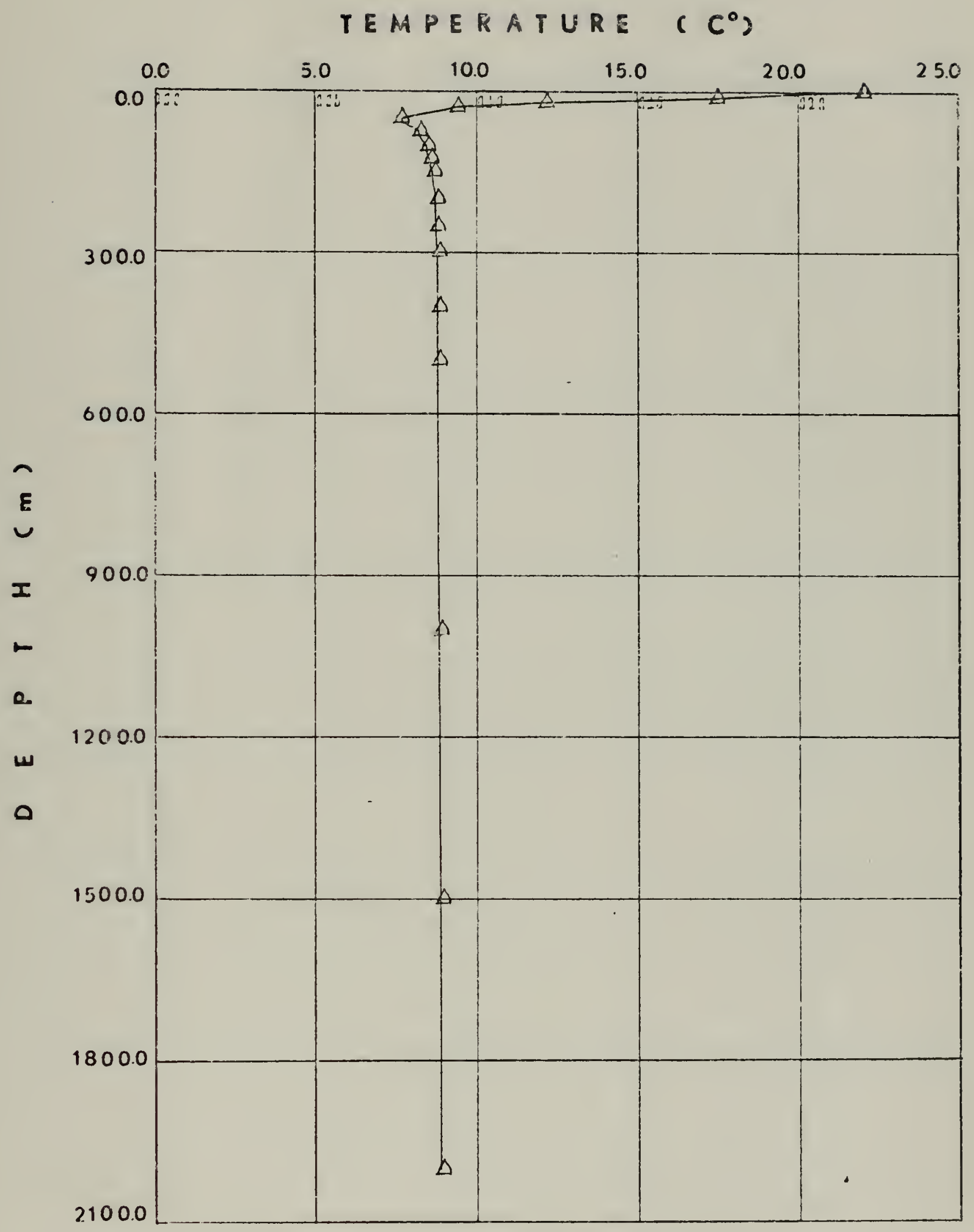

Figure 12. Average Temperature Profile for June. 


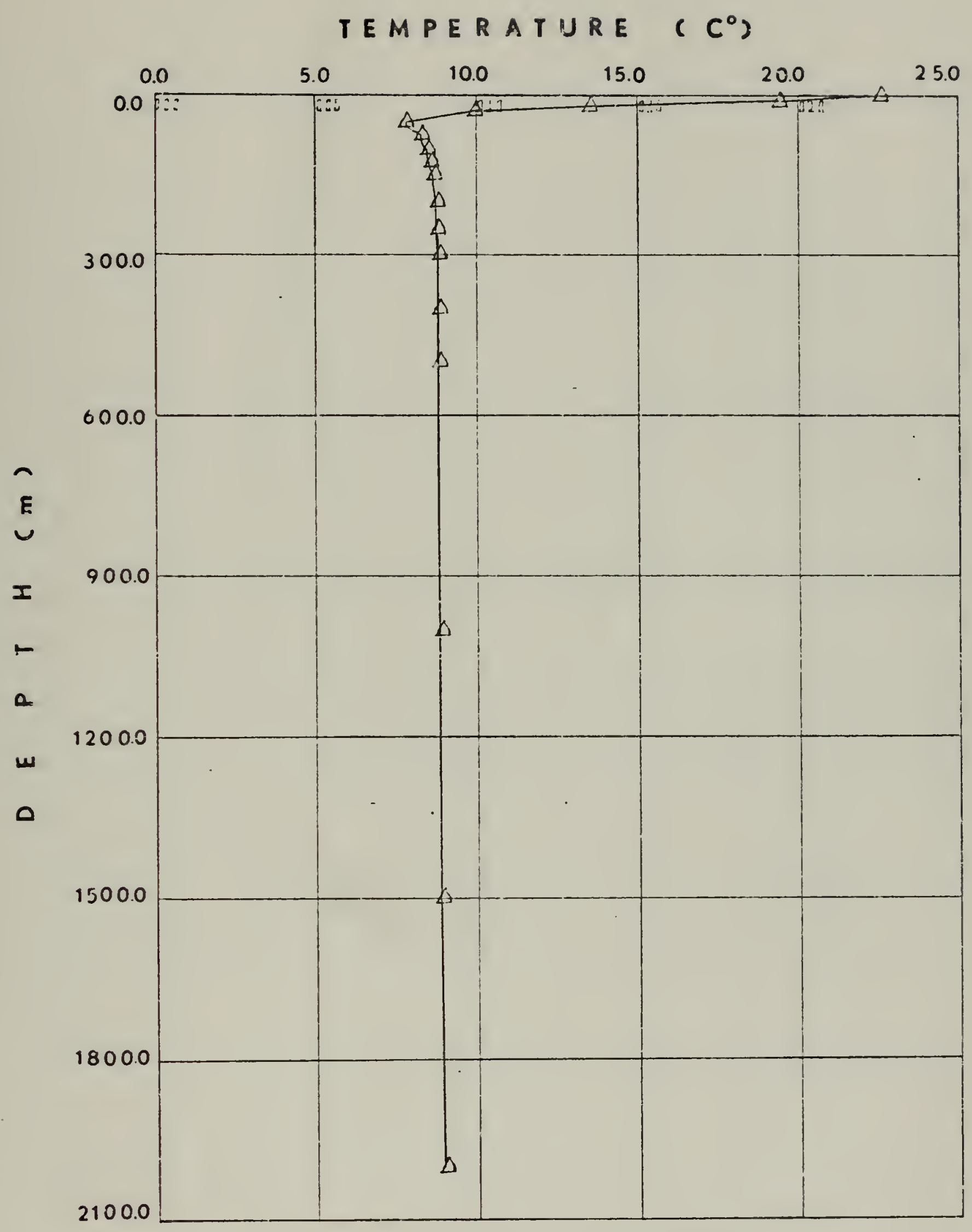

Figure 13. Average Temperature Profile for July. 


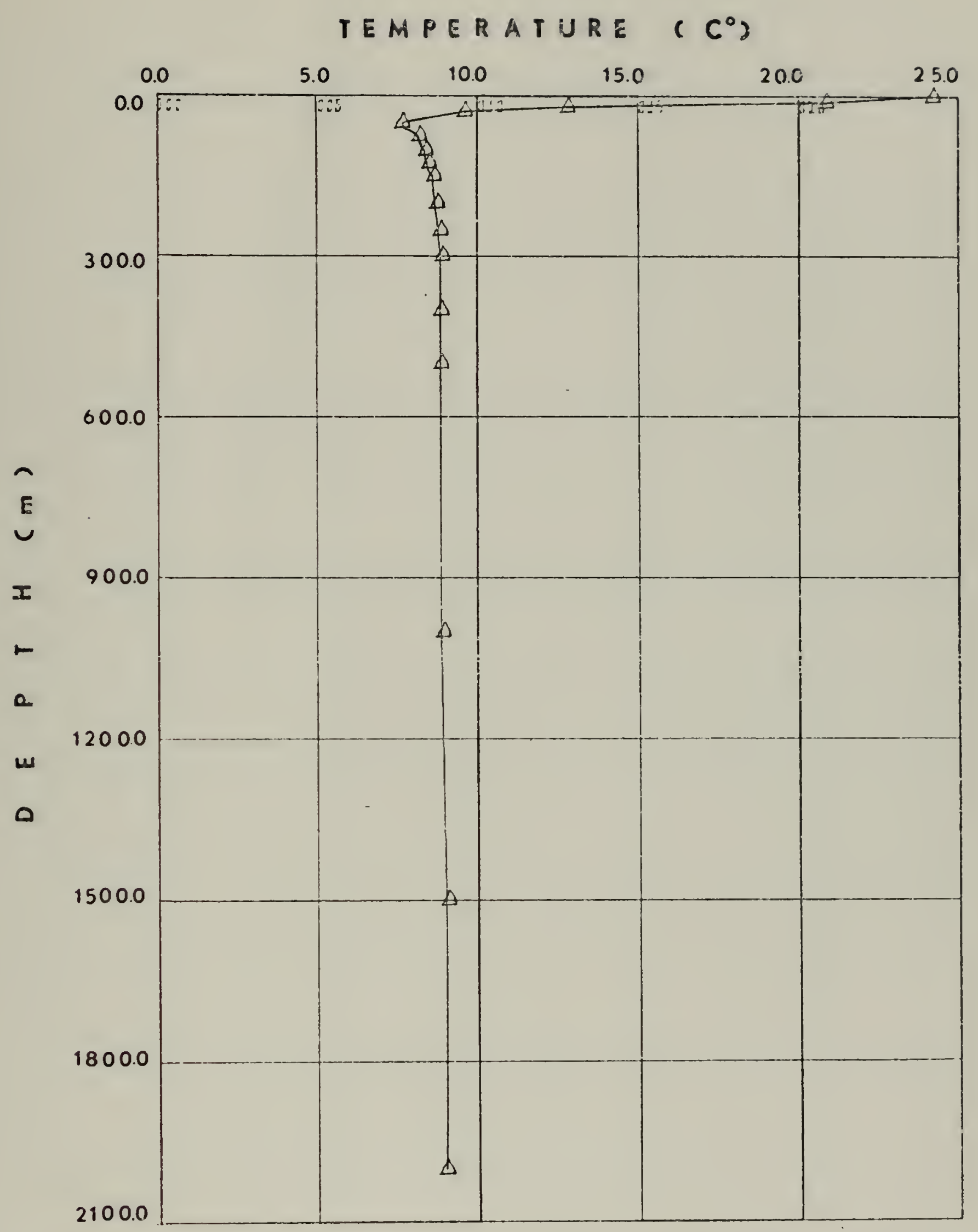

Figure 14. Average Temperature Profile for August. 


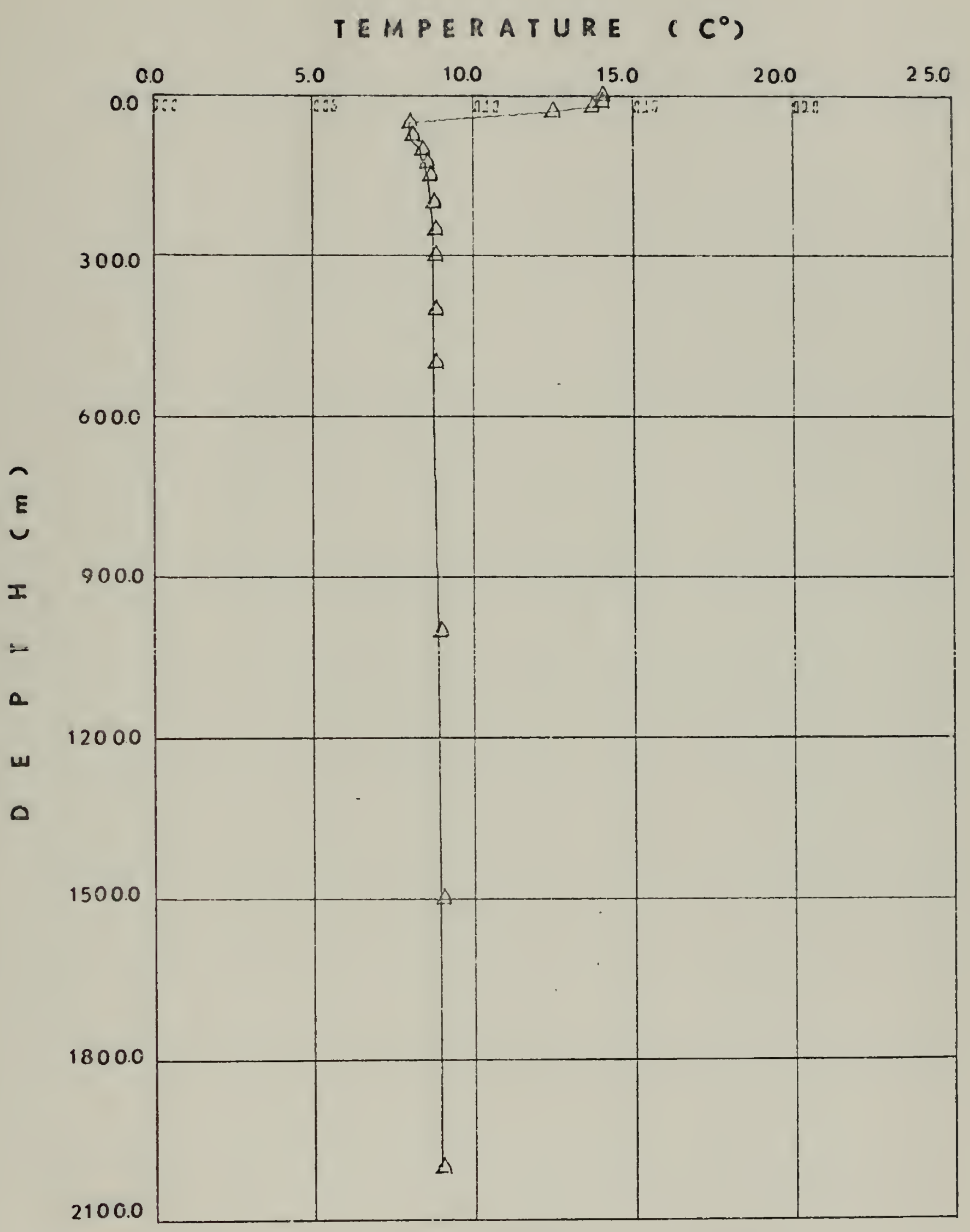

Figure 15. Average Temperature Profile for November. 



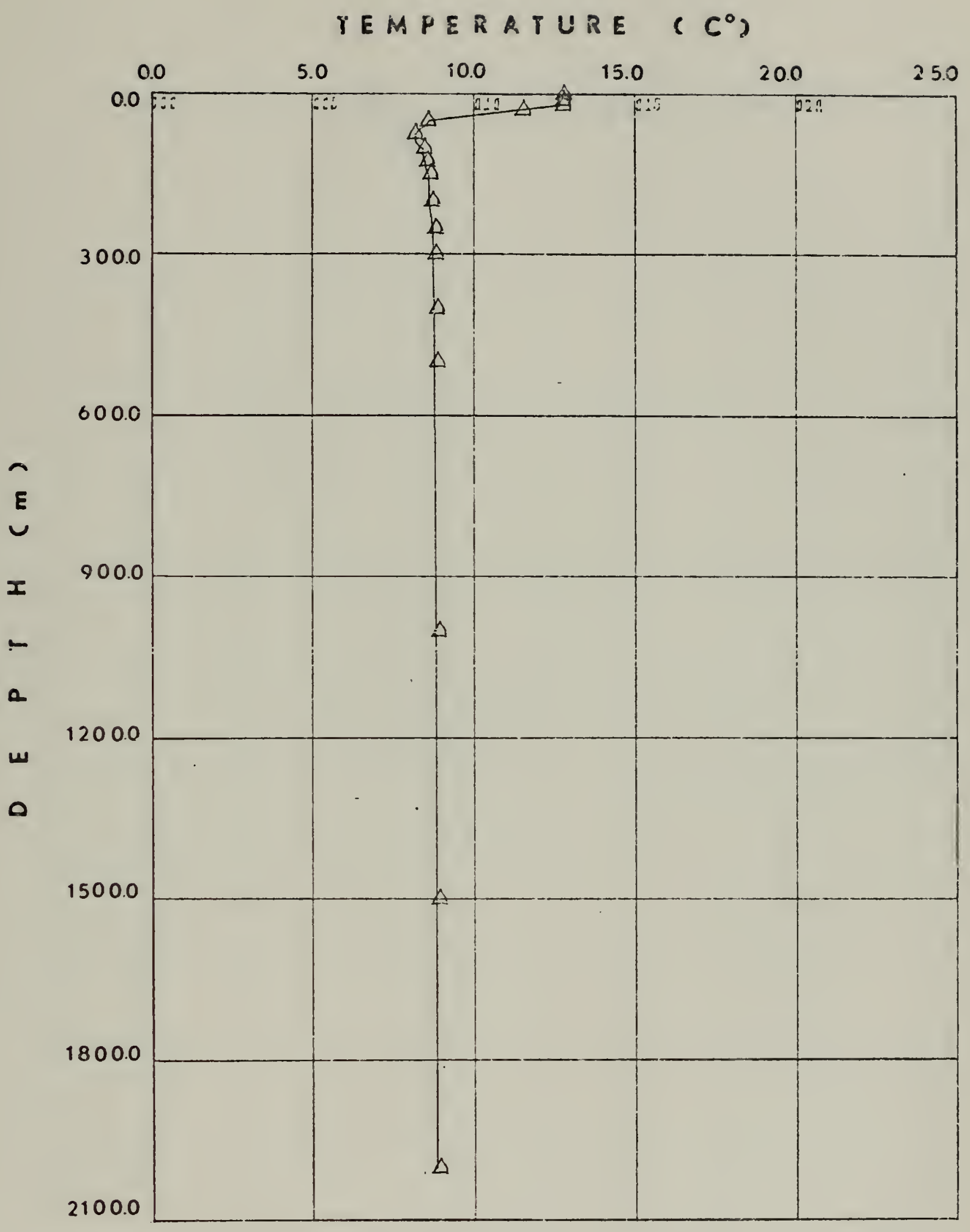

Figure 16. Average Temperature Profile for December. 


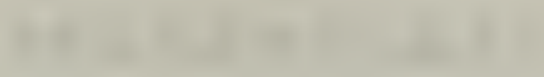

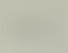

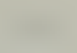

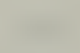

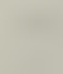

.

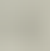

$\sqrt{2}+n^{2}$ 


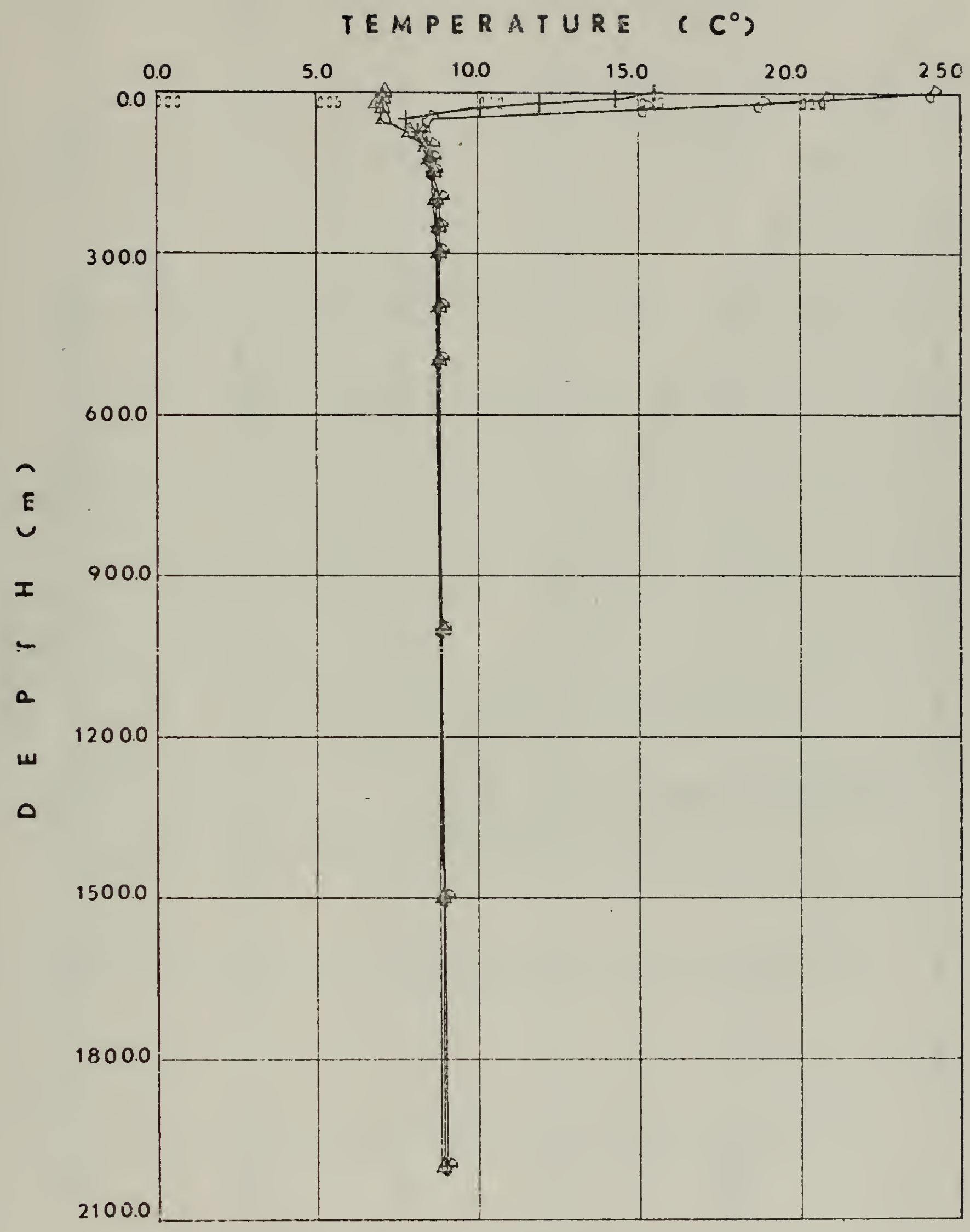

Figure 17. Annual Minimum, Maximum and Average Temperature Profiles. 


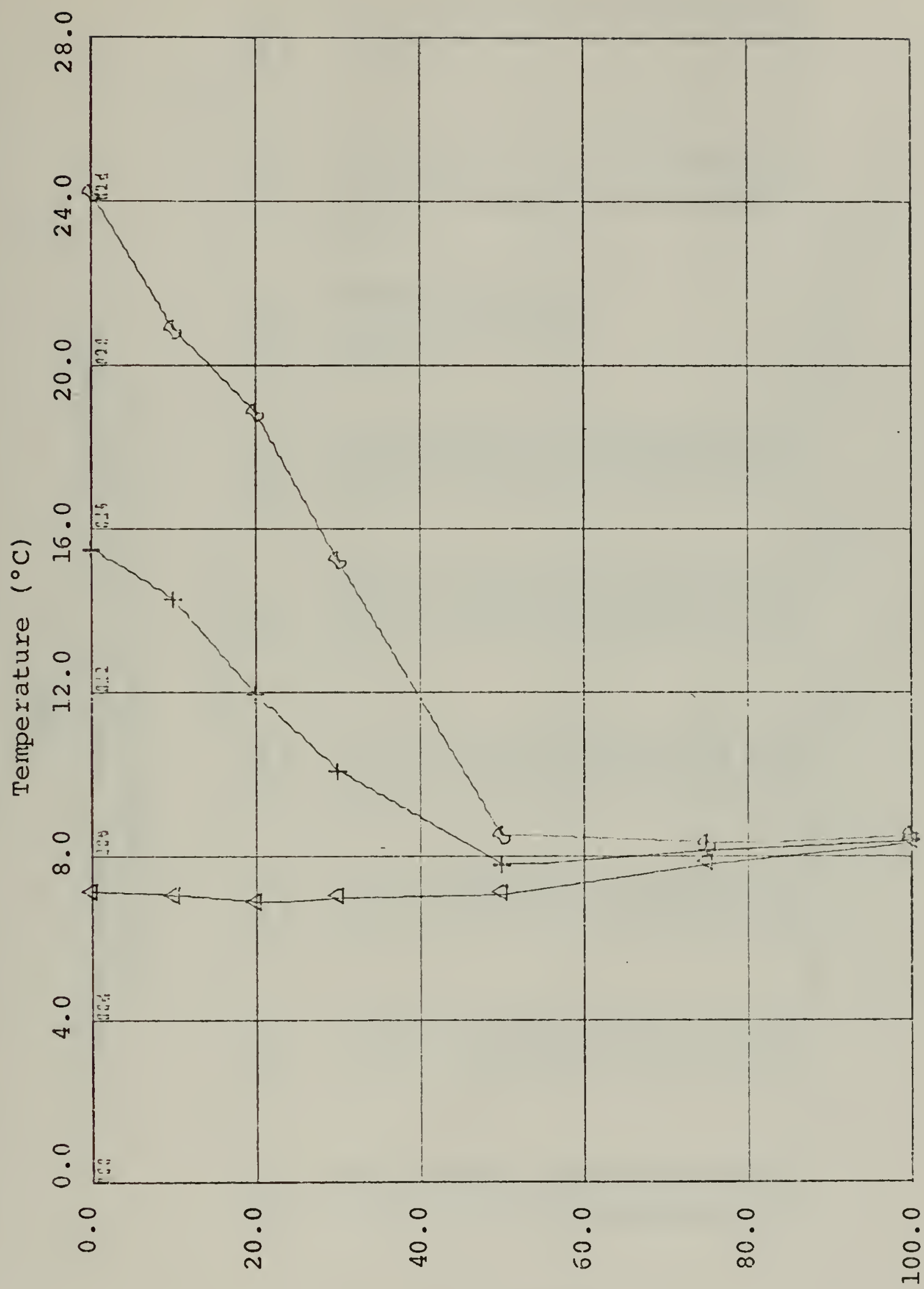

$\dot{\varepsilon}$

음

म्प

ํㅜㄴ

0
0
-1
$4-1$
0
0
0

है

()

ఠ్రా

a

శ్ర

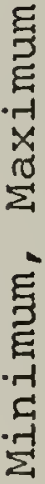

(ui) 47वेव

$\begin{array}{ll}0 & \\ 0 & \infty \\ 0 & 1\end{array}$

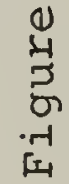




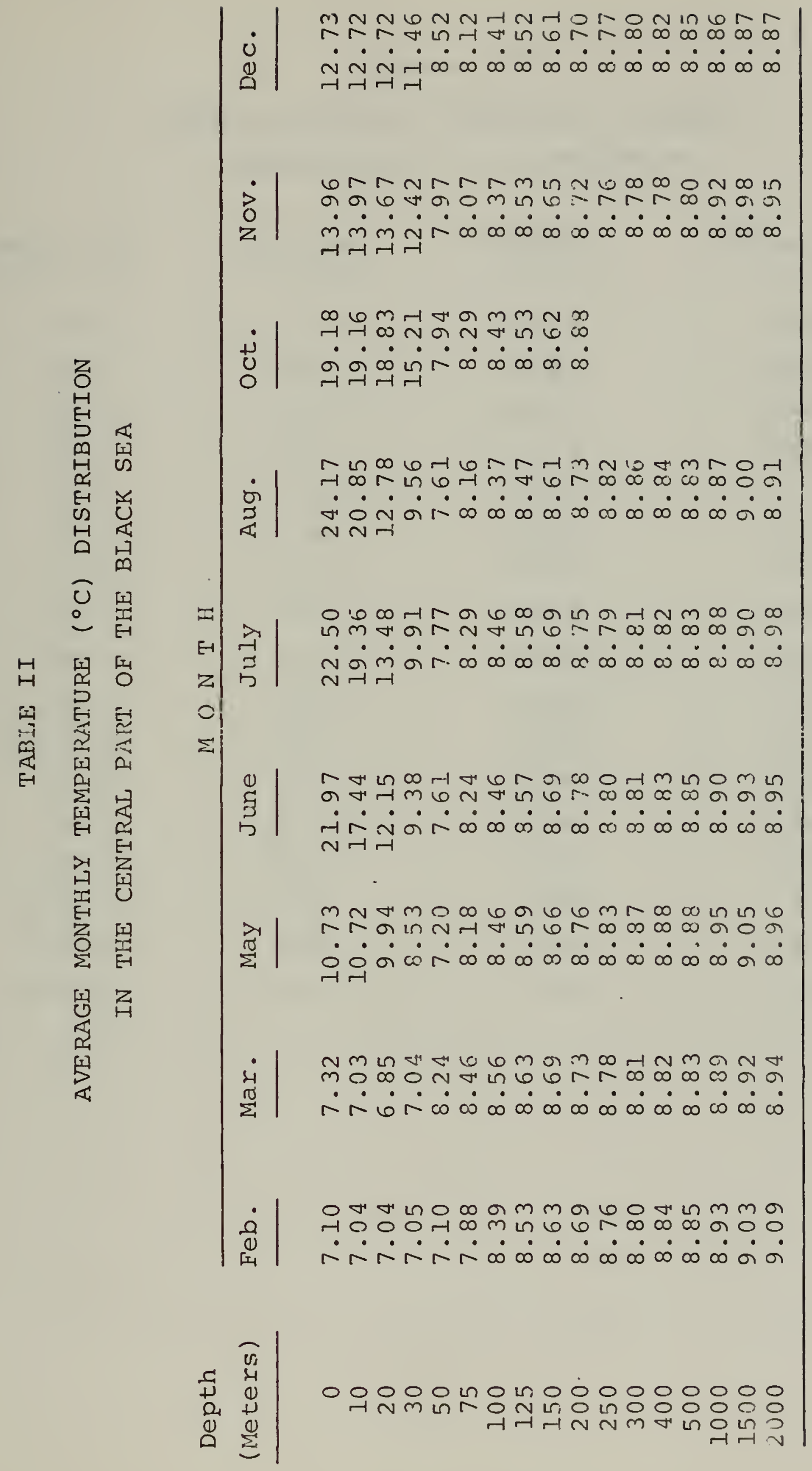




\section{Table III}

\section{ANNUAL MINIMUM, MEXIMUM AND AVERAGE}

TEMPERATURE $\left({ }^{\circ} \mathrm{C}\right)$ DISTRIBUTION

\begin{tabular}{|c|c|c|c|}
\hline Depth (m) & Minimum & Maximum & Annual Average \\
\hline 0.0 & 7.10 & 24.17 & 15.52 \\
\hline 10.0 & 7.03 & 20.85 & 14.25 \\
\hline 20.0 & 6.85 & 18.83 & 11.94 \\
\hline 30.0 & 7.04 & 15.21 & 10.06 \\
\hline 50.0 & 7.10 & 8.52 & 7.77 \\
\hline 75.0 & 7.88 & 8.29 & 8.19 \\
\hline 100.0 & 8.37 & 8.56 & 8.43 \\
\hline 125.0 & 8.47 & 8.63 & 8.55 \\
\hline 150.0 & 8.61 & 8.69 & 8.65 \\
\hline 200.0 & 8.69 & 8.88 & 8.75 \\
\hline 250.0 & 8.76 & $8.8 \overline{3}$ & 8.79 \\
\hline 300.0 & 8.78 & 8.87 & 8.82 \\
\hline 400.0 & 8.78 & 8.88 & 8.83 \\
\hline 500.0 & 8.80 & 8.88 & 8.84 \\
\hline 1000.0 & 8.86 & 8.95 & 8.90 \\
\hline 1500.0 & 8.87 & 9.05 & 8.96 \\
\hline 2000.0 & 8.87 & 9.09 & 8.96 \\
\hline
\end{tabular}



C. SALINITY DISTRIBUTION

The salinity distribution of the surface water for summer months (July, August and September) is presented in Figure 19 [7]. This Figure shows the salinity to be highest on the west coast of the Crimea and in the central parts of the eastern and western Black Sea basins. The highest salinity of these areas is greater than 18.2 paxts per thousand. Neumann concluded that the high salinity that occurs northwest of the Crimea in summer is due to extensive evaporation. The lowest salinity values are observed near the coast, especially in the northwestern part, off the mouths of great rivers. This is also significant in the southeastern part of the Black Sea where numerous small rivers supply much fresh water, and, according to Neumann [7], the low salinity on the Anatolia Coast, east of Bosporus, is the result of the fresh water discharge of the Sakarya River. Large seasonal salinity-variations occur only near the coast [7]. The minimum salinity values in the vicinity of the northwest coast are observed during April and May, when the fresh water Ilow through the rivers is heaviest. The occurrence of minimum salinity is observed later with increasing distance from the coast. A salinity minimum occurs in the northern part of the Black sea concurrently with the maximum river runoff during April and May. But, south of the Crimea $\left(44^{\circ} \mathrm{N}, 33^{\circ} \mathrm{E}\right)$, the minimum occurs about 3 to 4 months later [7] . 
The typical vertical salinity profiles in the central part of the Black Sea for several different months are shown in Figures 20 through 27. The monthly average salinity distribution for each depth is given in Table IV. Table V shows the minimum, maximum and average salinity values.

The average surface salinjity ranges from $17.70 \%$ in early summer to $18.25 \%$ in the winter. The minimum salinities have been observed during summer months due to maximum runoff during April and May which spreads over the central regions 3 to 4 months later.

It can be seen, from vertical salinity profiies, that salinity increases graaually from the sea surface to the cold intermediate layer, where it reaches 18.70 to $19.62 \%$ at the depths of 50 to $75 \mathrm{~m}$. The maximum seasonal range is found at a depth of $50 \mathrm{~m}$, typicaliy this range is approximately $1.60 \%$ (Figures 28 and 29). Below the cold intermediate layer, the steep positive halocline is obscrved to $300 \mathrm{~m}$, and the salinity increases markedily with depth by as much as $2.9 \%$ in an interval of $200 \mathrm{~m}$. After $300 \mathrm{~m}$, the salinity increases slightly with deptr. From à value of about $21.7 \%$ to $22.24 \%$ at a depth of $1000 \mathrm{~m}$, and finally to $22.33 \%$ near the bottom. 



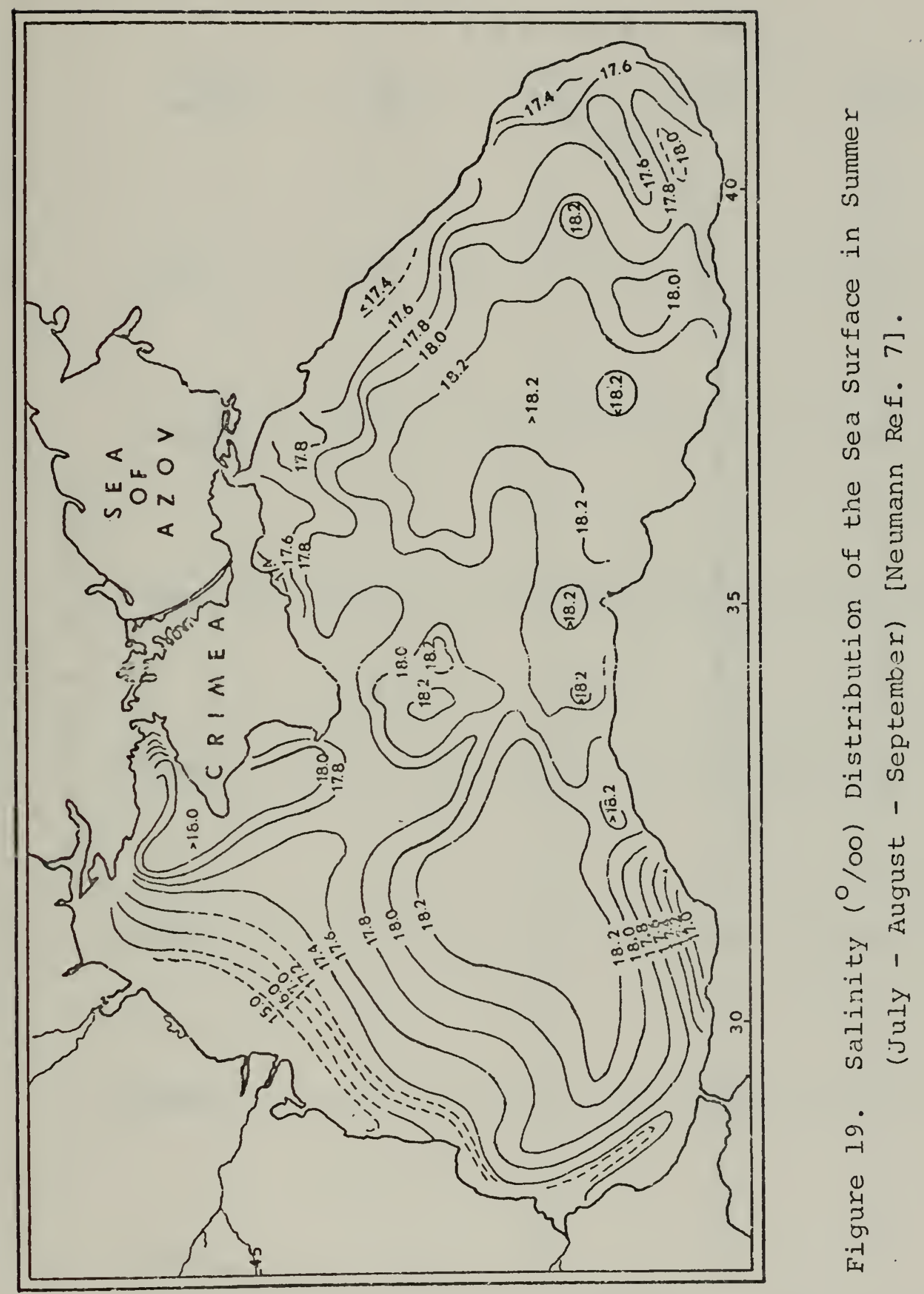





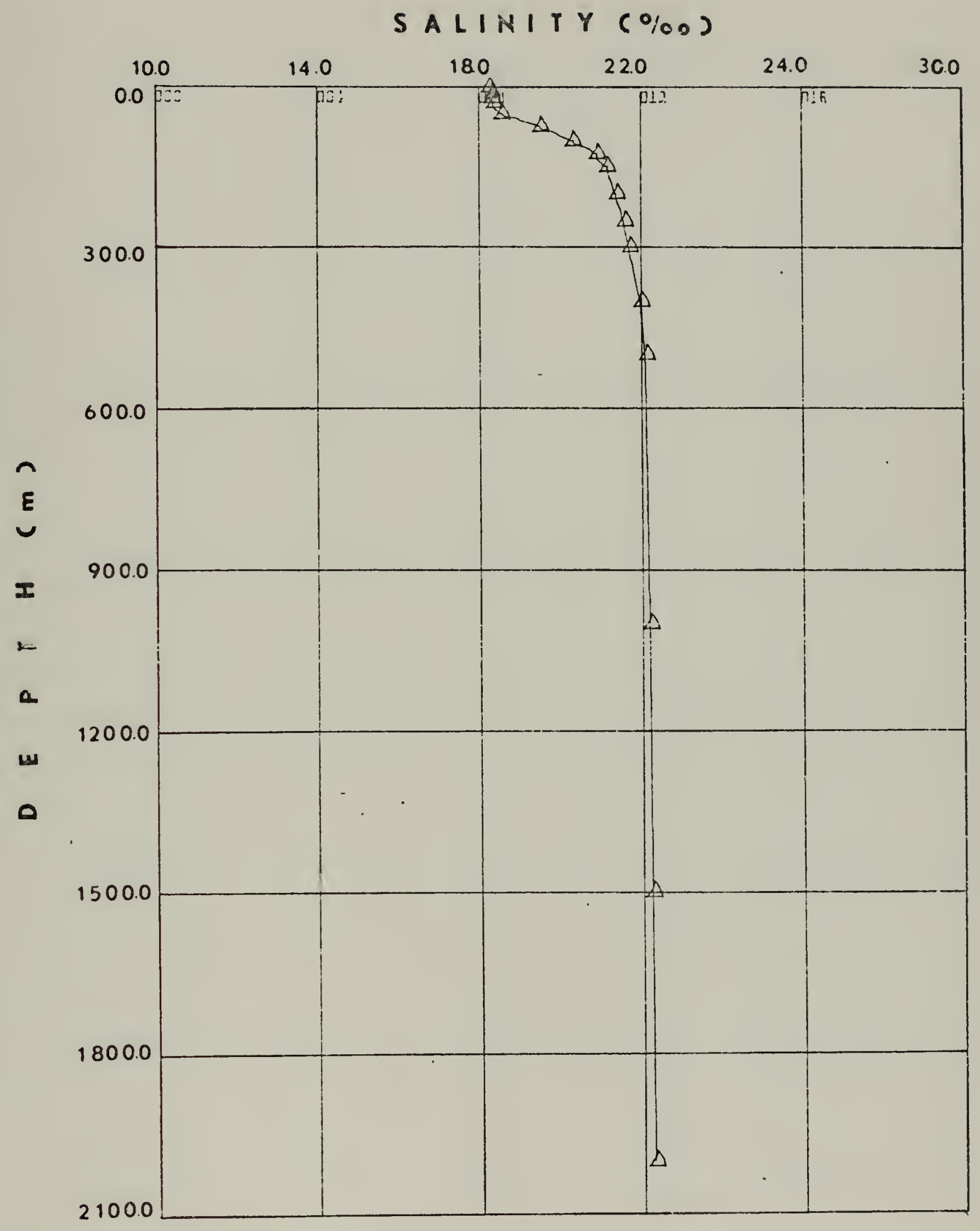

Figure 20. Average Salinity Profile for February. 


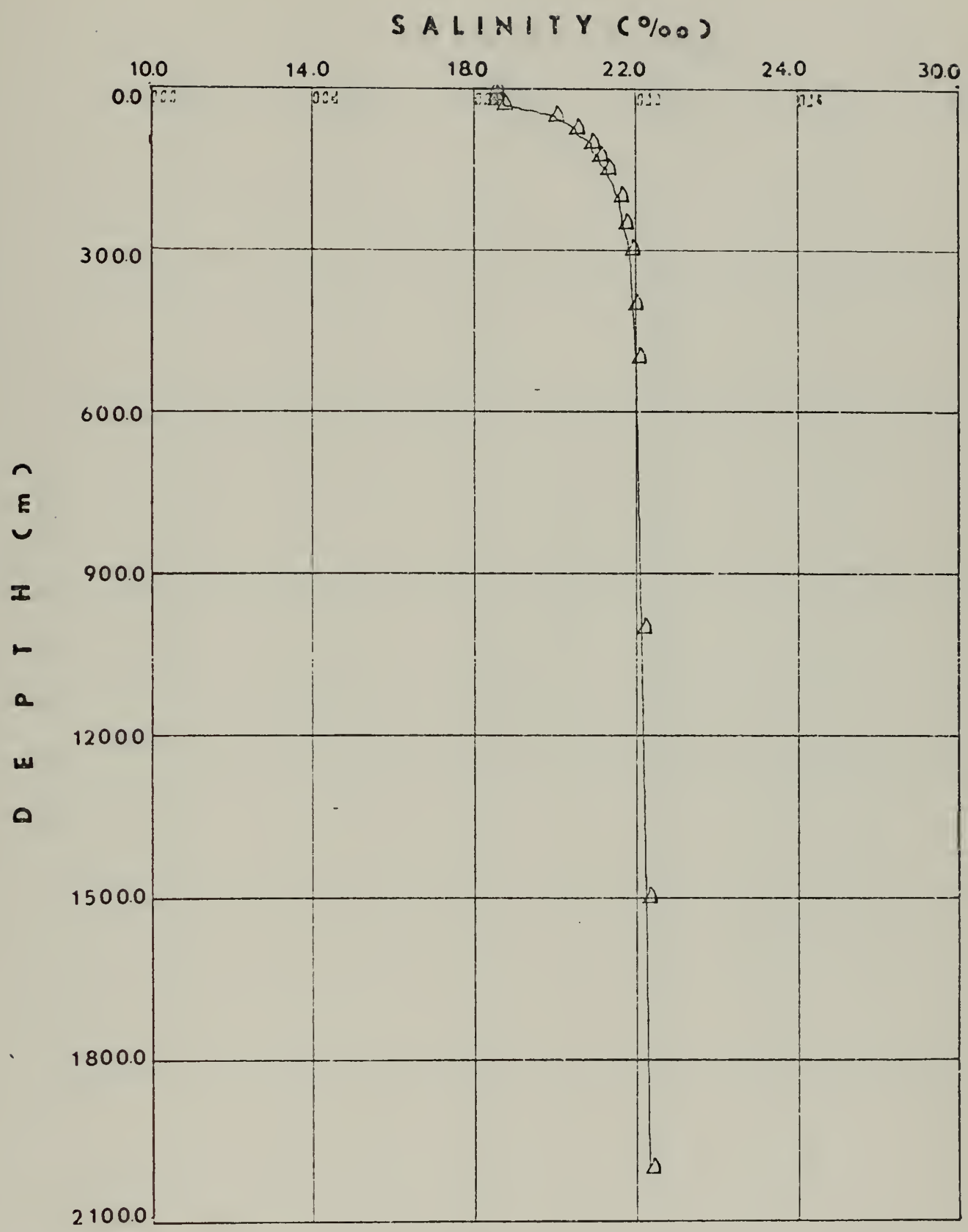

Figure 21. Average Salinity Profile for March. 



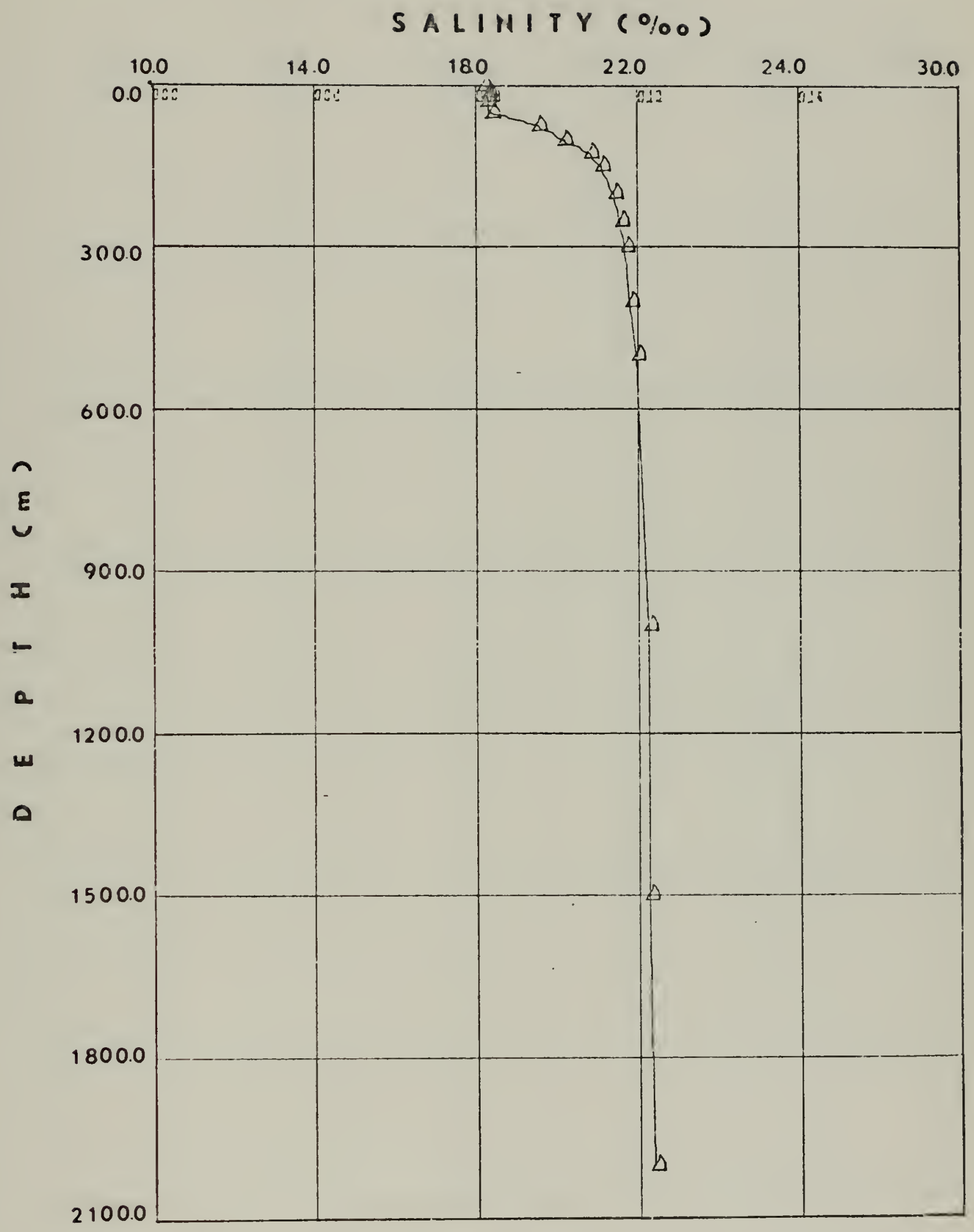

Figure 22. Average Salinity Profile for May. 


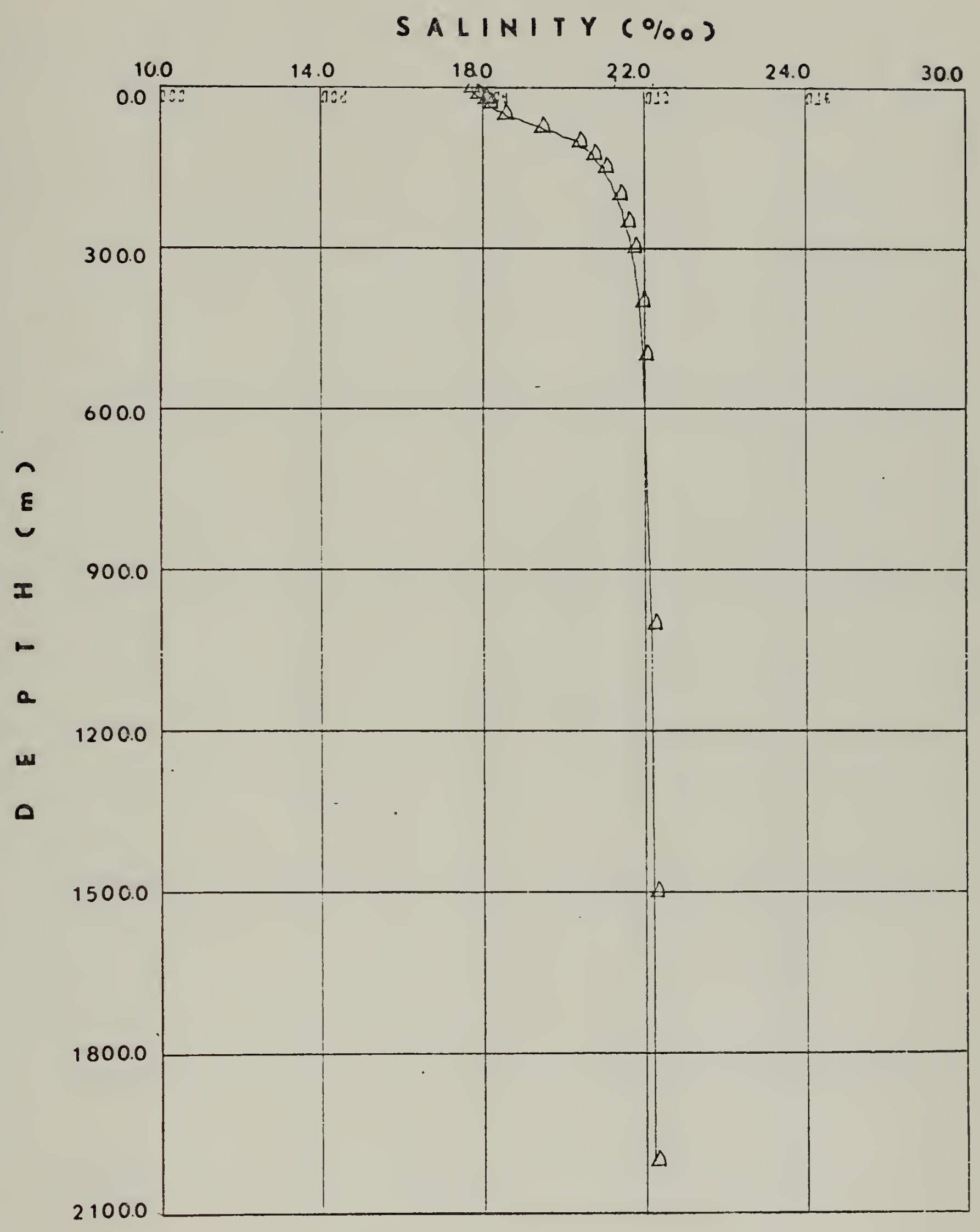

Figure 23. Average Salinity Profile for June. 



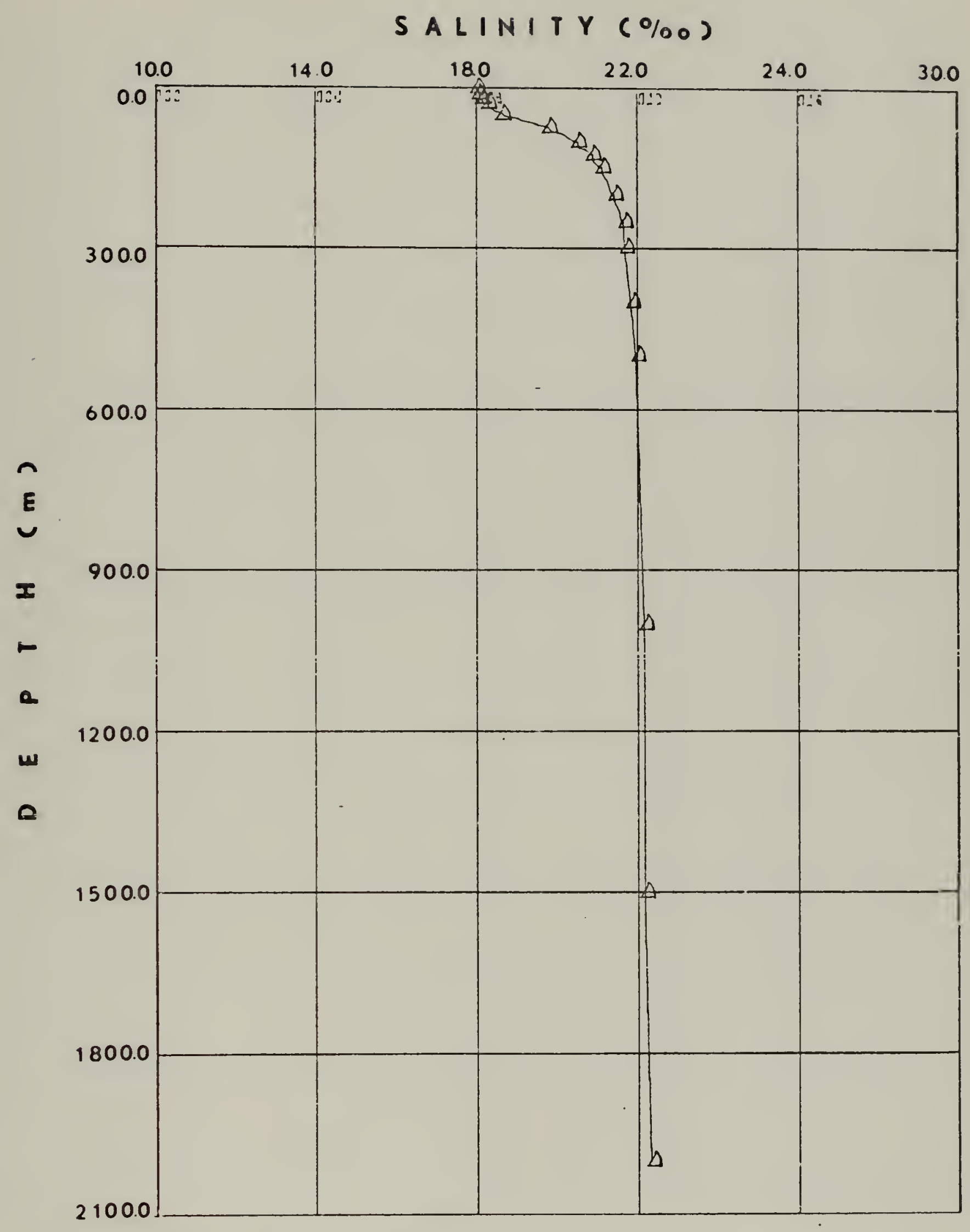

Figure 24. Average Salinity Profile for July. 



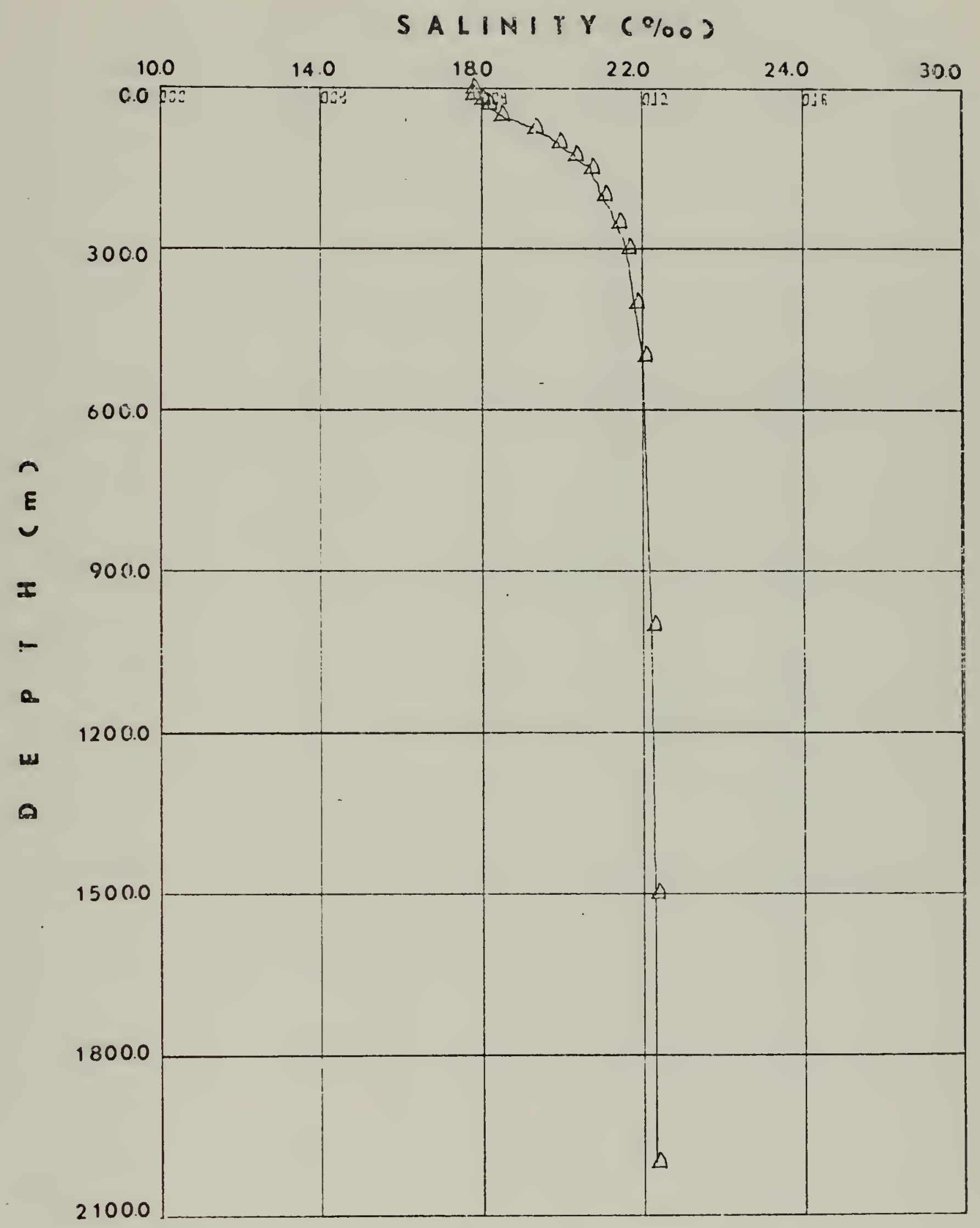

Figure 25. Average Salinity Profile for August. 



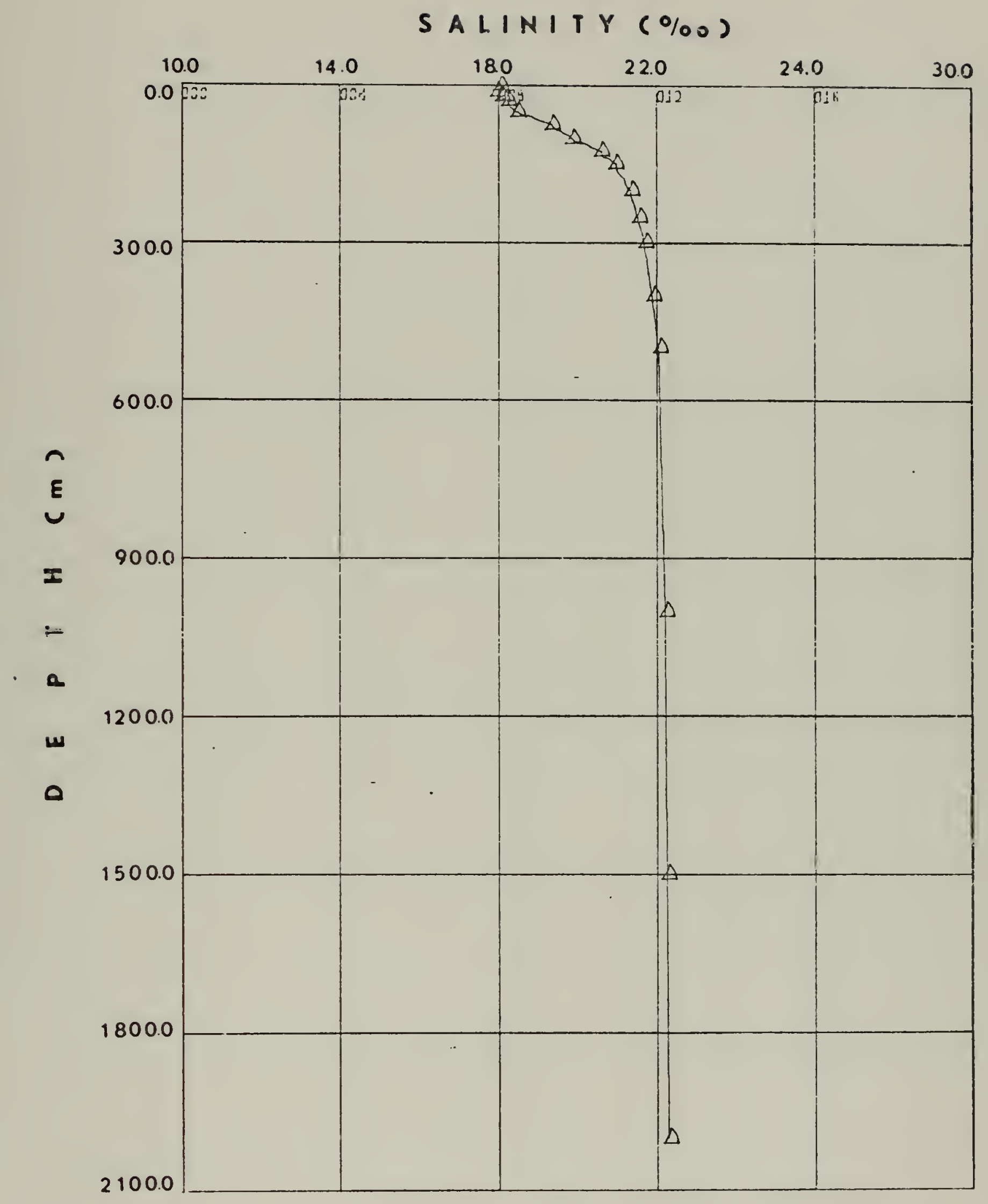

Figure 26. Average Salinity Profile for November. 


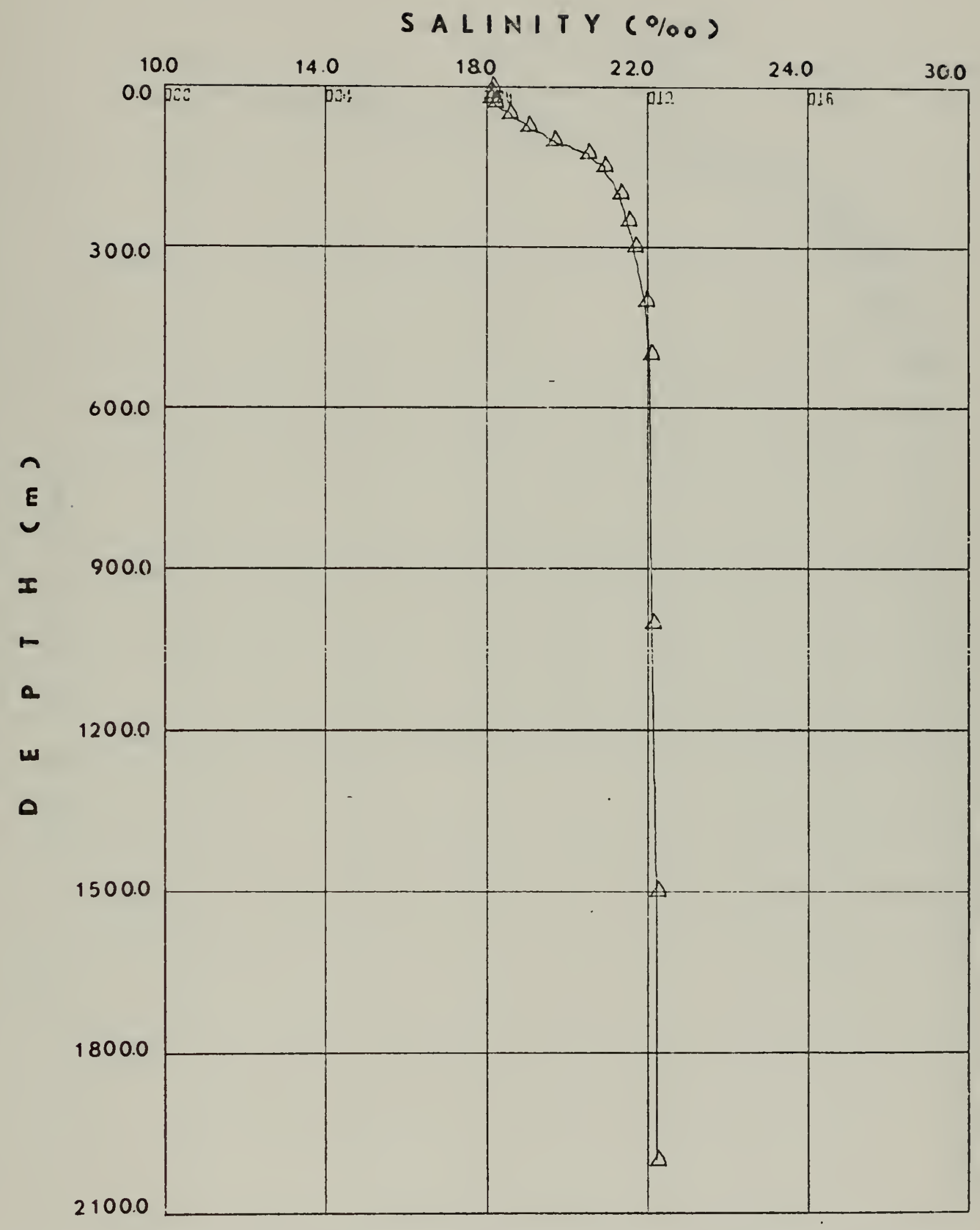

Figure 27. Average Salinity Profile for December. 


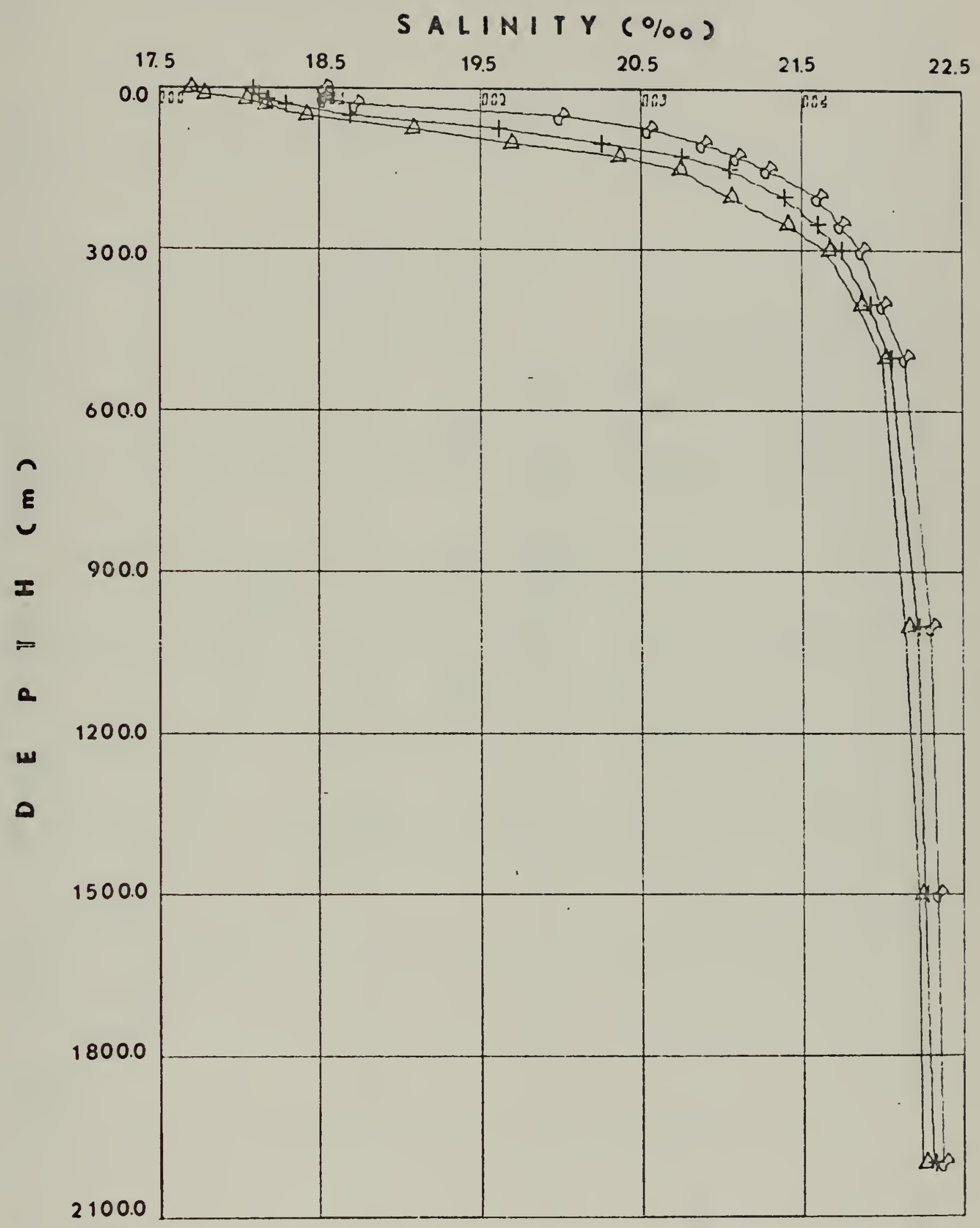

Figure 28. Annual Minimum, Maximum and Average Salinity Profiles. 



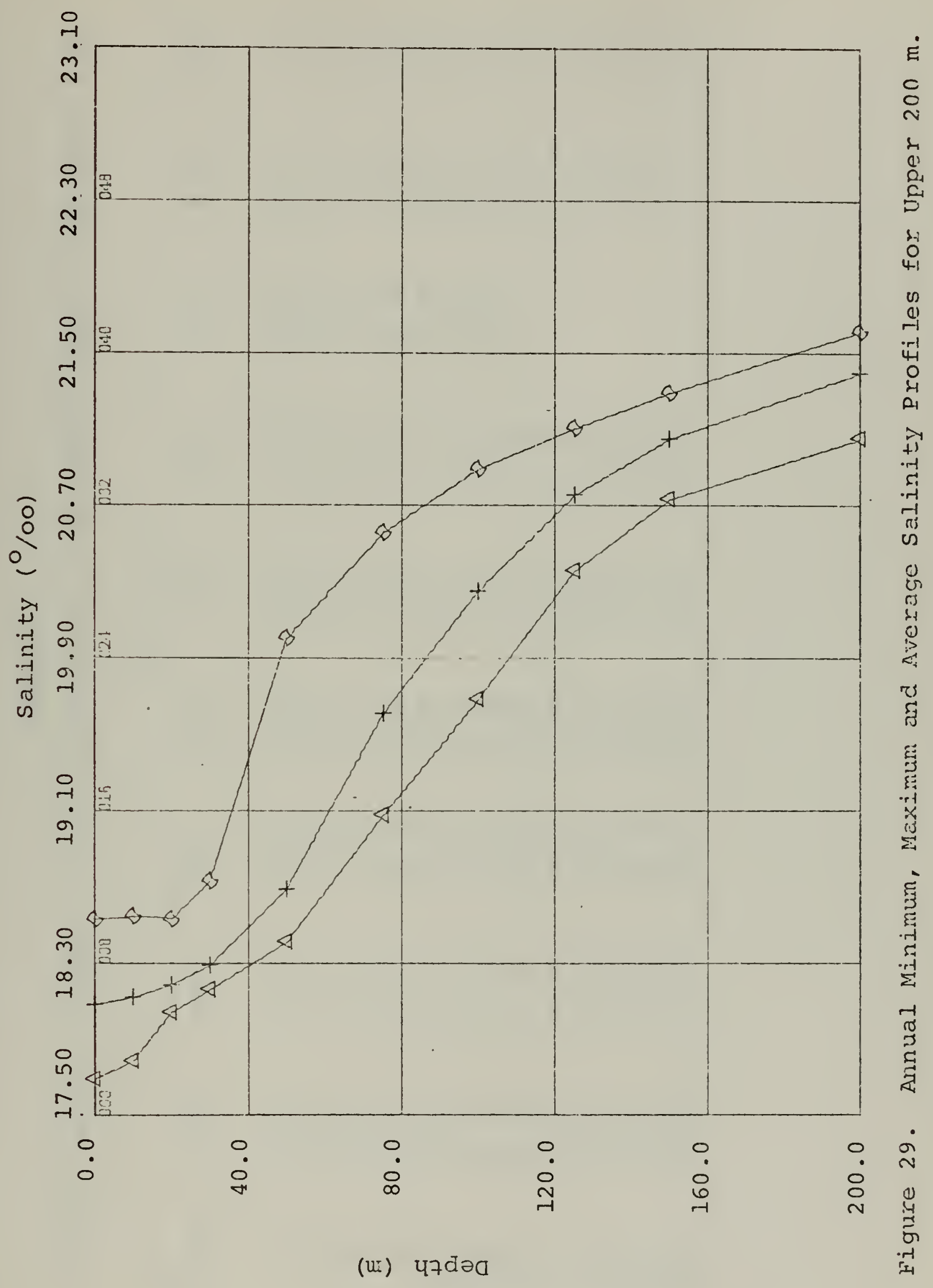





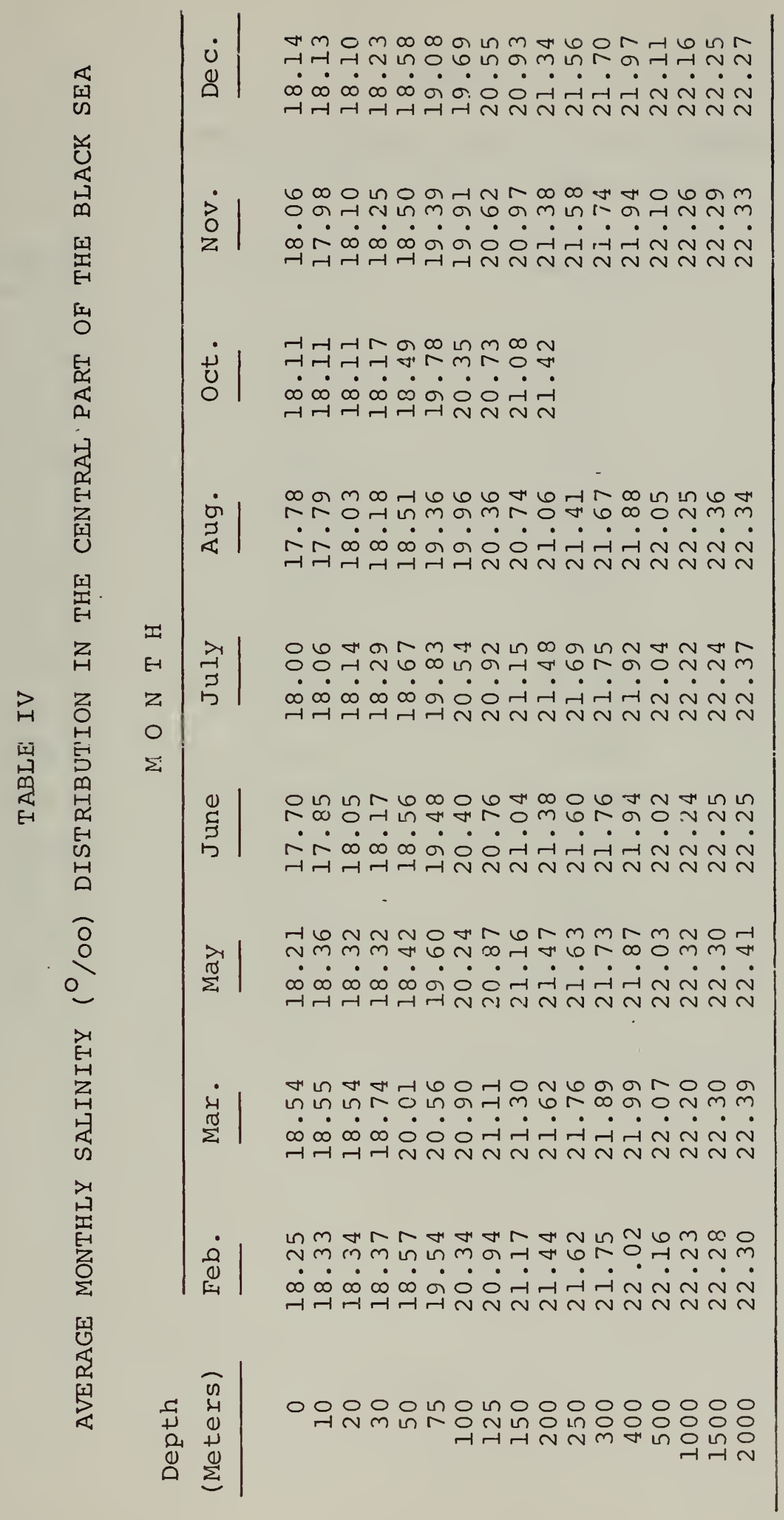


TABLE V

ANNUAL MINIMUM, MAXIMUM AND AVERAGE

SALINITY $(\%)$ DISTRIBUTION

\begin{tabular}{rccc} 
Depth & Minimum & Maximum & Average \\
\cline { 2 - 2 } 0.0 & 17.70 & 18.54 & 18.09 \\
10.0 & 17.79 & 18.55 & 13.13 \\
20.0 & 18.05 & 18.54 & 18.19 \\
30.0 & 18.17 & 18.74 & 18.30 \\
50.0 & 18.42 & 20.01 & 18.70 \\
75.0 & 19.08 & 20.56 & 19.62 \\
100.0 & 19.69 & 20.90 & 20.26 \\
125.0 & 20.36 & 21.11 & 20.76 \\
150.0 & 20.74 & 21.30 & 21.06 \\
200.0 & 21.06 & 21.62 & 21.40 \\
250.0 & 21.41 & 21.76 & 21.51 \\
300.0 & 21.67 & 21.89 & 21.75 \\
400.0 & 21.87 & 22.02 & 21.94 \\
500.0 & 22.02 & 22.16 & 22.07 \\
1000.0 & 22.16 & 22.32 & 22.24 \\
1500.0 & 22.24 & 22.36 & 22.28 \\
2000.0 & 22.25 & 22.39 & 22.33 \\
\hline
\end{tabular}





\section{BOTTOM SEDIMENTS}

Figure 30 is a bathymetric chart of bottom sediments prepared by Arkhangel'skiy using older bottom sediment information to supplement his data. According to Arkhangel'skiy and Strakhov, the sediments of the Black Sea are classified into three groups [17]:

\section{A. COASTAL SEDIMENTS}

The coastal sediments are represented by pebble, boulder, gravel and sand zones [18].

\section{Pebble Zone}

The pebbles are adjacent to the shore in depths of

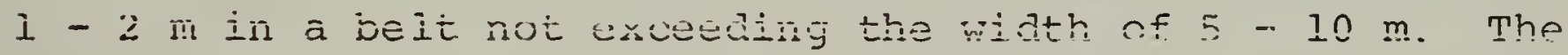
pebble belt is frequently interrupted by boulders and grave with a mixture of sand shingles. The petrographic composition of the pebbles is identical to the composition of the adjoining coastline and the alluvium supplied by the rivers.

\section{Boulder Zone}

The boulder accumulations are most commonly found in bays and along the coasts and are of igneous composition. The zone varies in width to $150 \mathrm{~m}$ and is found in depths 10 to $40 \mathrm{~m}$. In the estuarian areas, the zone is probably covered fragmented material transported by the rivers.

Usual.ly the boulders have rounded elipsoidal form. Their size varies from 0.5 to $1.2 \mathrm{~m}$ in diameter. 



\section{Gravel Zone}

There are several gravel belt.s. The assortment of gravel size is more or less uniform. The sizes rarge from 2 to $5 \mathrm{~mm}$. The aleurite and pelite fractions make up approximately 3 percent of the weil sorted gravel. Along the massifs of effusive rocks and fine grair. limestone, the gravel is represented by somewhat coarser fractions, including a large quantity of pebbles. In estuarian areas, the gravel belt begins at the shoreline and reaches a depth of 1.5 to $30 \mathrm{~m}$, forming a belt $5-60 \mathrm{~m}$ wide. In rare cases, the gravel is found at the depths of 10 - $40 \mathrm{~m}$ as a continuous independent zore, 40 to $800 \mathrm{~m}$ wide.

\section{Sand Zone}

Sand is widely distributed in areas of detritus from river alluvium, shore erosion and land slides. Water aeptins over sand sediment vary depending on the steepness of the shelf and the quantity and size of the deposited detritus. Along deep shores, the sanà usually extends to a depth of 25 $30 \mathrm{~m}$ and along shoaling shores it reaches depths of $15-20 \mathrm{~m}$. In estuarian areas, the depth of sand deposits varies and the width of the belt is irregular. In areas near large rivers, the sand belt begins adjacent to the coast and is composed mainly of medium and fine grain materials.

The distribution of sand is affected by the coastal configuration and the slope of the shelf. When the shelf is steep, the sand is found at maximum depths (to $50 \mathrm{~m}$ ), but the width of the beit is insignificant. In cape shoreline areas, 

sand grain size varies and is poorly sorted from gravel to fine aleurite and pelite particles, and contains a large quantity of organic shell materials.

\section{B. SHALLOW WATER SEDIMENTS}

The shallow water sediments are divided into the Mytilus mud (Mytilus galloprovincialis), lying to a depth of $60 \mathrm{~m}$ and the Phaseolina mud (Modiola phaseolina), found on the outer edge of the coastal platform [17]. Both of the sediments represent äarkish-gray plastic mass containing fragments and pieces of shells. Sometimes these sediments contain whole shell interlayers.

The Mytilus mud with respect to petrographic composition ana shape, differs little from Phaseolina mud. The former is characterized by a rather highor content of organic metter and a coarser mechanical composition than the Phaseolina mud. The mineral material of this mud consists of particles ranging from 0.05 to $0.01 \mathrm{~mm}$ and less than $0.0 \mathrm{l} \mathrm{mm}$ in diameter. Along the minerals, the angular grains of quartz prevail. In addition to quartz, muscovite, glauconite occasionally biotite, magnetite, anatite, homblende and sillimanite are found [17] .

C. DEEP WATER SEDIMENTS

Deep water sediments are found below the depth of $170 \mathrm{~m}$. Deep water sediments are sharply different from coastal anā shallow water sediments. These sediments show a complete absence of the remains of benthic organisms. The sediments consist of three types [17]: 

1. Gray deep water clay

2. Clayey calcareous (Transitional) mud

3. Calcareous mud

The clay material consists of terrigenous particles ( 73 percent on the average), whose diameters are smaller than $0.01 \mathrm{~mm}$, purverized calcite (approximately 15 percent) and organic matter ( 3 - 4 percent). The transitional clayey calcareous mud represents an elastic greenish-gray sediment with a marked stratification. In the bottom areas lying far off the coast, the transitional mild replaced by calcareous mud. This is a dirty white slightly plastic mass which brightens when drying and becomes fragile, breaking into irregular lumps. 



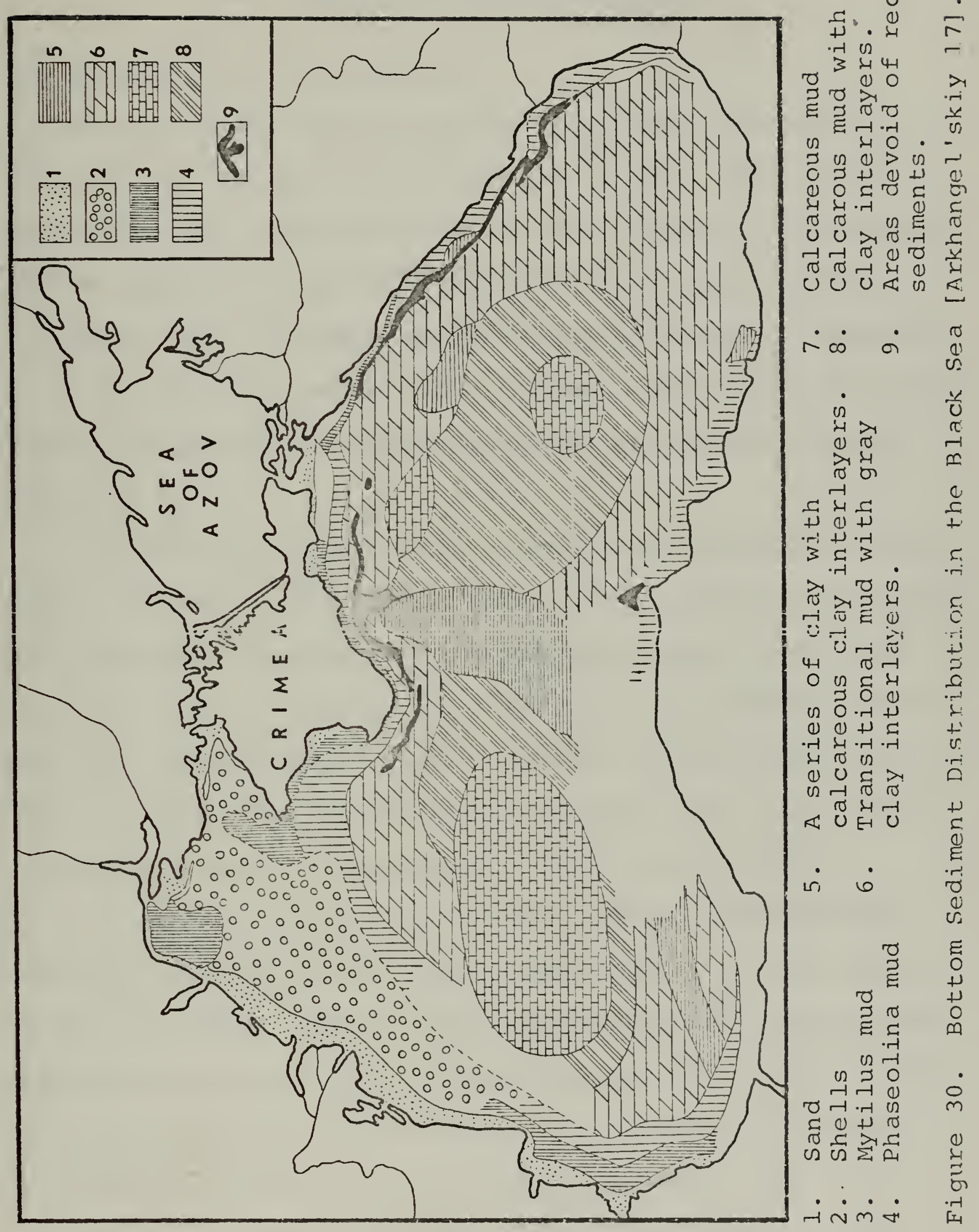





\section{ACOUSTICAI. CHARACTERISTICS}

\section{A. SOUND VELOCITY STRUCTURE}

The sound velocity structure is the most important factor for the propagation of sound in the sea. The typical sound velocity profiles in the central part of the Black Sea can be seen in Figure 31 through 38. The sound velocity profiles were calculated using Wilson's equation. Temperature and sälinity values were obtained from Tables II and IV. Detail information of sound velocity calculation is given in Appendix A.

The monthly average sound velocity distribution for each depth is given in Table VI. Table VII is obtained from Table VI, and shows the minimum, maximum and average sound velocity values. Figure 39 gives the profiles of the minimuin, maximum and average sound velocity values that are drawn from the data in Table VII. The profiles for upper $200 \mathrm{in}$ are represented in Figure 40 in expanded scale for resolution.

In the central part of the Black Sea, surface sound velocity changes within a year from $1457.8 \mathrm{~m} / \mathrm{sec}$ to 1513.9 $\mathrm{m} / \mathrm{sec}$ in summer. The minimum and maximum sound velocities always occurring in February and August respectively; February through August, the surface sound velocity increasing monotonically due to surface heating, however, the sumer freshening of the central Black Sea compensates for some of the increase expected from warming. After August, surface sound velocity decreases until February. 

During the winter, in the surface isothermal layer, the sound velocity increases approximately linearly to a depth of $50 \mathrm{~m}$. From $50 \mathrm{~m}$ to $200 \mathrm{~m}$, sound velocity increases more rapidly than in the surface layer due to sharp increases in salinity and temperature. Below $200 \mathrm{~m}$, the temperature and salinity continue to increase gradually with depth, ana the sound velocity increases with increasing depth and it reaches $1503.9 \mathrm{~m} / \mathrm{sec}$ at a depth of $2000 \mathrm{~m}$ in February.

During the spring, the surface temperature increases creating a shallow thermocline in the surface layer and for this reason, sound velocity increases at the surface (Figure 33). The sound velocity decreases monotonically from the lower limit of isothermal layer to the cold intermediate layer $(50-75 \mathrm{~m})$. Between 50 to $75 \mathrm{~m}$, sound velocity reaches its minimum value. So, the sound channel develops at depths below the shallow thermocline. The sound channel axis is seen at the bottom of the thermocline where the sound velocity is at a mirimum of $1459.3 \mathrm{~m} / \mathrm{sec}$ at a depth of $50-75 \mathrm{~m}$ in viay. During the summer, when the near-surface waters are warm, a well defined thermocline develops in the central part of the Black Sea. So, that near the surface the sound velocity decreases rapidly with depth, and at the bottom of thermocline, it reaches its minimum value. Within this negative sound velocity gradient, the sound velocity decreases by as much as $52 \mathrm{~m} / \mathrm{sec}$ an interval of $50 \mathrm{~m}$ (Figure 36). And, the sound channel axis occurs at a depth of $50 \mathrm{~m}$ in August. Below the sound channel axis, the sound velocity begins to increase vith depth until the bottom is reached. 

During the fall, the thermocline is not strong. Near the surface layer, a shallow isothermal layer develops with wind and convective mixing. Sound velocity increases with depth in the isothermal layer and then begins to decrease with temperature effect in the thermocline. Below the thermocline, it increases again to the bottom of the sea (Figure 37).

Large seasonal sound velocity variations occur only in the upper layer of the Black Sea. Maximum variation is seen at the surface and it decreases with depth. Below $125 \mathrm{~m}$, maximum variation is not more than $1 \mathrm{~m} / \mathrm{sec}$ at the same depths for each month (Table VII), so, it can be concluded, below $125 \mathrm{~m}$ in the Black Sea, sound velocity profiles do not show significant seasnnal changes. 



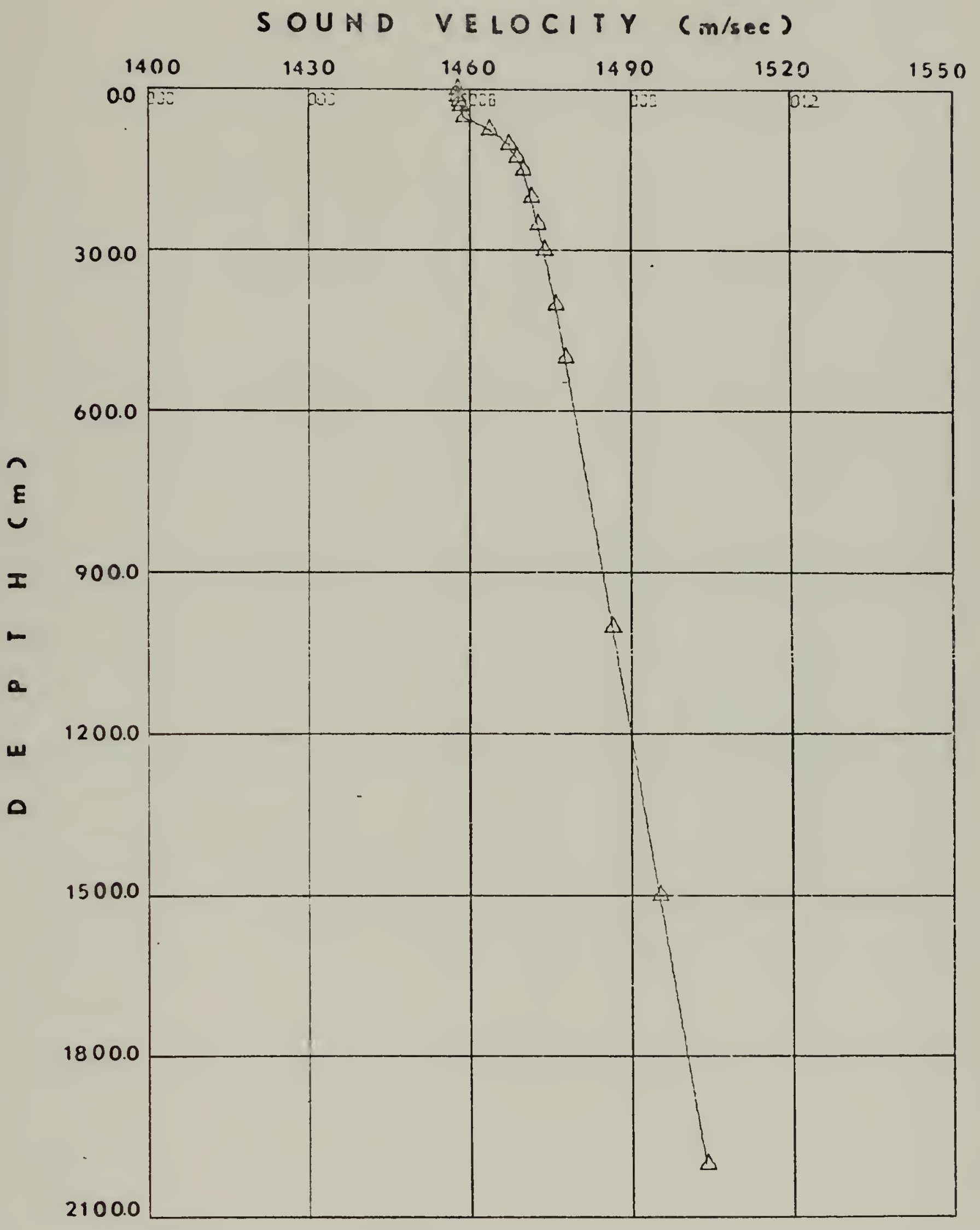

Figure 31. Average Sound.Velocity Profile for February. 



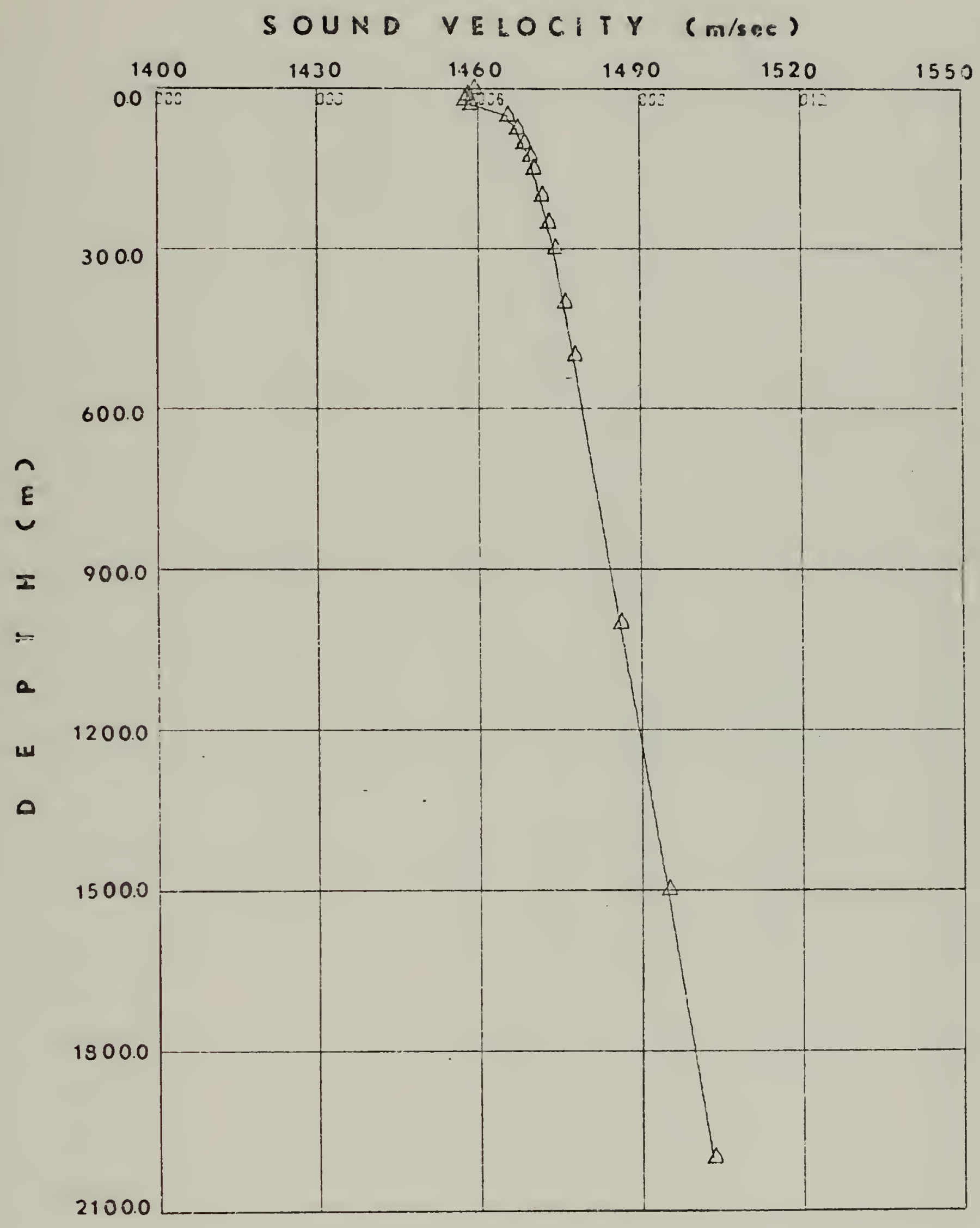

Figure 32. Average Sound Velocity Profile for March. 



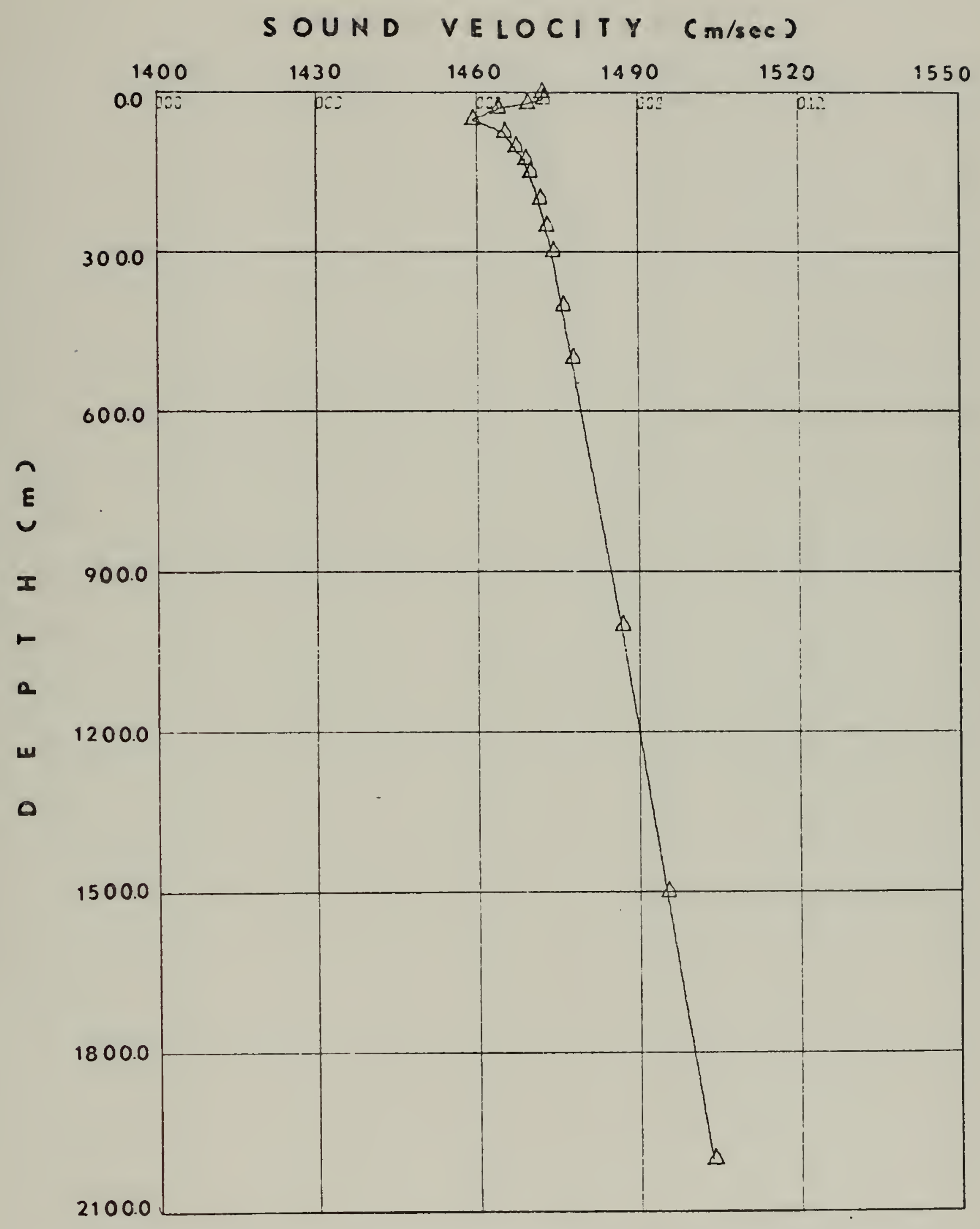

Figure 33. Average sound Velocity Profile for May. 



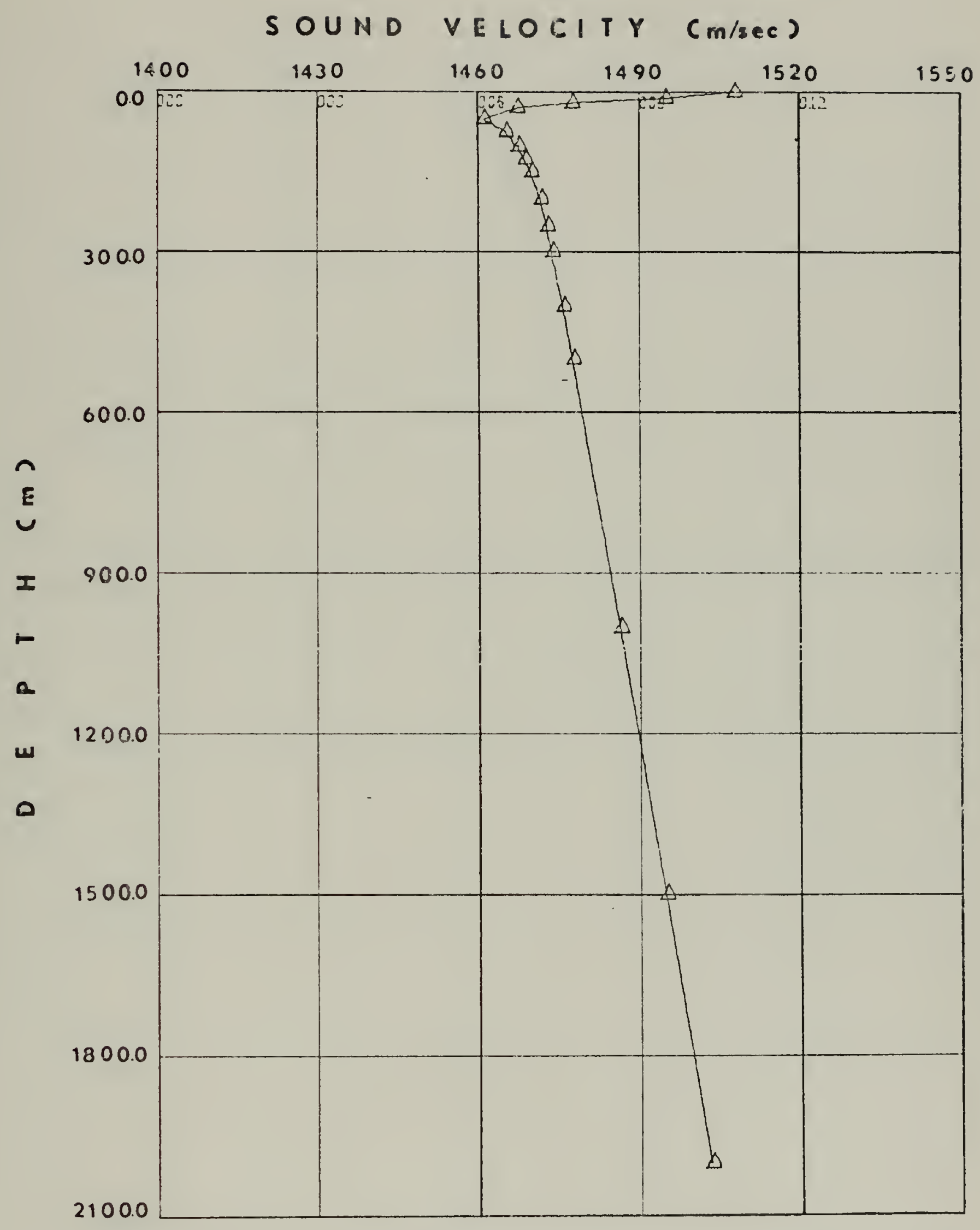

Figure 34. Average Sound Velocity Profile for June. 



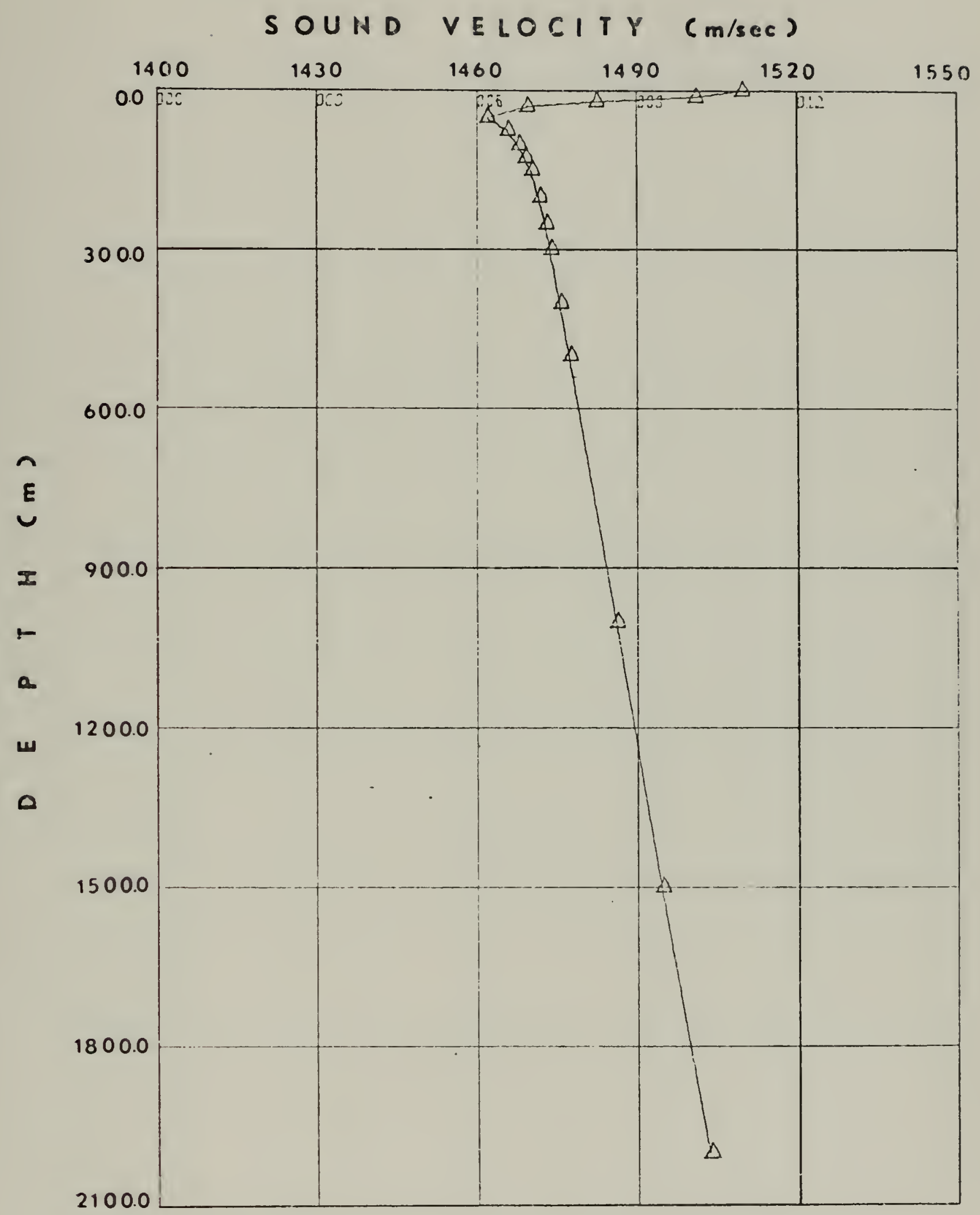

Figure 35. Average Sound Velocity Profile for July. 



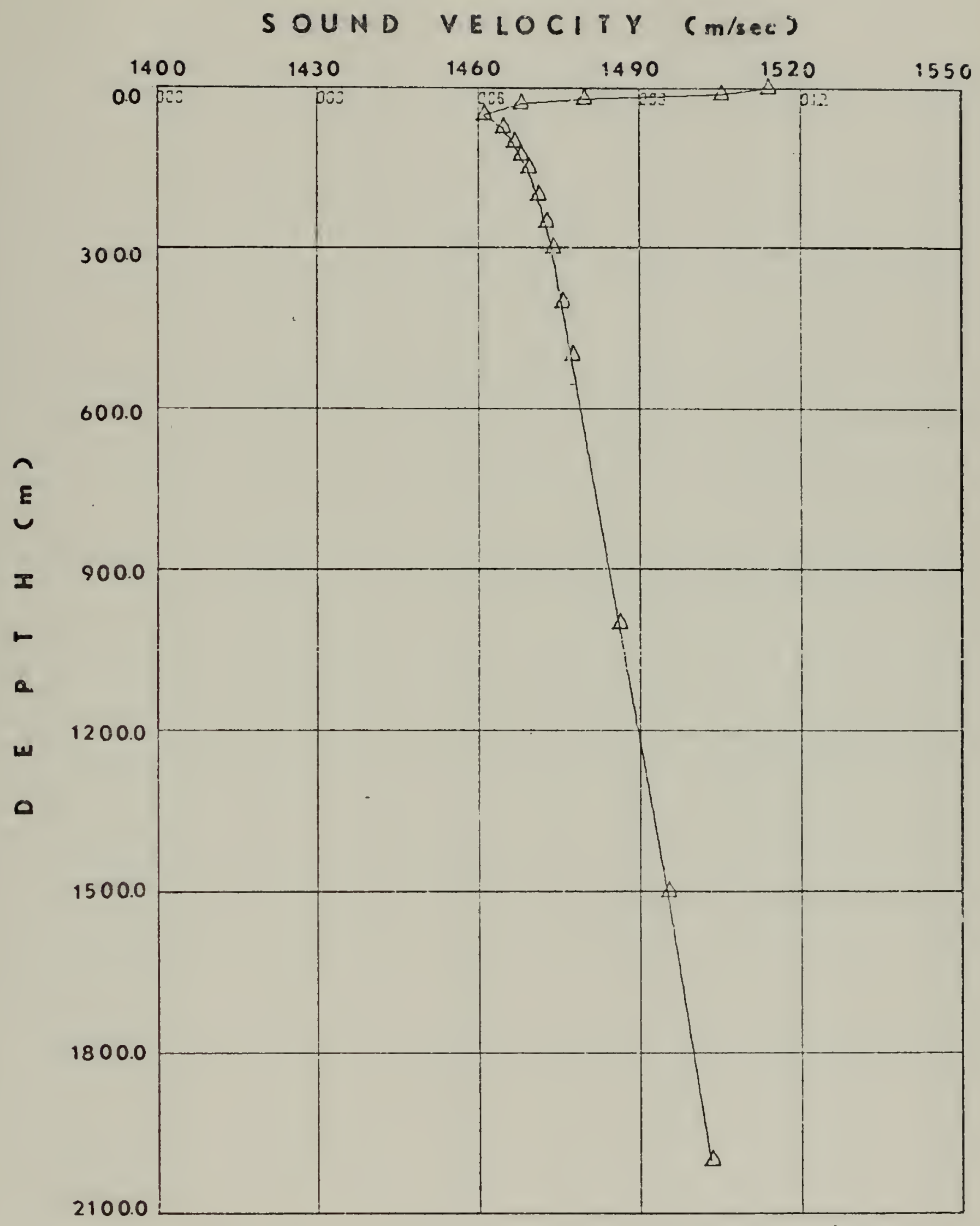

Figure 36. Average Sound Velocity Profile for August. 



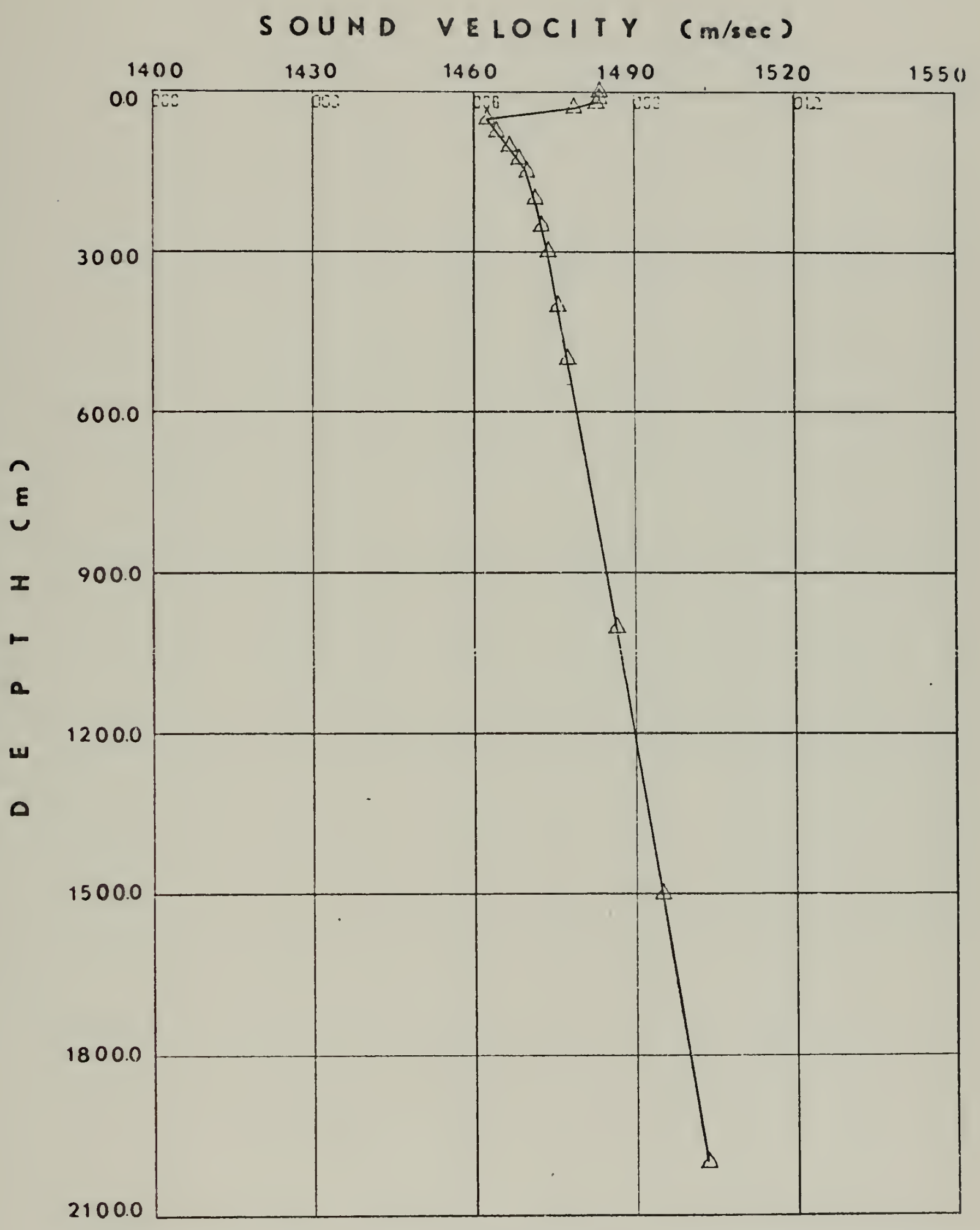

Figure 37. Average Sound Velocity Profile for November. 


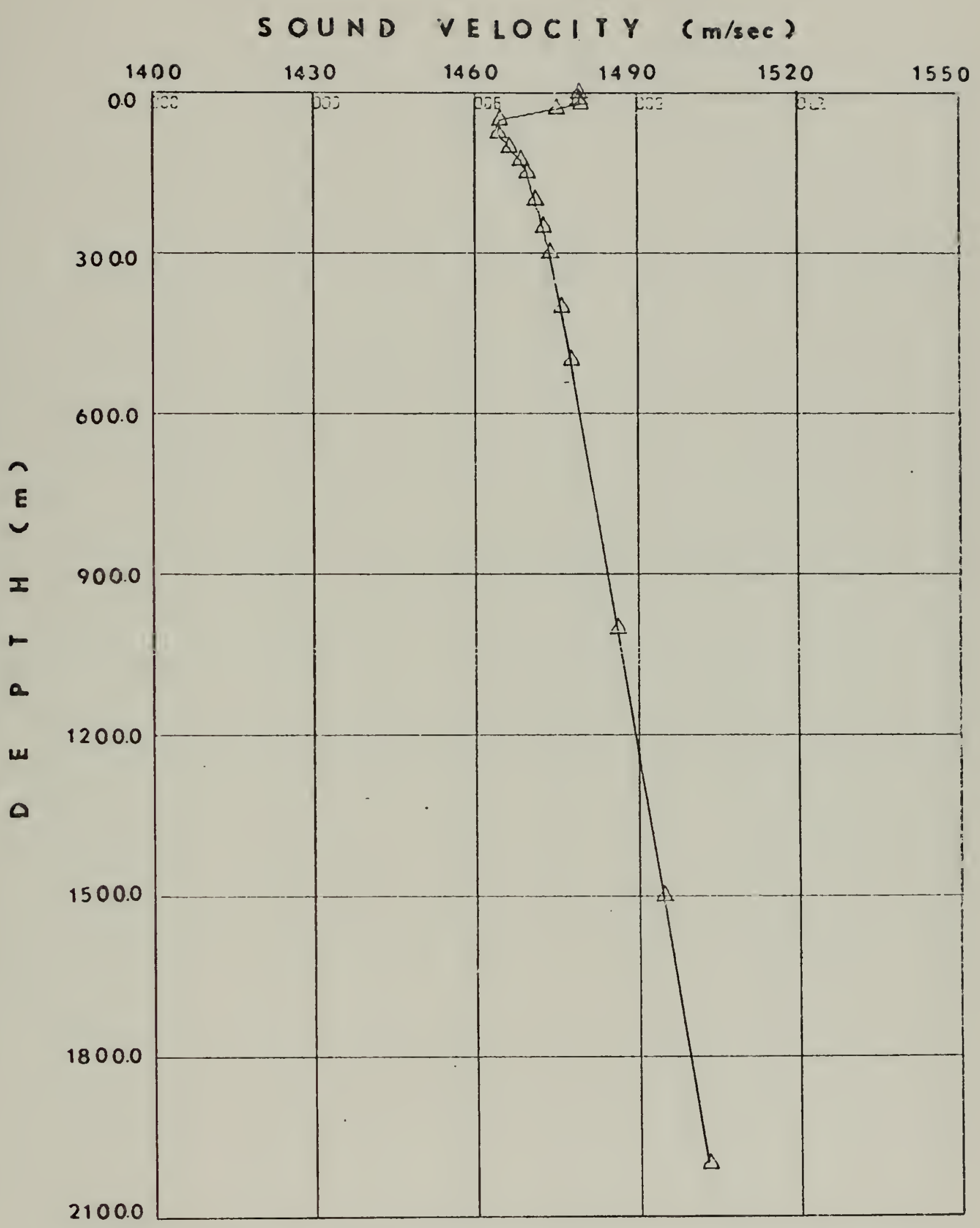

Figure 38. Average Sound Velocity Profile for December. 



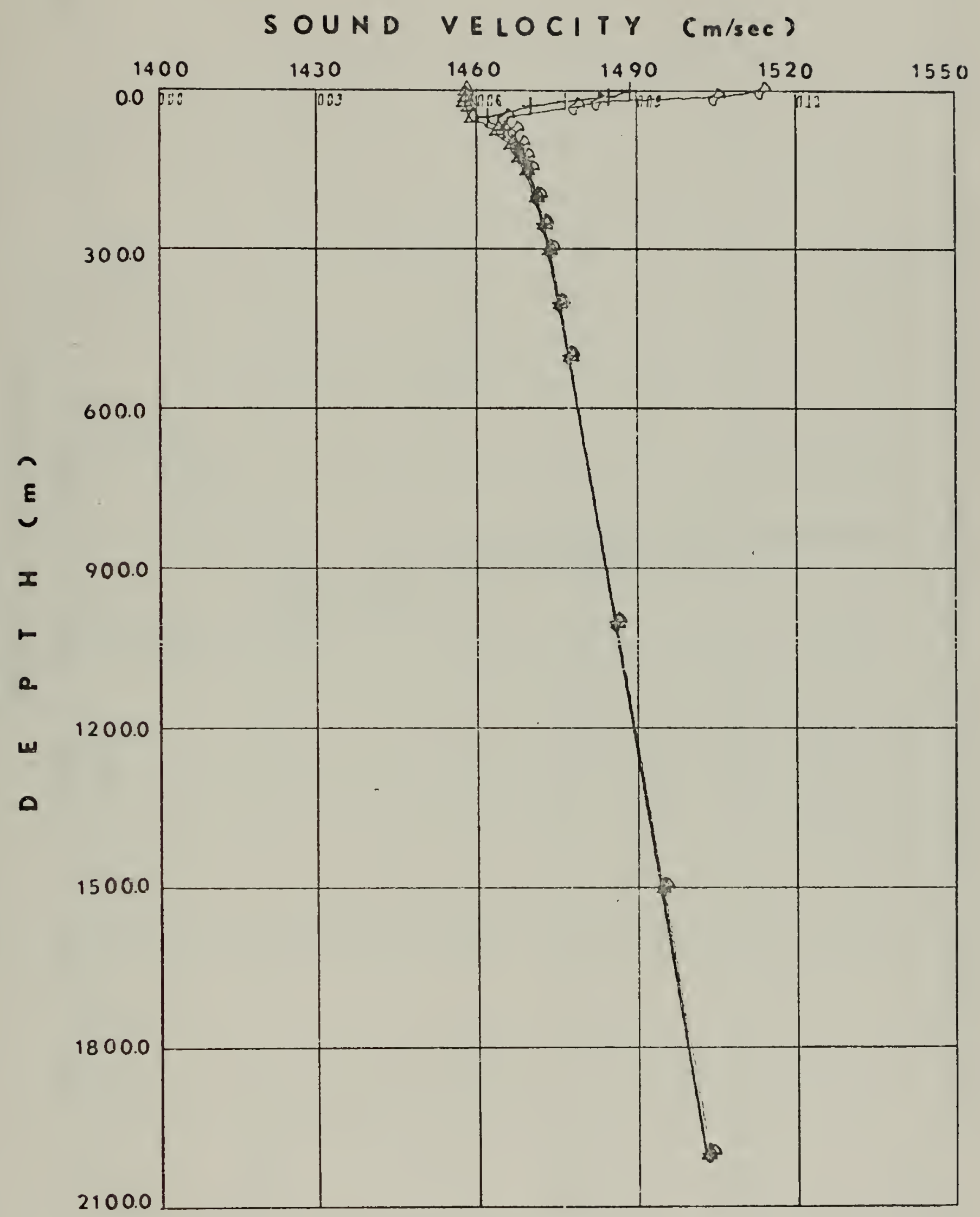

Figure 39. Annual Minimum, Maximum and Average Sound Velocity Profiles. 



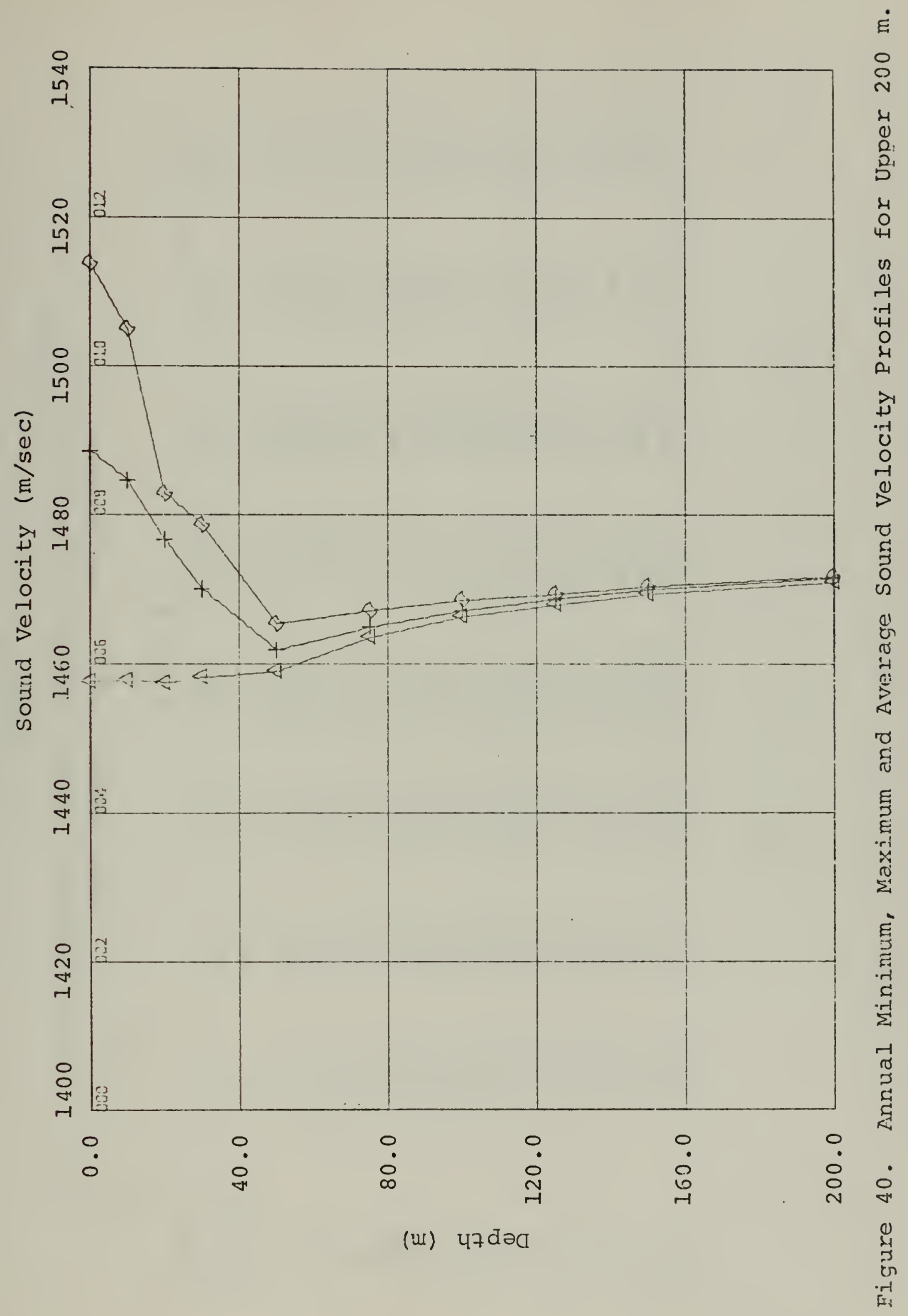





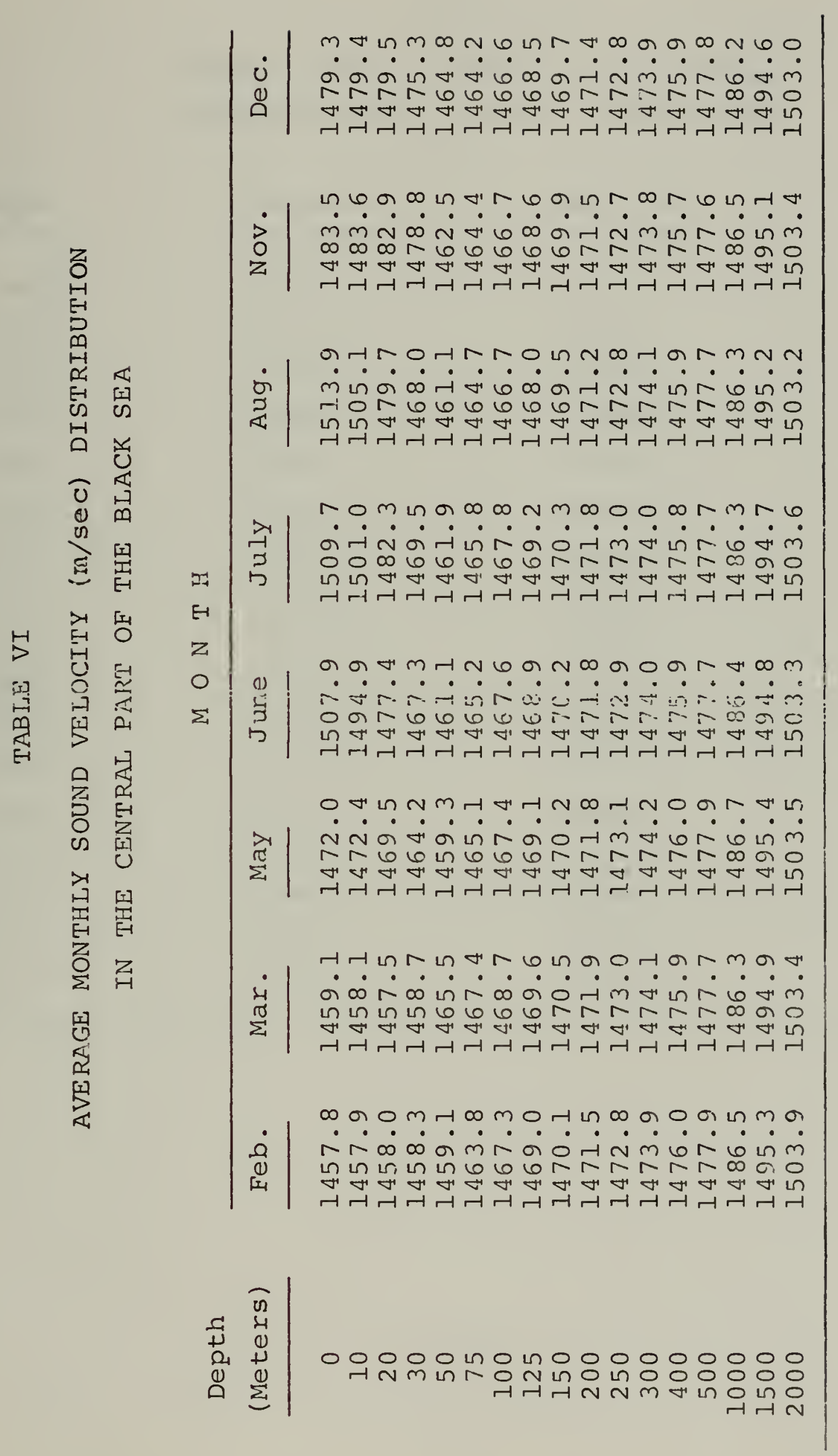





\section{TABLE VII}

ANNUAL MINIMUM, MAXIMUM AND AVERAGE SOUND VELOCITY (m/sec) DISTRIBUTION

\begin{tabular}{rccc} 
Depth & Minimum & Maximum & Average \\
\cline { 2 - 3 } 0.0 & 1457.8 & 1513.9 & 1488.8 \\
10.0 & 1457.9 & 1505.1 & 1484.7 \\
20.0 & 1457.5 & 1482.9 & 1476.8 \\
30.0 & 1458.3 & 1478.8 & 1470.1 \\
50.0 & 1459.1 & 1465.5 & 1461.9 \\
75.0 & 1463.8 & 1467.4 & 1465.2 \\
100.0 & 1466.6 & 1468.7 & 1467.3 \\
125.0 & 1468.0 & 1469.6 & 1468.9 \\
150.0 & 1469.5 & 1470.5 & 1470.0 \\
200.0 & 1471.2 & 1471.9 & 1471.7 \\
250.0 & 1472.7 & 1473.1 & 1472.9 \\
300.0 & 1473.8 & 1474.2 & 1474.0 \\
400.0 & 1475.7 & 1476.0 & 1475.9 \\
500.0 & 1477.6 & 1477.9 & 1477.7 \\
1000.0 & 1486.2 & 1486.7 & 1436.4 \\
1500.0 & 1494.6 & 1495.4 & 1495.0 \\
2000.0 & 1503.0 & 1503.9 & 1503.4 \\
\hline
\end{tabular}



B.

BOTTOM REELECTION

The sea bottom plays an important role in the propagation of sound acting as an acoustical reflector. A sound ray striking the bottom will be partly reflected and partly transmitted depending on the acoustic impedance contrast. The character of the bottom topography and the bottom sediments are the most important considerations. A flat bottom of nearly uniform compasition of clastic sediment provides very good bottom reflective conditions. For example, sand, would be expected to absorb a small fraction of the incident sounc and consequently reflect very well. But, irregular bottom topography and poorly sorted or soft sedinents tend to worsen bot-tom reflective conditions. Mud might be expected to absorb a Iarge iraction uf incident scume

According to Liebermann 19], the reflection properties of bottom sediments are classified such as:

"Mud is the poorest reflector, mud-sand nearly
as poor, sand-mud appreciably better, and sand
the best reflector of all; stony bottoms are
better reflectors than mud but worse, in
general, than sand."2

The bottom reflection coefficients in the central part of the Black Sea are calculated with several assumptions, because the bathymetry and the distribution of bottom sediments are not well known, and in addition the physical properties of

2 Liebermann, L. N., "Reflection of Sound from Coastal Sea Bottom," The Journal of the Acoustical Society of America, v. 20, No. 3, p. 305-309, May 1948. 

these sedimerts have not been determined. Therefore, the following assumptions are necessary:

1. The bottom of the sea is smooth and uniform.

2. The bottom is covered by clay. And the physical properties of this clay are taken to be the same as gray clay, which was described-by Nafe and Drake-[10].

The physical properties of sea water and bottom sediments in the selected stations are represented in Talle VIII.

The critical angle is the most important feature in bottom reflection. Because, as the sound hits the bottom with an angle less than critical angle, a part of the energy is transmitted to the bottom and the ray rapidly becomes weaker. But, if the sound ray hits the bottom with an -ancle equal to or greater hath the citidal ongle, little acoustic energy is transmitted into the bottom.

The bottom critical angles in the: Black Sea were calculated by Snell's law where the critical angle is defined by the relation [1].]:

$$
\sin \theta_{c}=\frac{c_{1}}{c_{2}}
$$

where,

$$
\begin{aligned}
& \theta_{c}=\text { Critical angle (Degrees) } \\
& c_{1}=\text { Sound velocity in the sea water (m/sec) } \\
& c_{2}=\text { Sound velocity in the bottom sediment (m/sec) }
\end{aligned}
$$

Computed critical angles in selected stations for several months are given in Table IX. It can be seen from the table, that the critical angles in the central part of the Black Sea 

change from $69^{\circ} 40^{\prime}$ to $73^{\circ} 19^{\prime}$. Therefore, any sound ray that hits the bottom with an angle greater than $73^{\circ} 19^{\prime}$ will be mostly reflected.

The bottom reflection coefficients are obtained from Rayleigh's formula. According to this formula, bottom amplitude reflection coefficients are defined by the relation [12]:

$$
R=\frac{\rho_{2} c_{2} \cos \theta_{i}-\rho_{1} c_{i} \cos \theta_{t}}{\rho_{2} c_{2} \cos \theta_{i}+\rho_{1} c_{1} \cos \theta_{t}}
$$

where,

$$
\begin{aligned}
& \mathrm{R}=\text { Reflection coefficient } \\
& \rho_{1}=\text { Density of the sea water }\left(\mathrm{g} / \mathrm{cm}^{3}\right) \\
& c_{1}=\text { Sound velocity in the sea water }(\mathrm{m} / \mathrm{sec}) \\
& \hat{\theta}_{2}=\text { nonsity cf the bottom sediment }\left(\mathrm{g} / \mathrm{cm}^{3}\right) \\
& c_{2}=\text { Sound velocity in the bottom sediment (m/sec) } \\
& \theta_{i}=\text { Incident angle (Degrees) } \\
& \theta_{t}=\text { Transmitted aingle (Degrees) }
\end{aligned}
$$

Reflection coefficients for each incident angle are given in Table IX. From this table, it can be observed that the reflection coefficients change very slightly with incident angle and they reach unity at the critical angle. Figure 4l, 42 and 43 represent reflectivity versus incident angle diagrams for Fetruary, May and October. The data for these diagrams is obtained from $\mathrm{Table} I X$. 



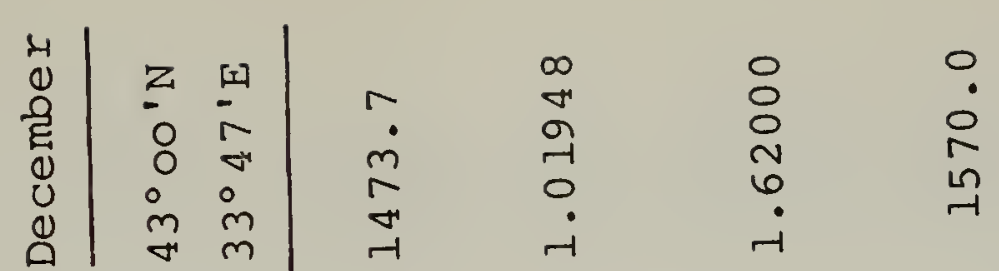

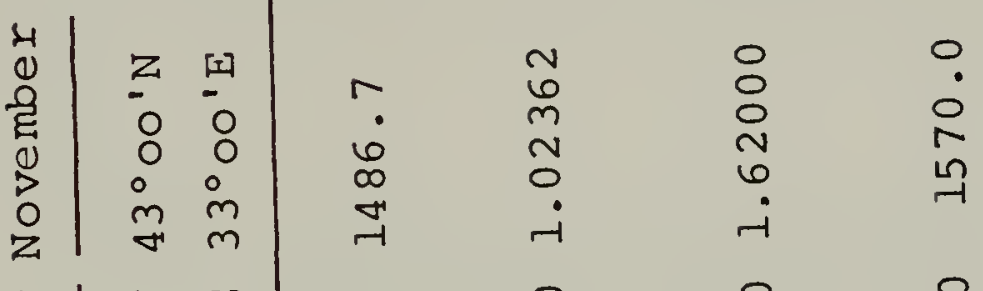

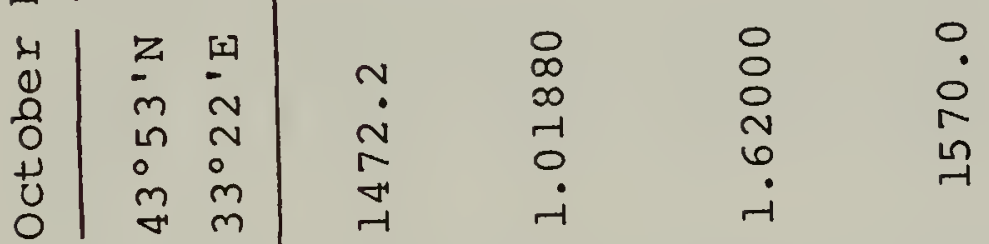

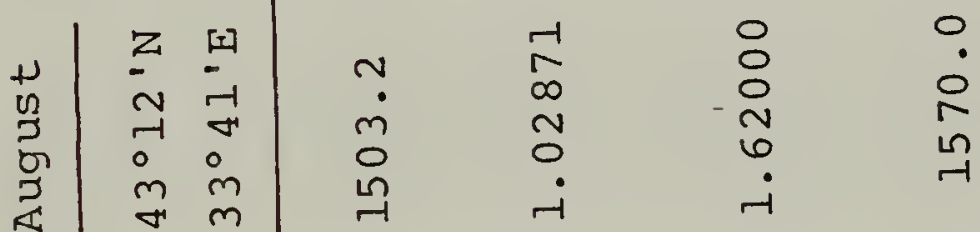

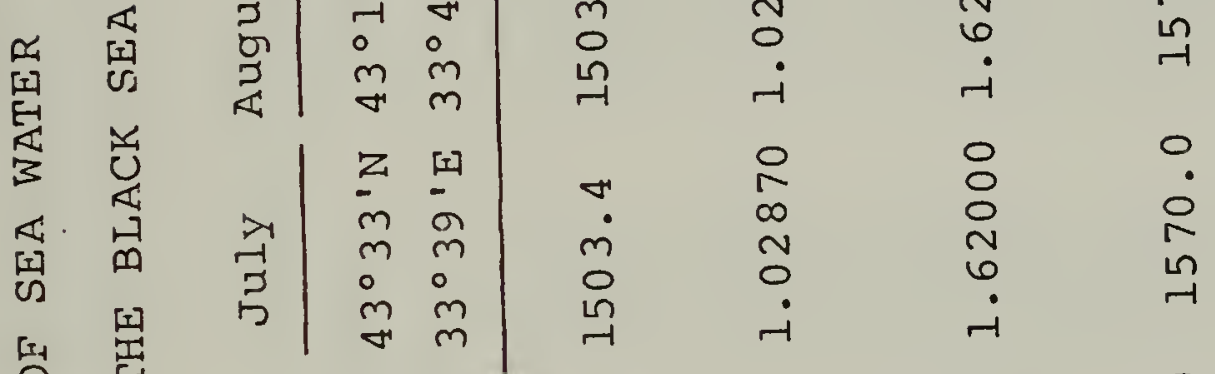

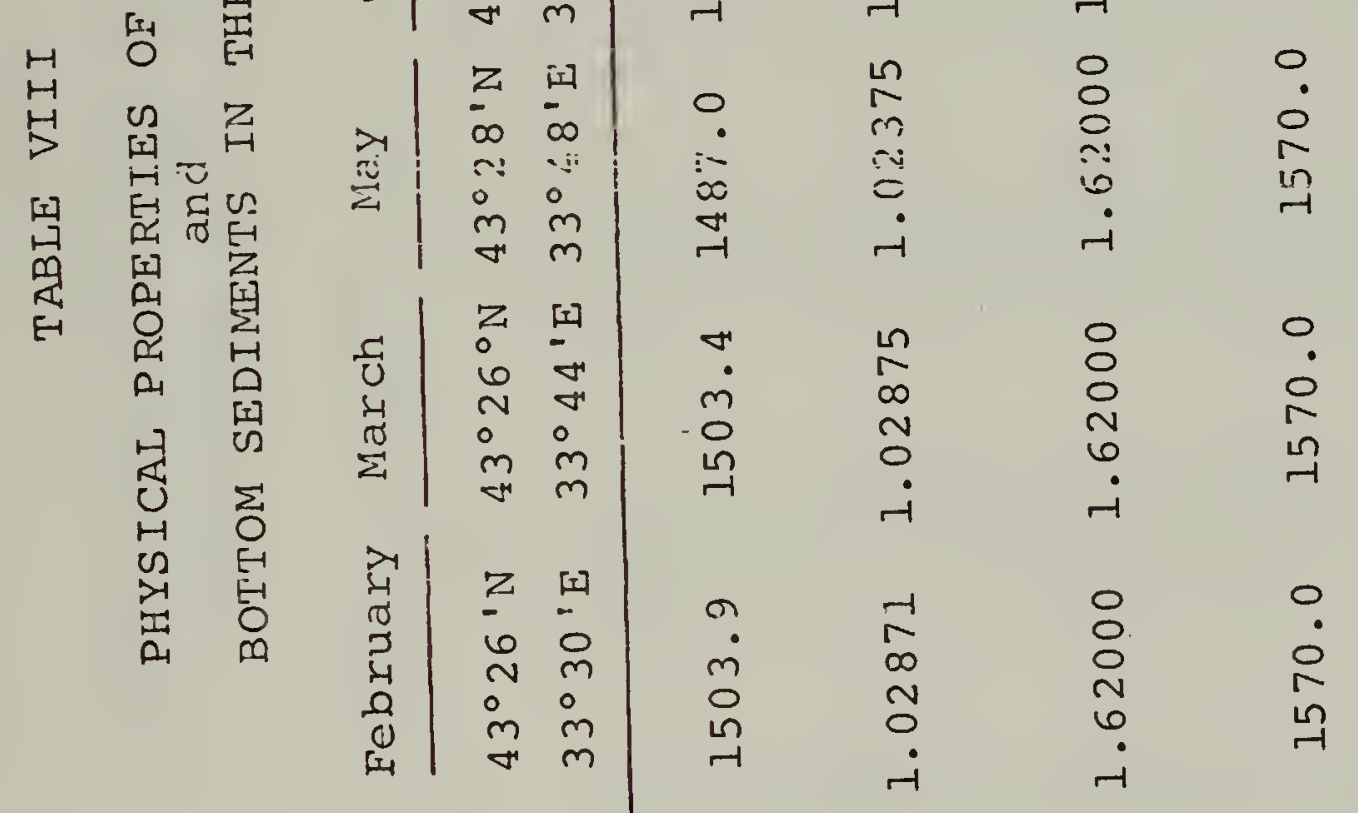

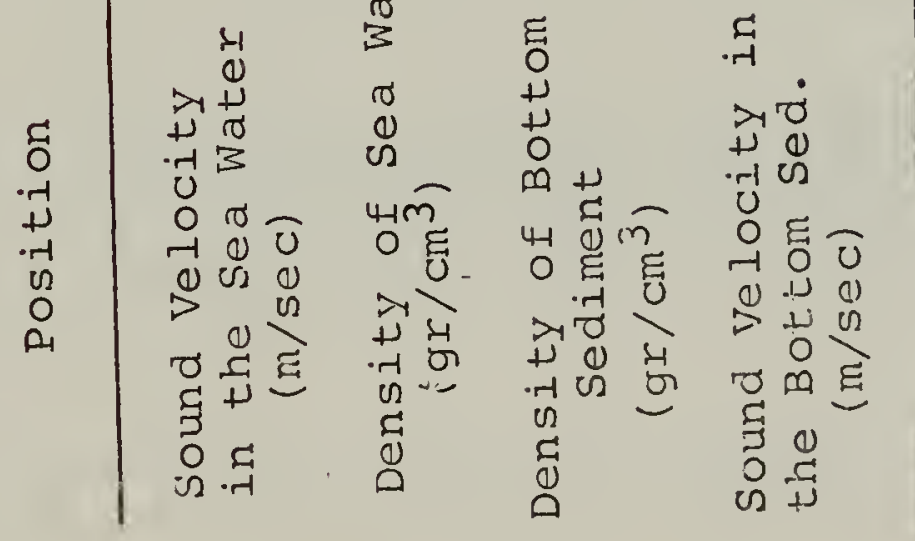





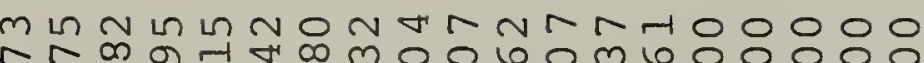

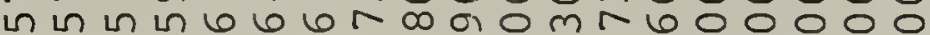
nN N N N N N N N

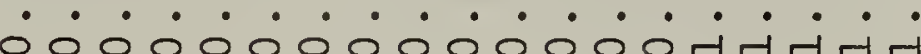

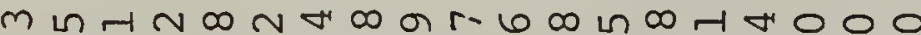

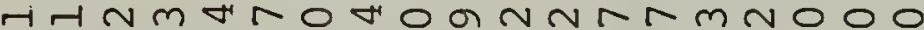

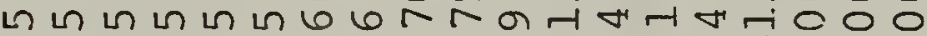
N $N$ N $N$ N N N

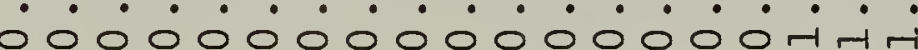

으의에 $\infty \pi$ a on

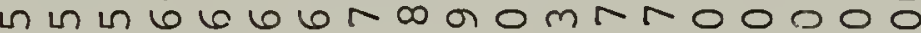

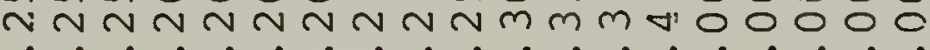

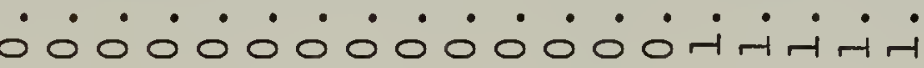

narmb

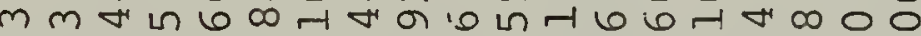

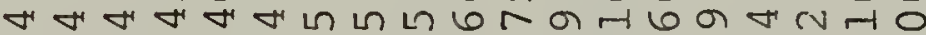
N N N N N N N N N M T I 6 T 0 0ं0் $0 \dot{0} 0 \dot{0} \dot{0} 0 \dot{0} \dot{0} \dot{0} 0 \dot{0}$

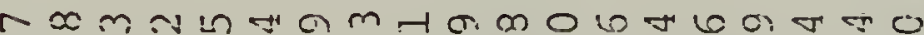
m m न in $6 \infty$ o

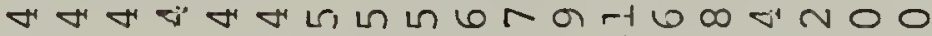
N N N N N N N N N N N M M L 0ं0் $\dot{0} \dot{0} \dot{0} \dot{0} \dot{0} \dot{0} \dot{0} \dot{0} \dot{0} \dot{0} \dot{1}$

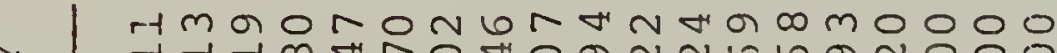
Hनm

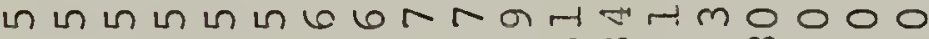
N N N N N N N N N $N$ N

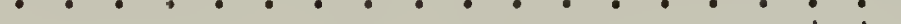
$00000000000000004 \mathrm{H}^{-1}$

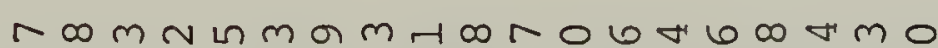

5
-1
$\sum$ $m m$ in $6 \infty 0$ \% A A A A t N N N N N N N N $N$ M

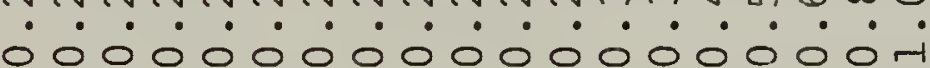

\section{मे
0
3
दे
0
0
01
[1}

Ln NOmNR

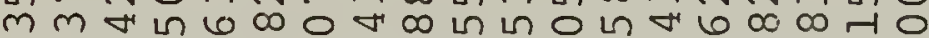

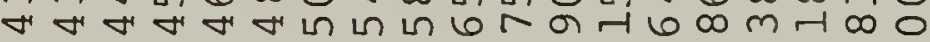

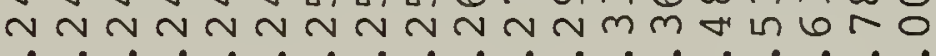
0 $\dot{0} \dot{0} \dot{0} \dot{0} \dot{0} \dot{0} \dot{0} \dot{0} \dot{0} \dot{0} \dot{0} \dot{0} \dot{0}$ 



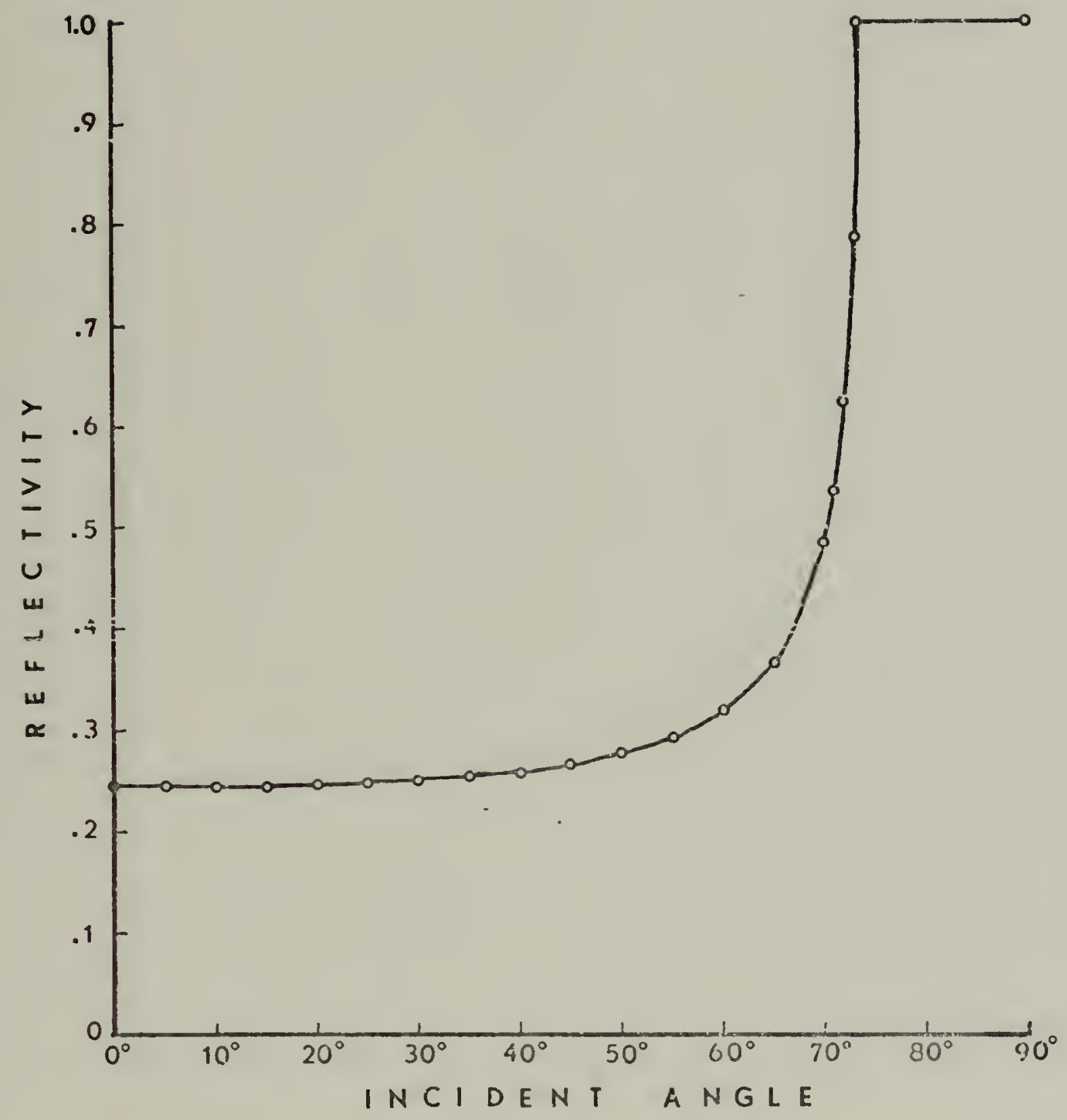

Figure 41. Reflectivity Versus Incident Angle Diagram for February. 



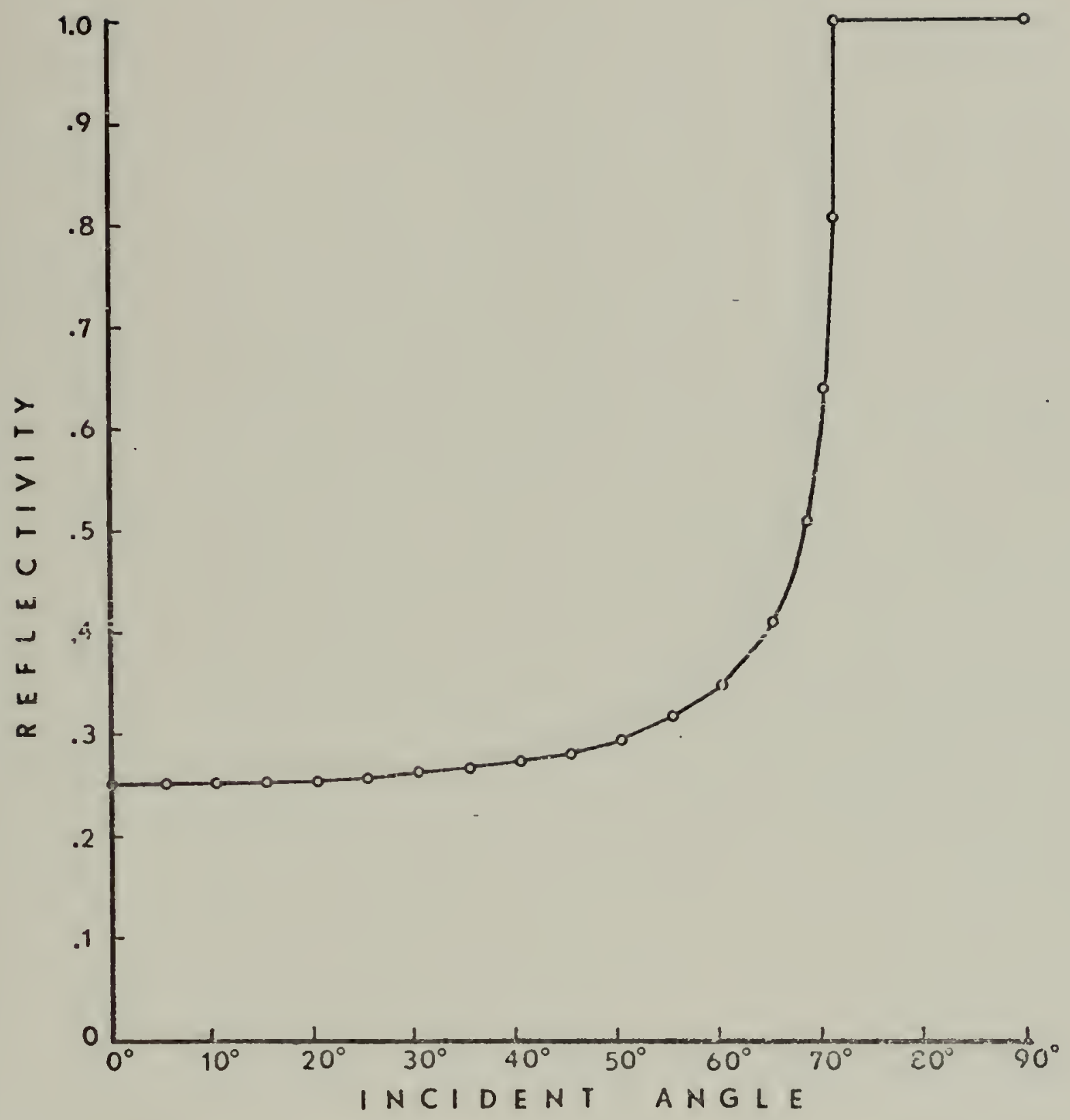

Figure 42. Reflectivity Versus Incident Angle Diagram for May.

80 



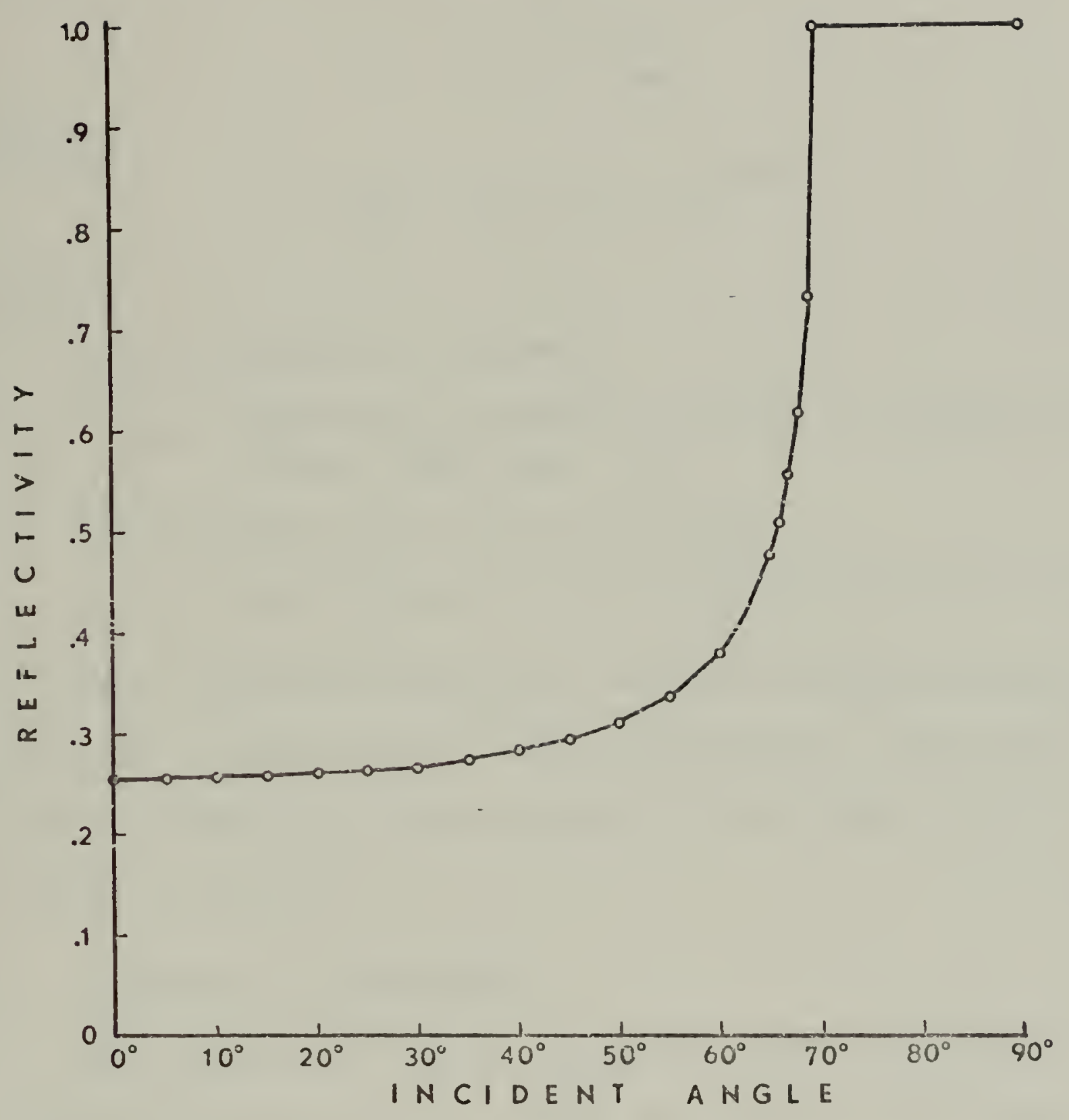

Figure 43. Reflectivity Versus Incident Angle Diagram for october. 



\section{DUCT PROPAGATION}

Duct propagation in the Black Sea is limited as the mixed layer is very shallow if present. The maximum wavelength that can be contained in a duct is given by:

$$
E_{c}=\frac{C}{\lambda_{\max }}
$$

where,

$$
\lambda_{\max }=4.7 \times 10^{-3} \mathrm{H}^{3 / 2}
$$

and,

$$
\begin{aligned}
& \mathrm{f}_{\mathrm{C}}=\text { Cutoff low frequency } \\
& \begin{aligned}
\lambda_{\text {max }}= & \text { Maximum wavelength that can be trapped in a } \\
& \text { mixed layer duct ( } \mathrm{ft})
\end{aligned} \\
& \mathrm{H}=\text { Mixed layer duct thick ( } \mathrm{It}) \\
& \mathrm{C}=\text { Sound velocity in the mixed layer duct (ft/sec) }
\end{aligned}
$$

For frequencies below the cutoff irequency attenuation increases rapidly during duct propagation. Low cutoff frequency values for several months in the Black Sea are represented in Table $x$.

\section{SURFACE BACKSCATTERING}

The surface of the sea plays an important part in the propogation of acoustic energy by confining and dispersing sound that impinges upon it. If, the surface of the sea was an ideal plane surface, it should act like a mirror, merely reflecting any incident sound energy into the reflected angle and producing no distribution of energy other than this single change of direction. But the sea surface is generally 

rough, when a pulse of underwater sound strikes the surface, a portion of its energy is returned or reradiates back to the source. This reradiation of sound is called sea surface backscattering [13].

The degree of scattering of the sea surface has been found to change with grazing angle, frequency and the roughness of the surface.

The sea surface backscattering strength in the central part of the Black Sea for several months was calculated using the formula of Schulkin and Shaffer's [14]. According to this formula, backscattering strength is given by the relation:

$$
s_{s}=10 \log (f h \sin \theta)^{0.99}-45.3
$$

where,

$$
\begin{aligned}
& \mathrm{s}_{\mathrm{S}}=\text { Sea surface backscattering strength } \\
& \mathrm{h}=\text { The mean peak-trough sea surface roughness (ft) } \\
& \mathrm{f}=\text { Frequency ( } \mathrm{kHz} \text { ) } \\
& \theta=\text { Grazing angie (Degrees) }
\end{aligned}
$$

To obtain backscattering strength, a relationship was used between sea surface roughness and wind speed which was also given by Schulkin and Shaffer as:

$$
\mathrm{h}=0.026 \mathrm{v}^{5 / 2}
$$

where,

$$
\begin{aligned}
& \mathrm{V}=\text { Wind speed }(\mathrm{knt}) \\
& \mathrm{h}=\text { Sea surface roughness (ft) }
\end{aligned}
$$



Monthly wind speed values in the central part of the Black Sea were obtained from surface wind charts [16].

Table XI gives backscattering strength as found from the above formula. The frequency used to calculate backscattering strength was the lowest frequency that could be contained in the surface duct. Frequencies lower than this would be strongly attenuated by leakage from the duct. Figures 44 through 50 are obtained from Table XI, and show backscattering versus grazing angle diagrams for several months. Tables XII, XIII, and XIV give backscattering strength values calculated for 10,15 and $20 \mathrm{kHz}$.

Given the backscattering strength $\left(S_{S}\right)$ as a function of grazing angle $(\theta)$ the reverberation level $\mathrm{RL}_{\mathrm{S}}$ can be calculated by the following relationship [20]:

$$
R L_{S}=S L-40 \log r+S_{S}+10 \log A
$$

where,

$$
\begin{aligned}
S L & =\text { Source level } \\
r & =\text { Range } \\
A & =\frac{C \gamma}{2} \phi_{r}
\end{aligned}
$$

and

$$
\begin{aligned}
C & =\text { Speed of sound } \\
\gamma & =\text { Ping length } \\
\Phi_{r} & =\text { The equivalent ideal width }
\end{aligned}
$$

The reverberation level expected for a given range can be determined if the ray path from the source is known. The ray diagram provides this information 

TABLE $X$

MONTHLY SURFACE BACKSCATTERING PARAMETERS

in

THE CENTRAL PART OF THE BLACK SEA

Sea

\begin{tabular}{|c|c|c|c|c|}
\hline Month & $\begin{array}{c}\text { Wind } \\
\text { Velocity } \\
\text { (Knt.) }\end{array}$ & $\begin{array}{c}\text { Surface } \\
\text { Roughness } \\
(\text { Ft.) }\end{array}$ & $\begin{array}{l}\text { Cutoff } \\
\text { Frequency } \\
(\mathrm{Hz} .)\end{array}$ & $\begin{array}{c}\text { Duct } \\
\text { Thickness } \\
\text { (Ff.) }\end{array}$ \\
\hline May & 16.71 & 2.985 & -1915.14 & 66.0 \\
\hline June & 19.43 & 4.343 & 5523.68 & 33.0 \\
\hline July & 5.83 & 0.214 & 5558.92 & 33.0 \\
\hline August & 10.49 & 0.935 & 3079.46 & 49.0 \\
\hline October & 23.51 & 7.020 & 1411.60 & 82.0 \\
\hline ivovemiuer & 6.99 & $\hat{0} .338$ & 2054.70 & 39.0 \\
\hline De cember & 6.99 & 0.338 & 1395.01 & 82.0 \\
\hline
\end{tabular}





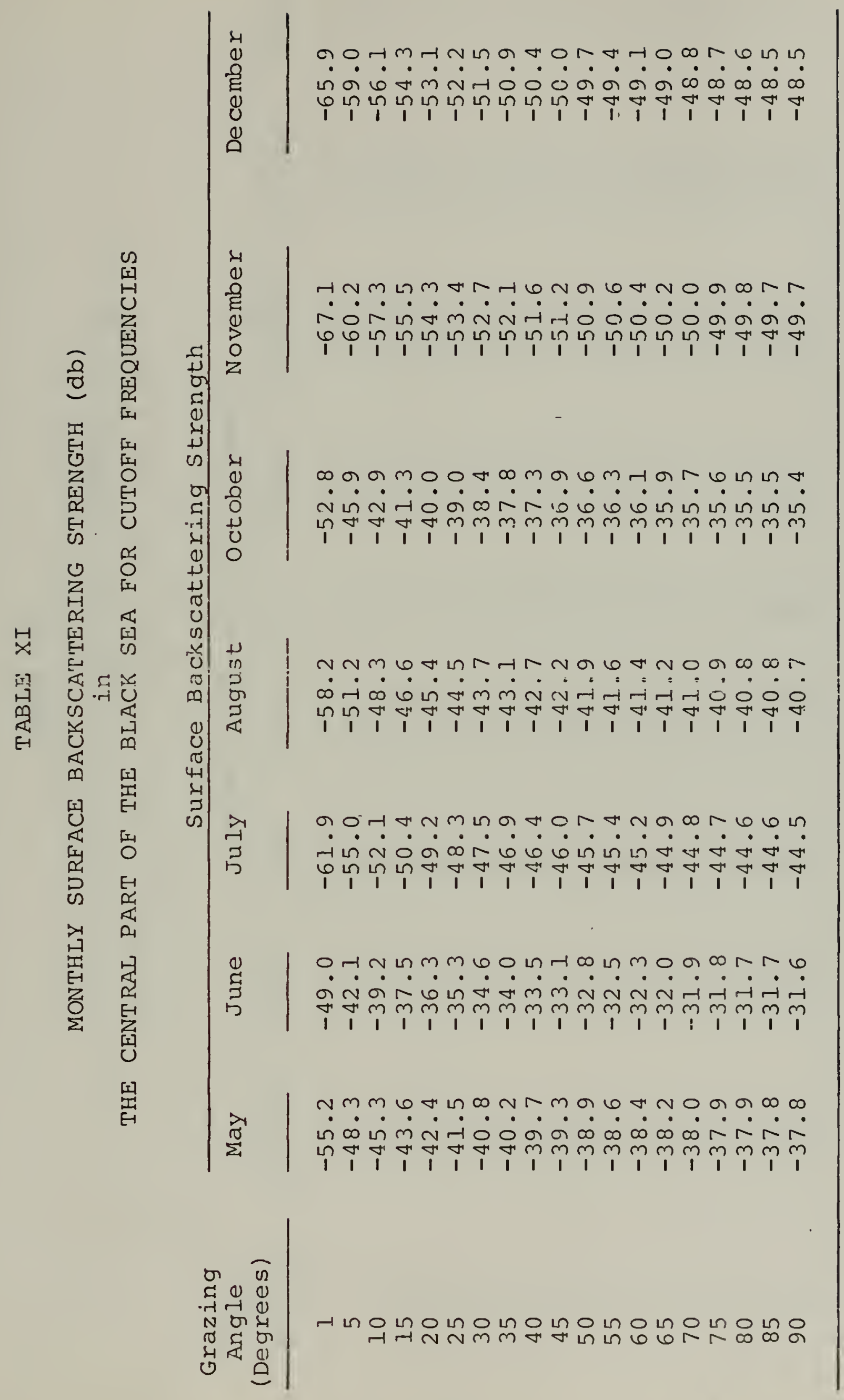





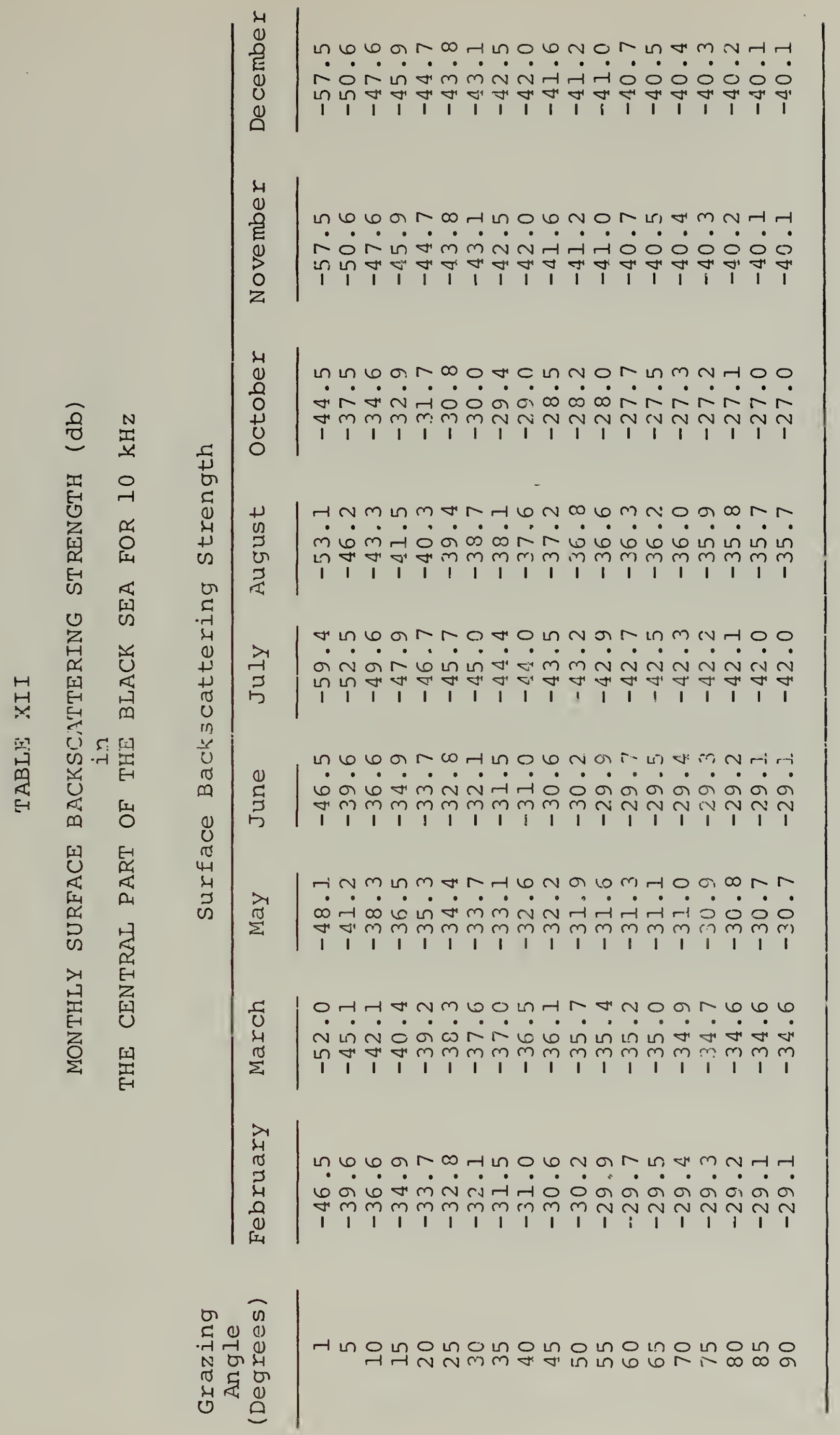





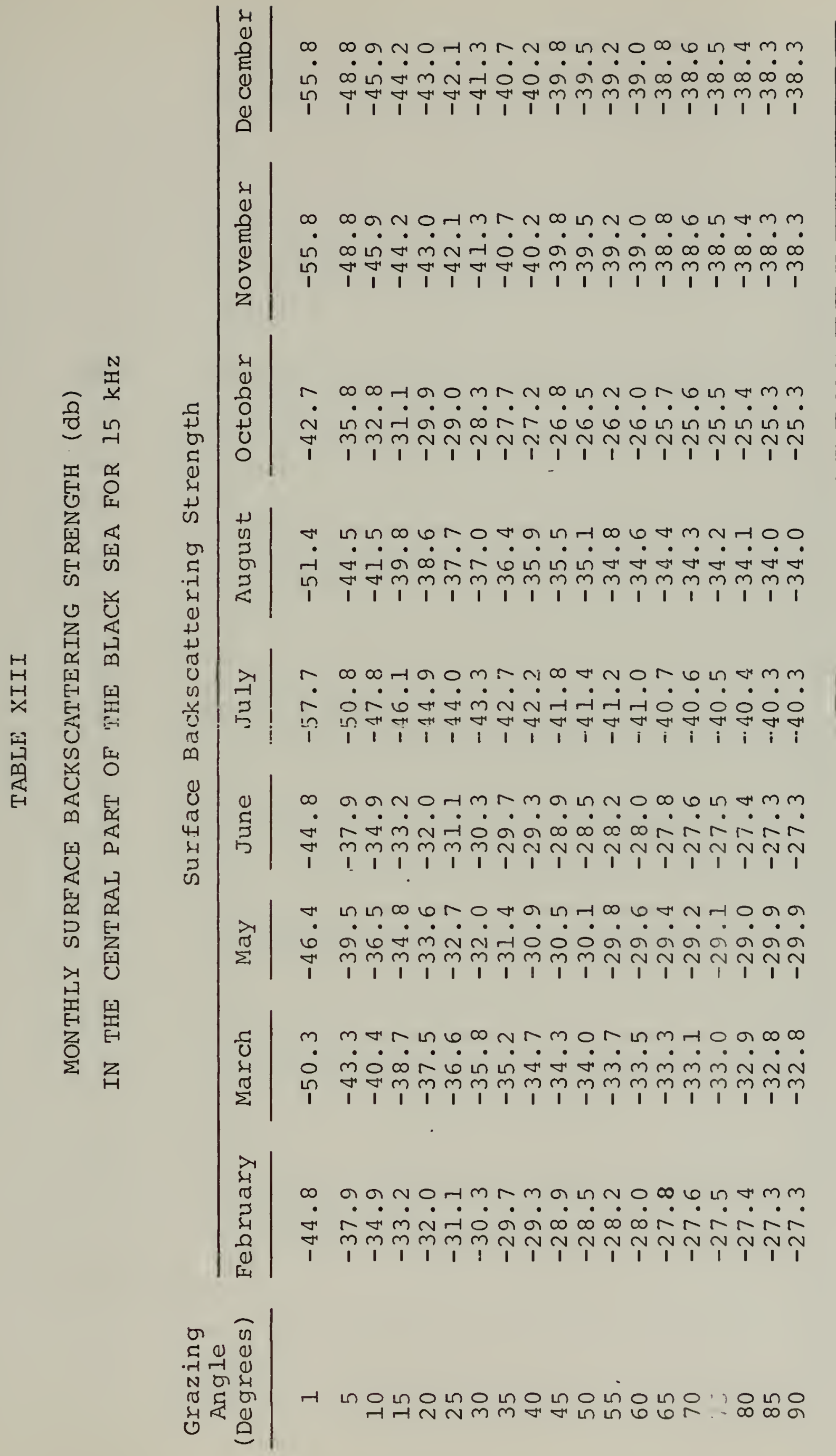





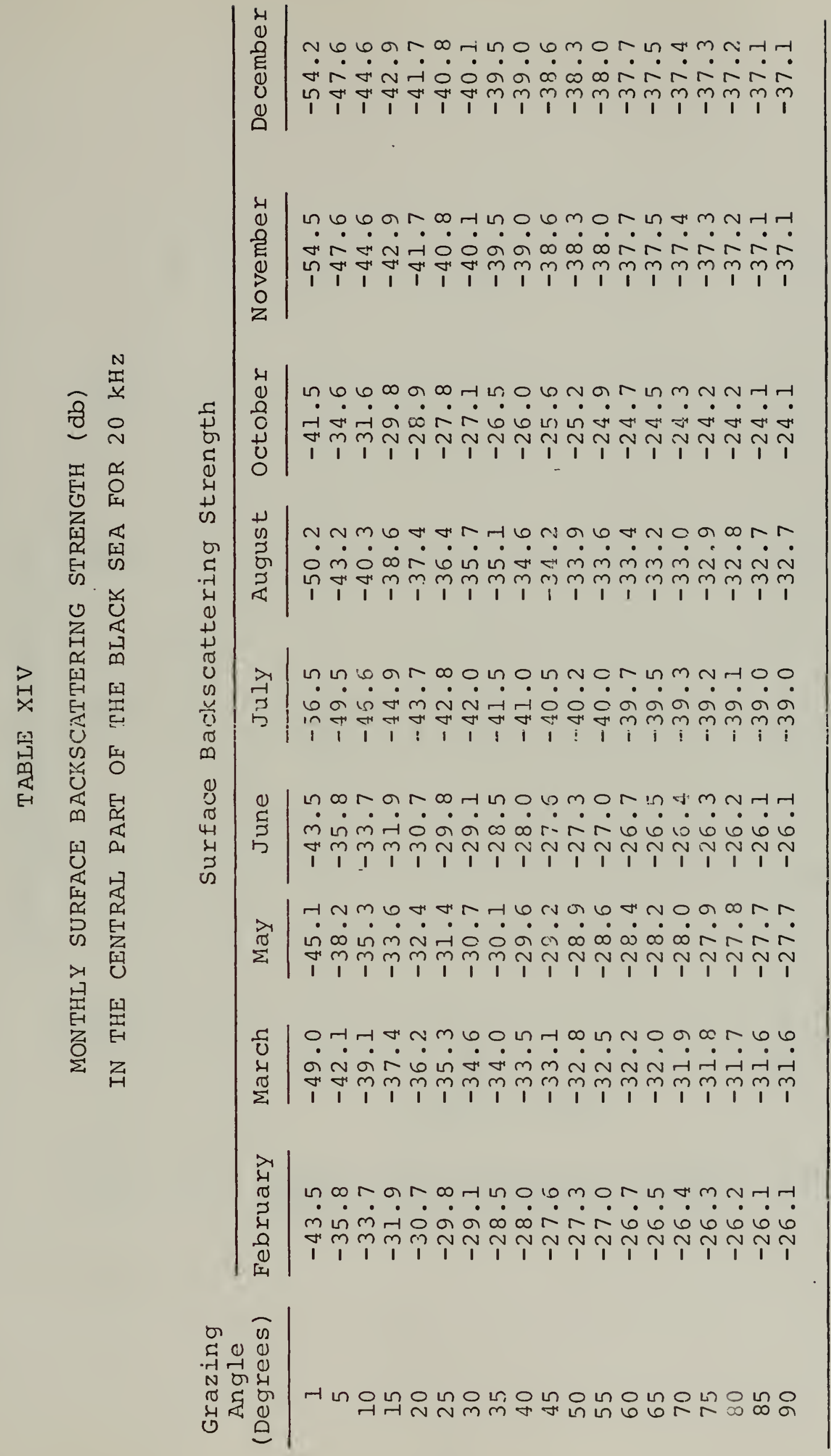





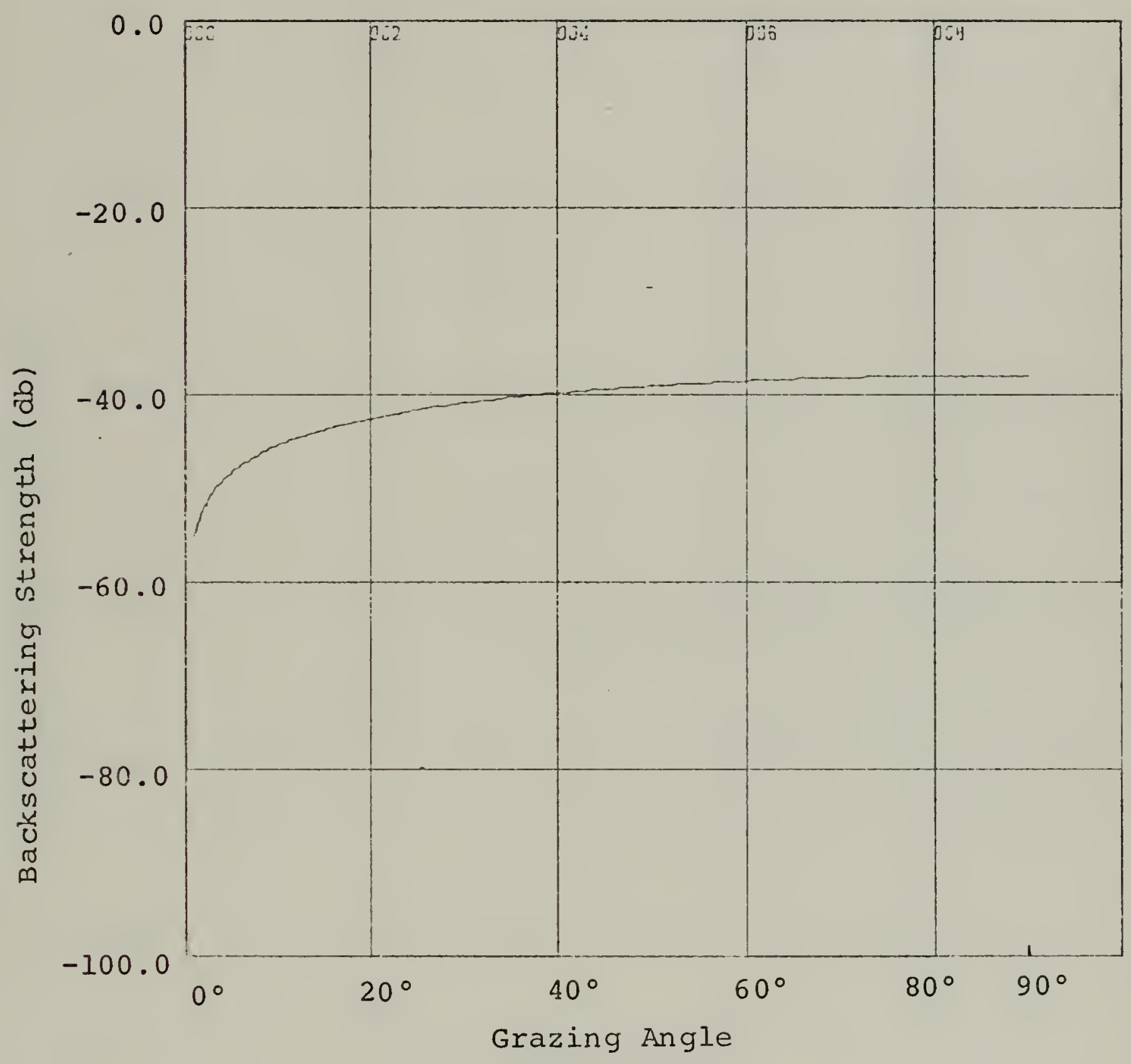

Figure 44. Surface Backscattering Strength Versus Grazing Angle Diagram for May. 



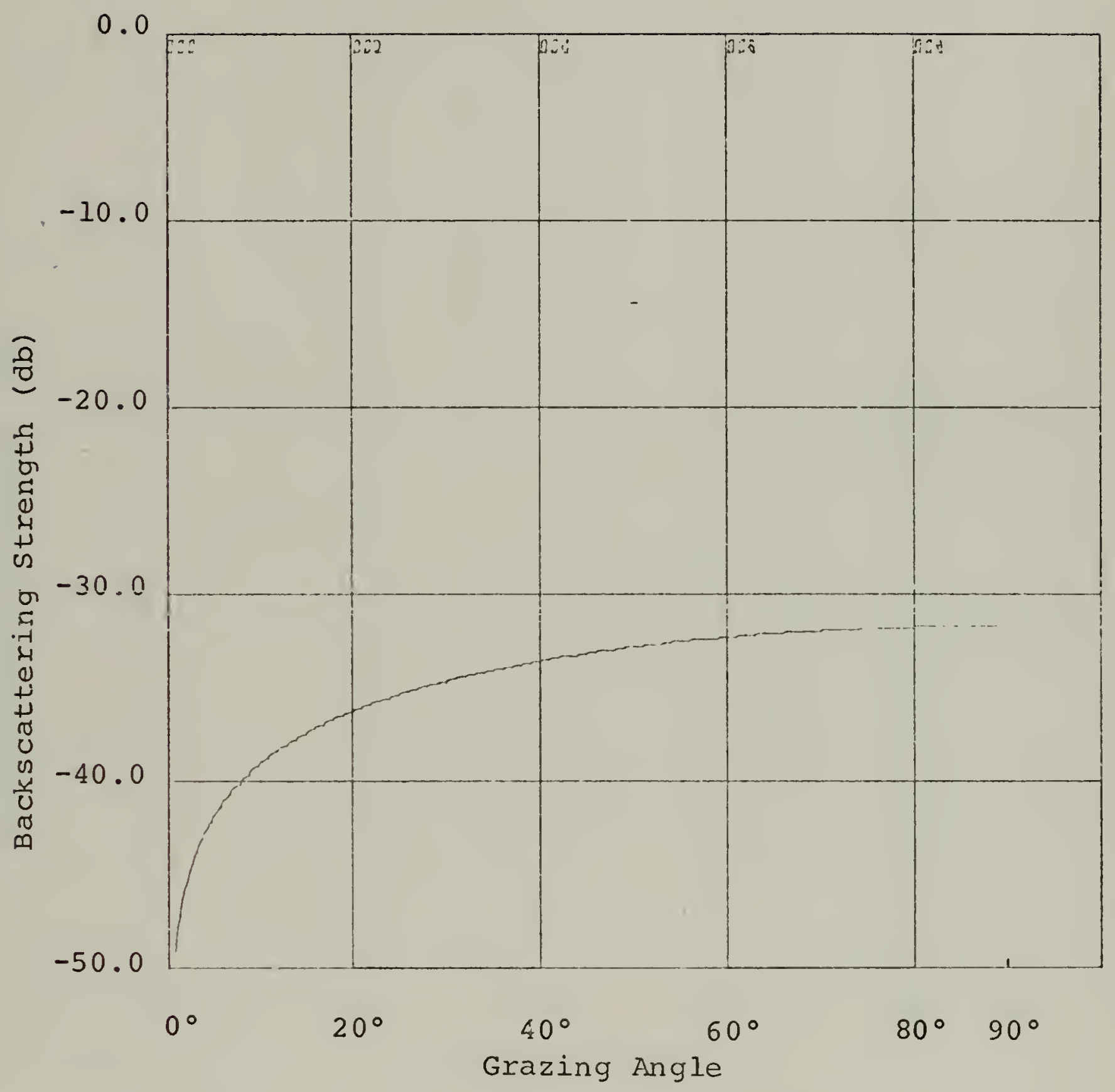

Figure 45. Surface Backscattering Strength Versus Grazing Angle Diagram for June. 



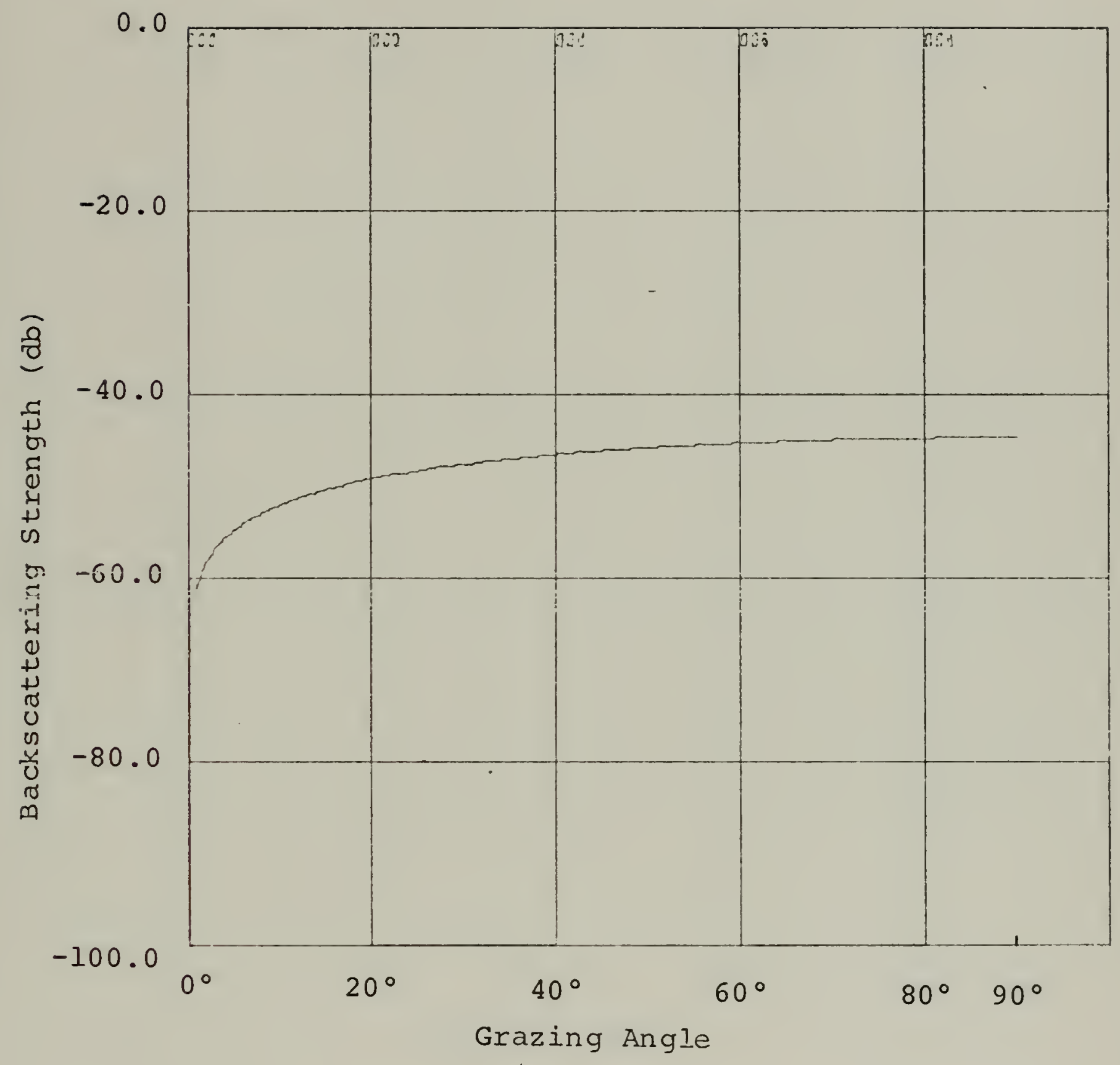

Figure 46. Surface Backscattering Strength Versus Grazing Angle Diagram for July. 



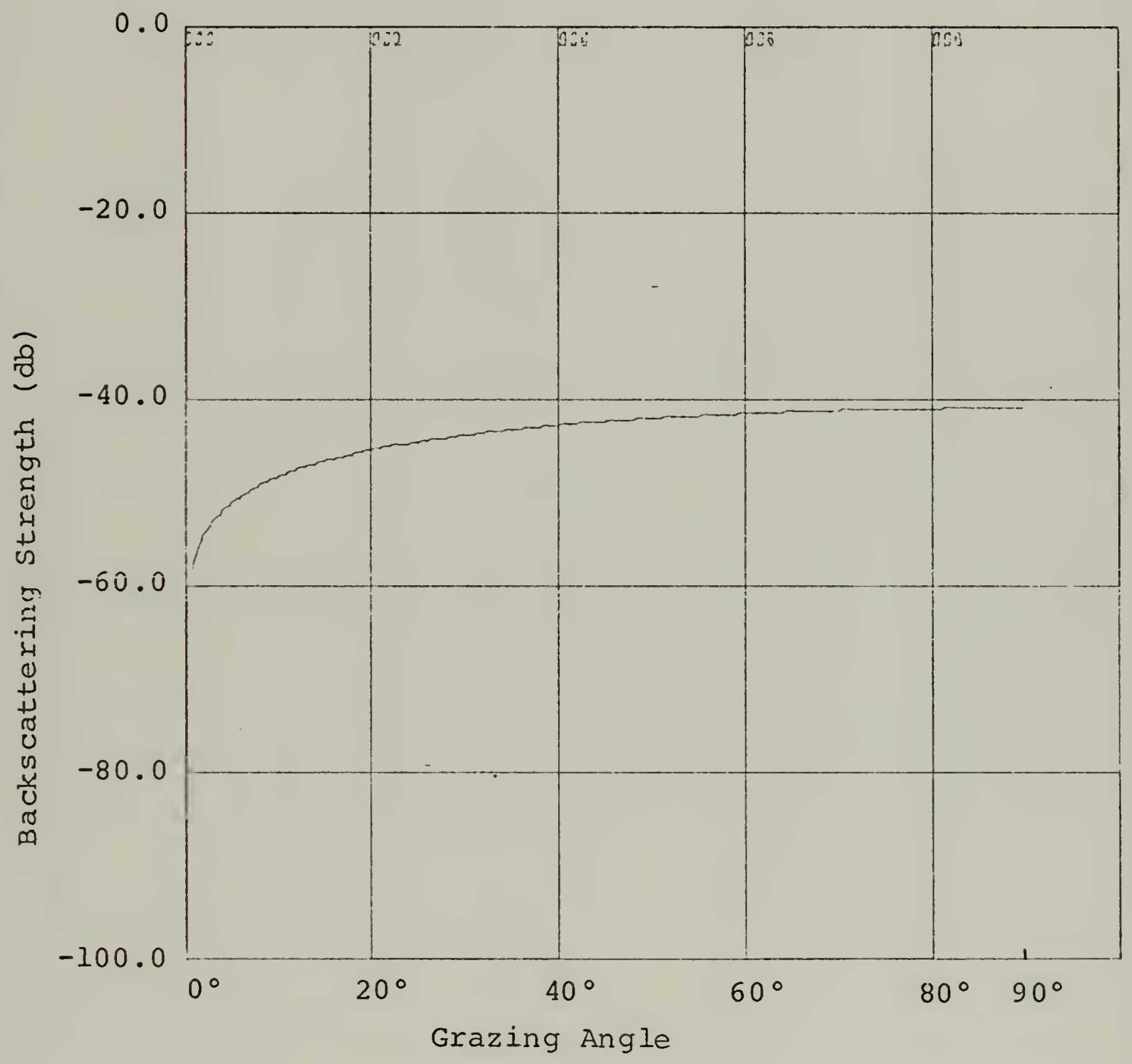

Figure 47. Surface Backscattering Strength Versus Grazing Angle Diagram for August. 



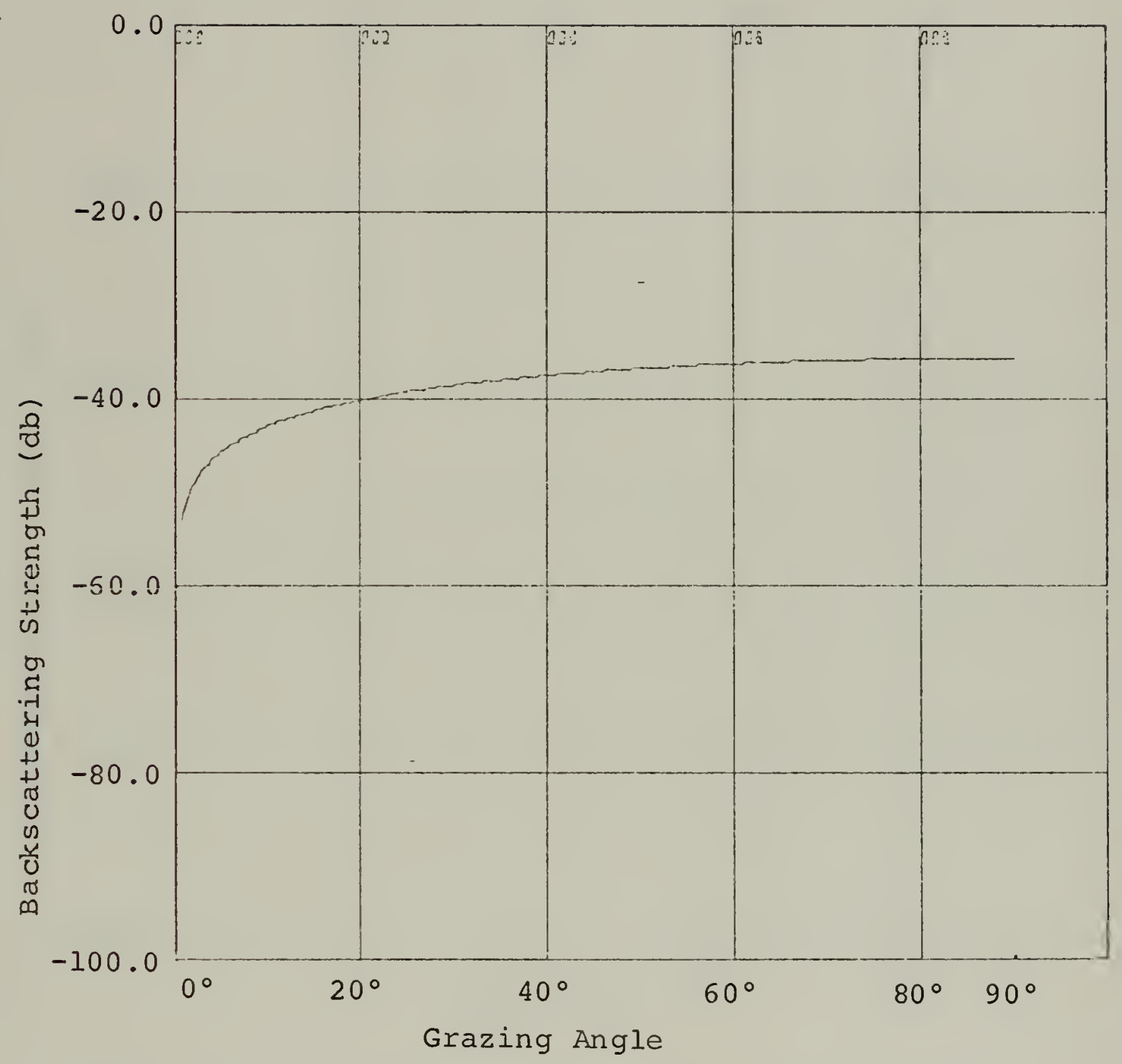

Figure 48. Surface Backscattering Strength Versus Grazing Angle Diagram for October. 



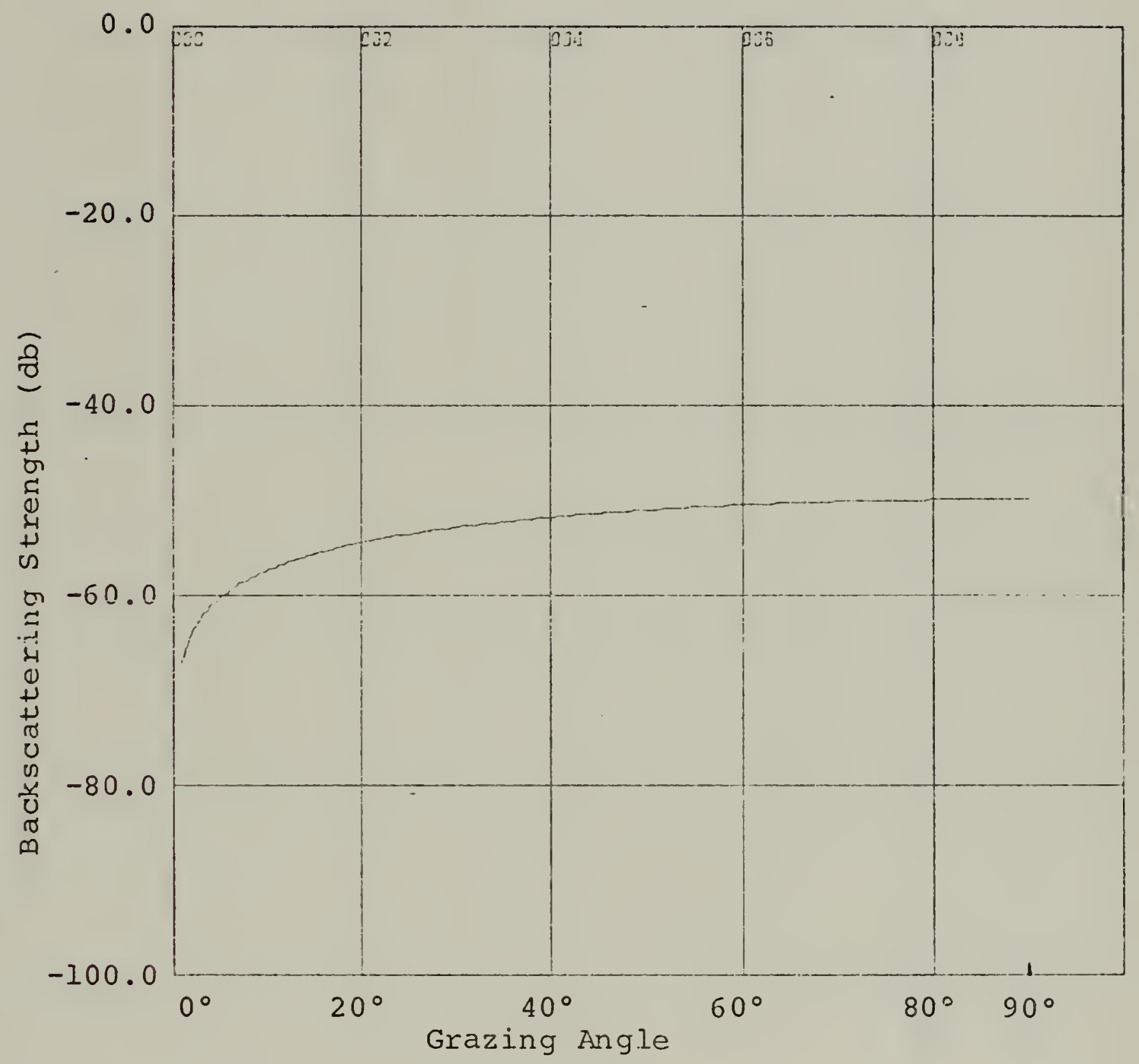

Figure 49. Surface Backscattering Strength Versus Grazing Angle Diagram for November. 



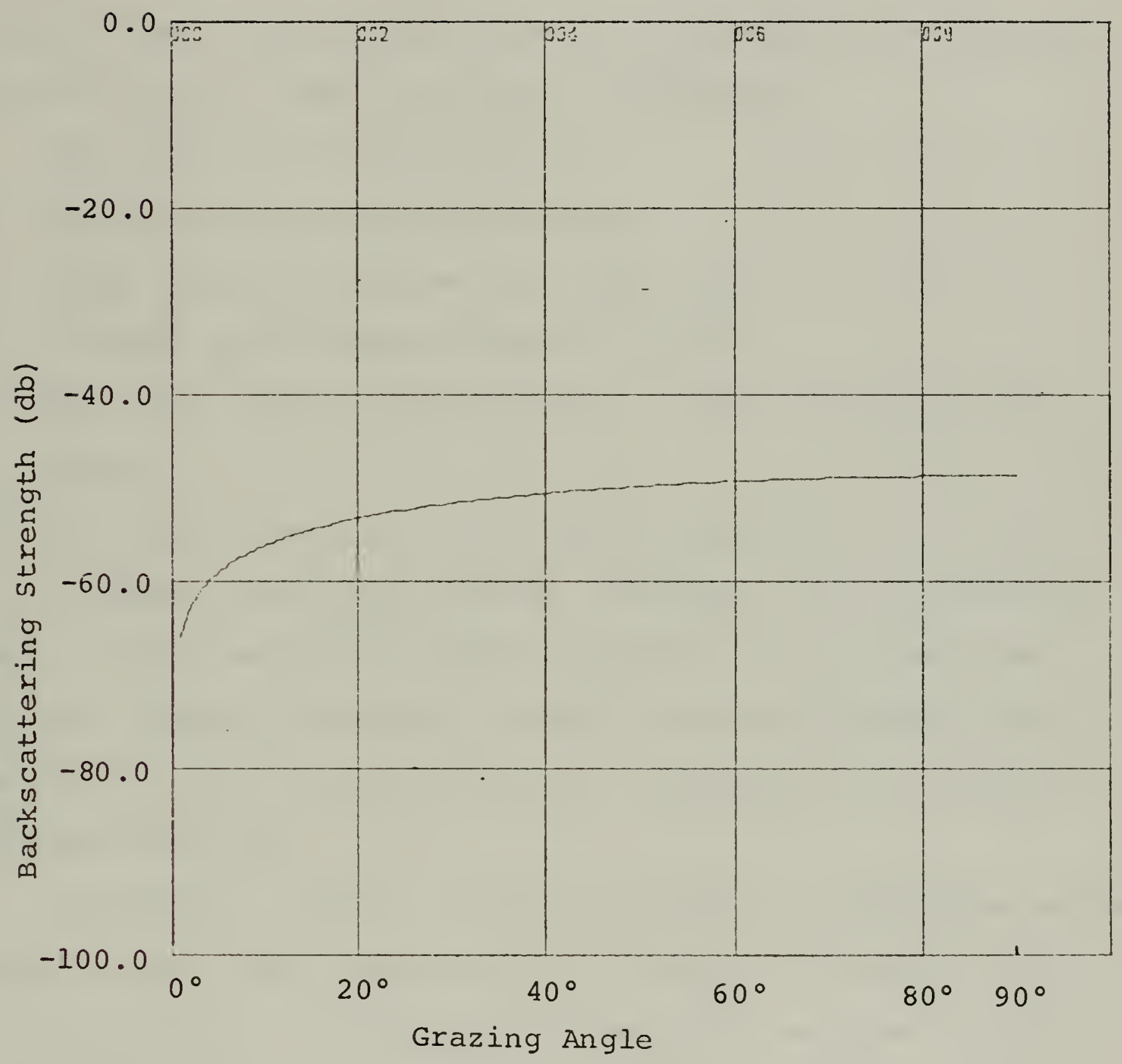

Figure 50. Surface Backscattering Strength Versus Grazing Angle Diagram for December. 

E. RAY DIAGRAMS

The ray diagrams for several months in the central part of the Black Sea are presented in Figures 51, 52, 53, 54, 55, 56, 57, and 58. The ray diagrams were obtained using a sophisticated digital ray trace program from Fleet Numerical Weather Central (FNWC), Monterey, California.

Data inputs to the program are:

1. Acoustic source depth is 20 feet.

2. Sound velocity profiles from Table VI.

3. A smooth flat bottom of depth 2,000 m.

4. Rays with source angles between -2 and +20 degrees are traced.

5. Rays were traced out to a maximum range of $34 \mathrm{~N}$. Miles. A tynical winter ray diagram (February) for the contral part of the Black Sea is shown in Figure 51. As mentioned earlier, during the winter, a positive sound velocity gradient exists from surface to bottom. Therefore, all rays are refracted upwards.

In February, between -2 and +16 degrees transmission angle, sound reaches long ranges only by repeated reflections from the sea surface, to which it is repeatedly returned by upward refraction (Refracted Surface - Reflected) path. The refraction is strong in the upper layers and 290 feet is the maximum depth to penetration for rays having an angle of depression less than $6^{\circ}$ resulting in duct like propogation in the upper layers. This surface duct would be uniformly in sonified for frequencies above $207.34 \mathrm{~Hz}$, the cutoff frequency. 

Beyond $\mathrm{a}+16$ degrees angle, bottom incident sound rays are reflected. The transmission angles between +16 and +20 degrees reach the bottom with incident angles of 76 $83^{\circ}$. Therefore, almost 100 percent of the initial transmit.ted energy would be available in the upper layers. (According to Table IX). However, beyond the $21^{\circ} 55^{\prime}$ degrees transmission angle, the rays would be strongly absorbed in the sea bottom.

Horizontal range from the source to the first surface reflection is 39,020 yd for the +14 degrees transmission angle in February.

Similar sound ray propagation is seen during March. The bottom reflectivity is unity beyond the critical angle $\left(73^{\circ}\right.$ 15'). And, at angles greater than 21\%51' sound energy will be strongly absorbed by the sea bottom.

Convergence zone formation exists only during early winter (Decenber), because at a well defined sound channel at depths of $50-75 \mathrm{~m}$ (Figure 58). Therefore, the ray that leaves the source between +2 and +10 degrees will be refracted downward at steep angles until it crosses the axis of the sound channel, after which it will be refracted upward until it is horizontal, finally turning upward and crossing the axis, arriving at the surface once again horizontally. The convergence $z$ one is composed of these rays which penetrate below the sound channel axis.

Convergence zone width with +2 to +10 degrees transmission angles in December is 17,204 yd and horizontal range from 

the source to the first surface reflection is 39,020 yd for +10 degrees transmission angle.

The transmission angles between +12 and +20 degrees reach the bottom with $84^{\circ} 02^{\prime}-72^{\circ} 29^{\prime}$ degrees incident angles. Therefore, bottom reflectivity is almost unity due to Table IX. The critical angle for December has been previously calculated as $69^{\circ} 50^{\prime}$, and after $23^{\circ} 00^{\prime}$ degrees transmission angle, sounc rays will be strongly absorbed in the sea bottom. In May, the convergence zone propogation is available with transmission angles between +2 and +10 degrees (Figure 53). The convergence zone width in May, between +2 and +10 degrees transmission angles is 22,564 yd and horizontal range: from the source to the first surface reflection is 34,361 yd for the $\div 10$ degrees ray.

The typical value of critical angle in May is $71^{\circ} 17^{\prime}$ and beyond 21 ${ }^{\circ} 58^{\prime}$ degrees transmission angle, bottom absorption will be important.

In summer (July-August), a very unique sound propogation occurs in the central part of the Black Sea. No refracted sound propogation is seen, and all rays that leave the source at any angle are reflected from the bottom of the sea. The reason is a strong surface negative velocity gradient. So the sourd level near the surface decreases rapidly in a horizontal direction away from the source. Thus resulting in shadow zone formation (Figures 55 and 56 ).

The critical angles for July and August have been previously calculated $73^{\circ} 15^{\prime}$ and $73^{\circ} 14^{\prime}$ (Table IX). Therefore, 

all the rays leaving the source beyond $17^{\circ} 17^{\prime}$ and $16^{\circ} 38^{\prime}$ transmission angles would be strongly absorbed. Therefore, little bottom reflected energy would be available in the upper layers.

During the fall, in November, sound propagation paths are the same as in December. A well defined convergence zone occurs within 20 miles of the source, and its width is 10,148 yd wi.th +2 to +8 degrees transmission angle.

In November, the bottom reflected sound propagation commence with transmission angle between +8 and +10 degrees. Beyond this transmission angle, all sound rays reflect from the bottom. A sound ray leaving the source at less than 2103' transmission angle will mostly reflect. The critical angle in înoveriber is $71^{\circ} 15^{\prime}$. 



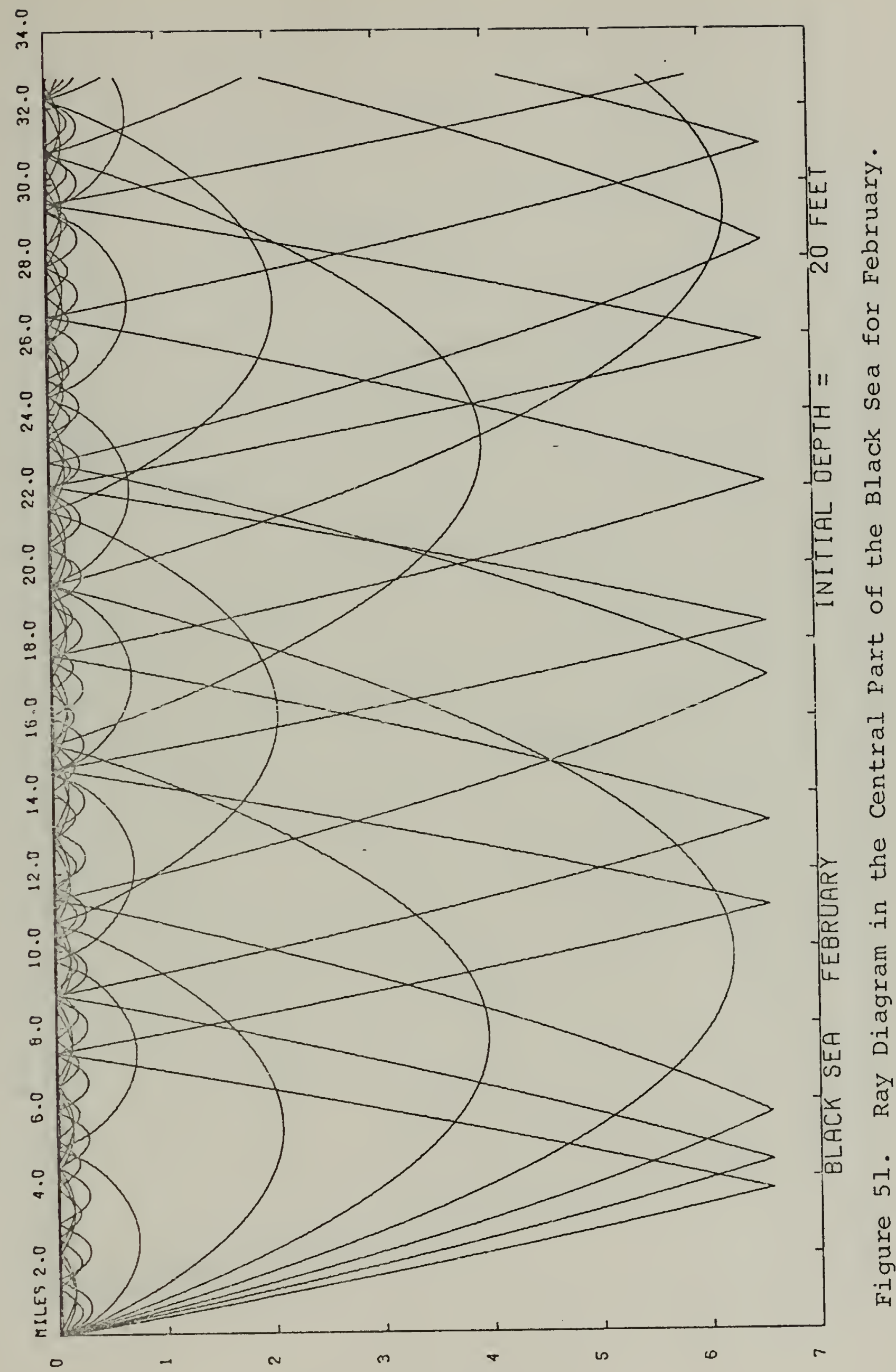

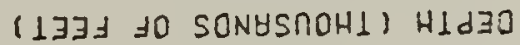





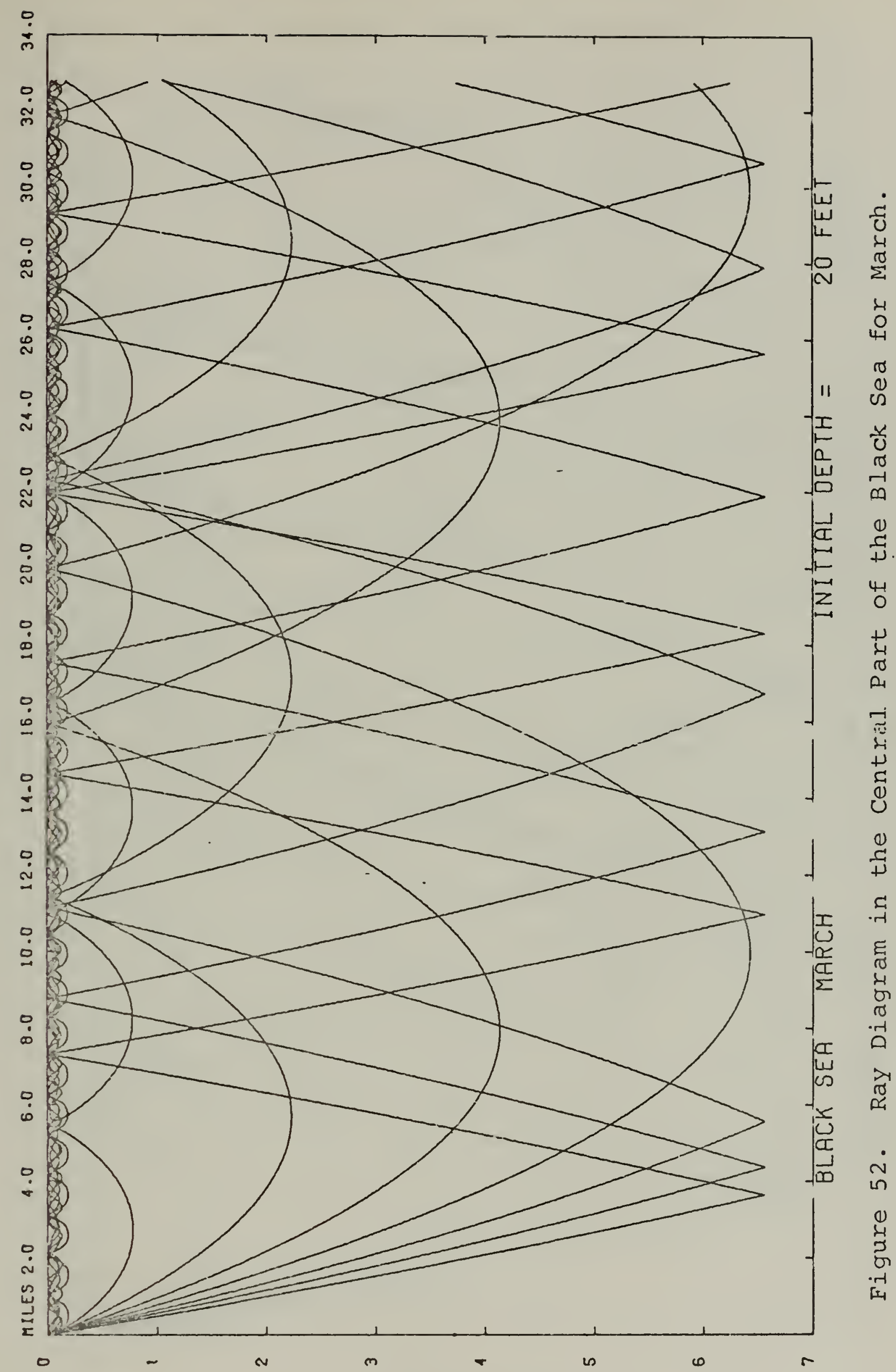

(133f to SONYSNOHI) HId3O 



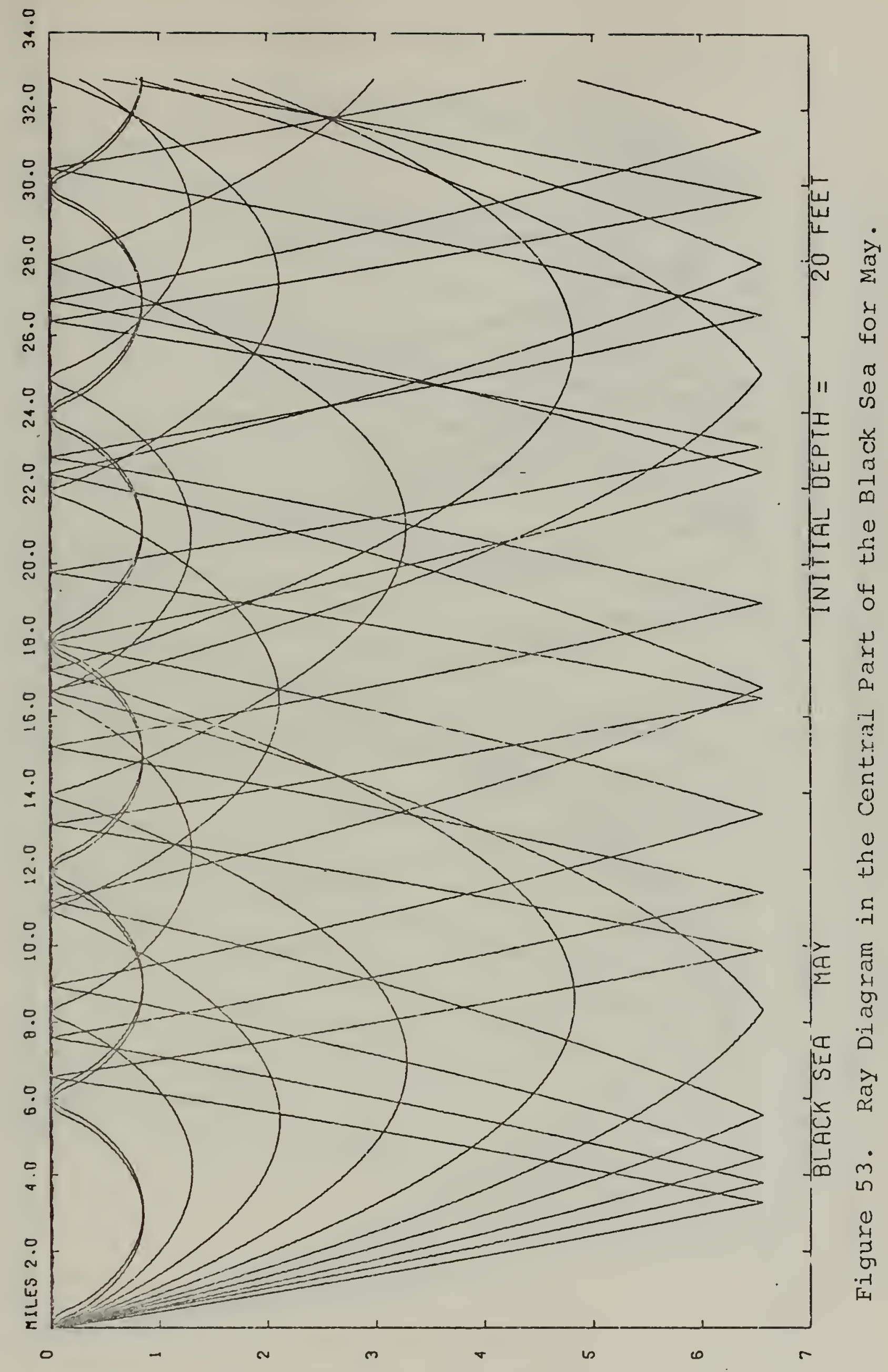

(1.jaA JO SONGSOOHL HIdJO 



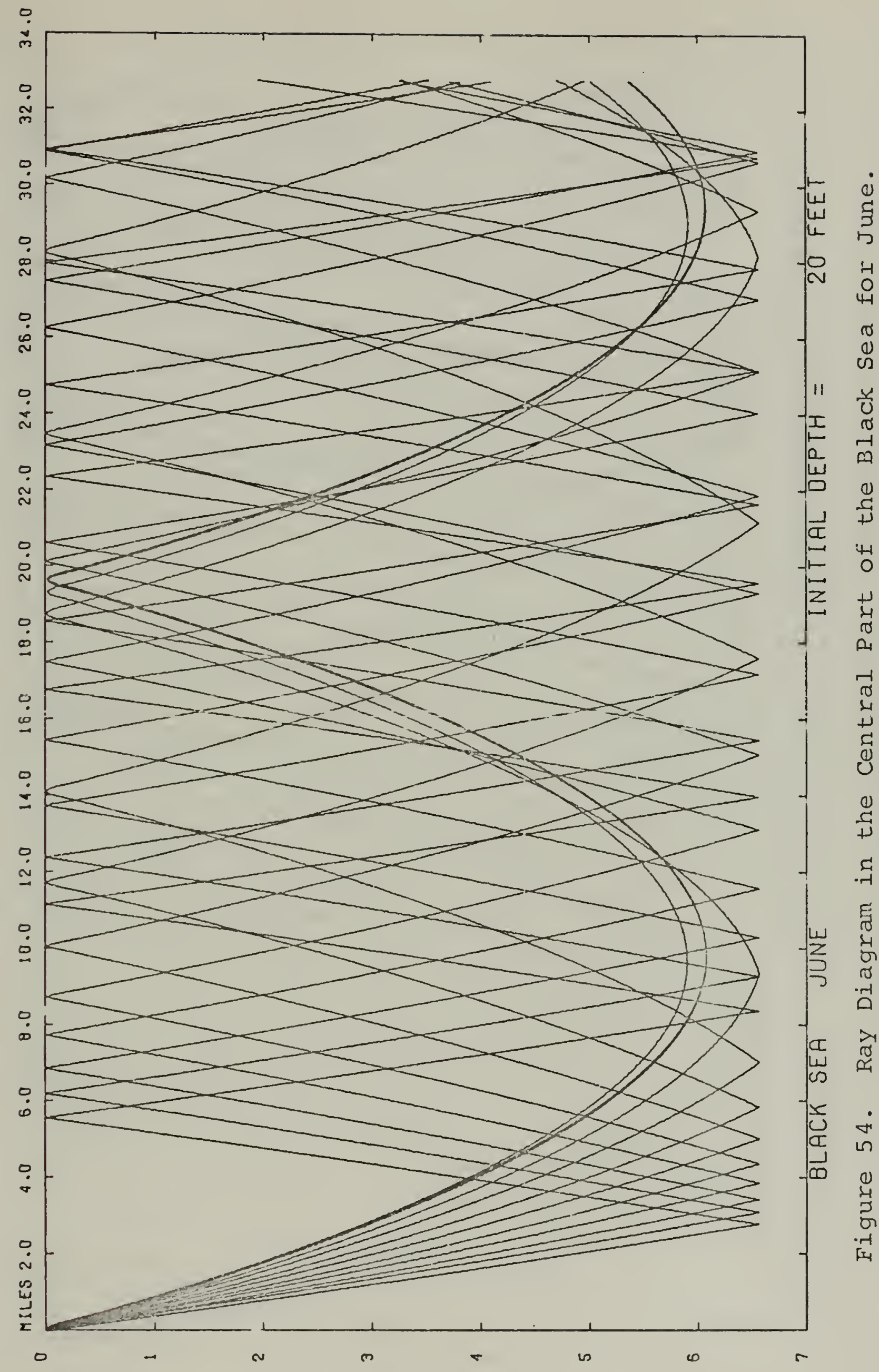

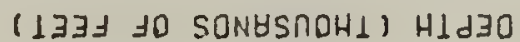





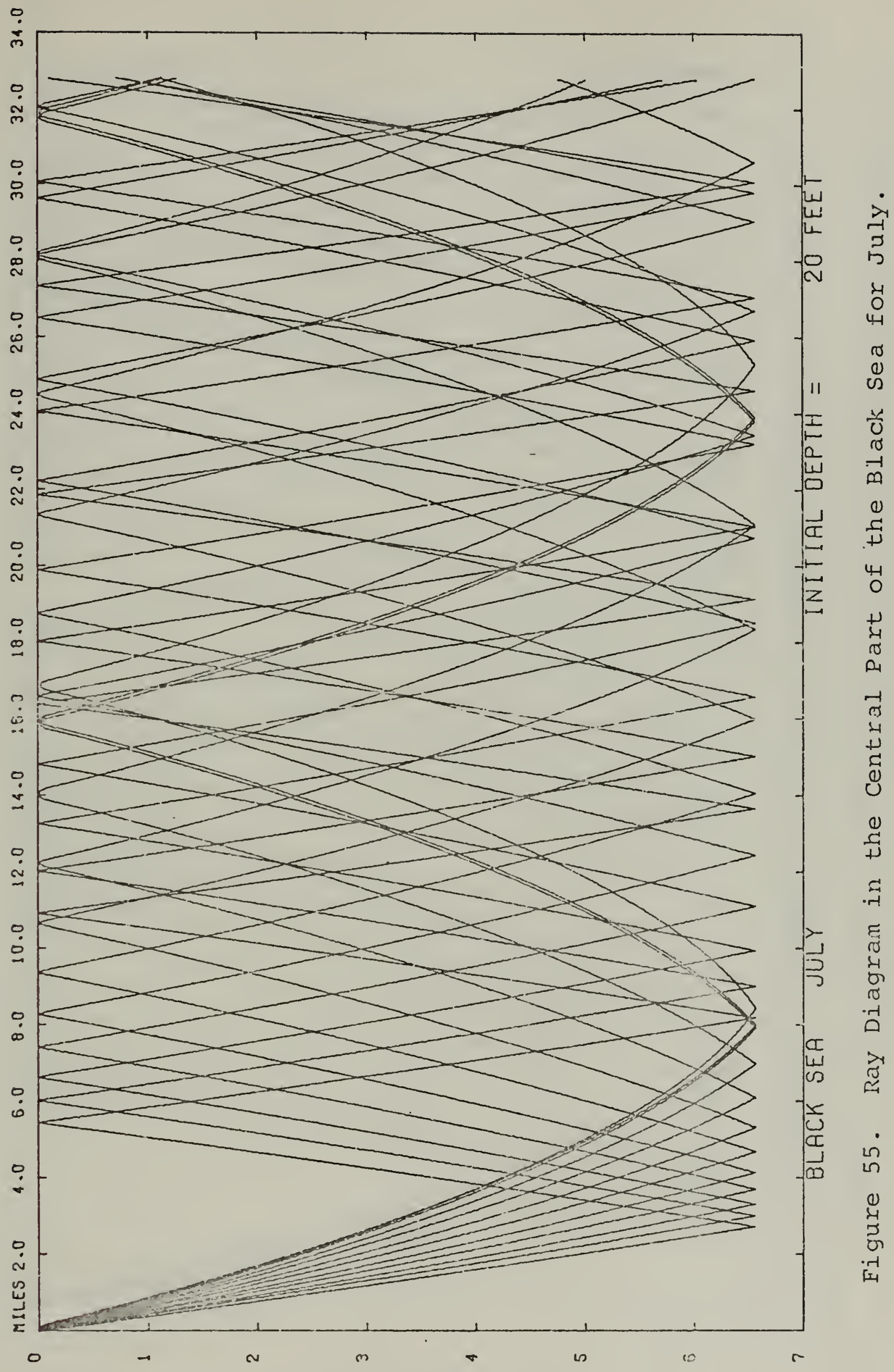

(1331 SD SONGSกDHA) HId 30 



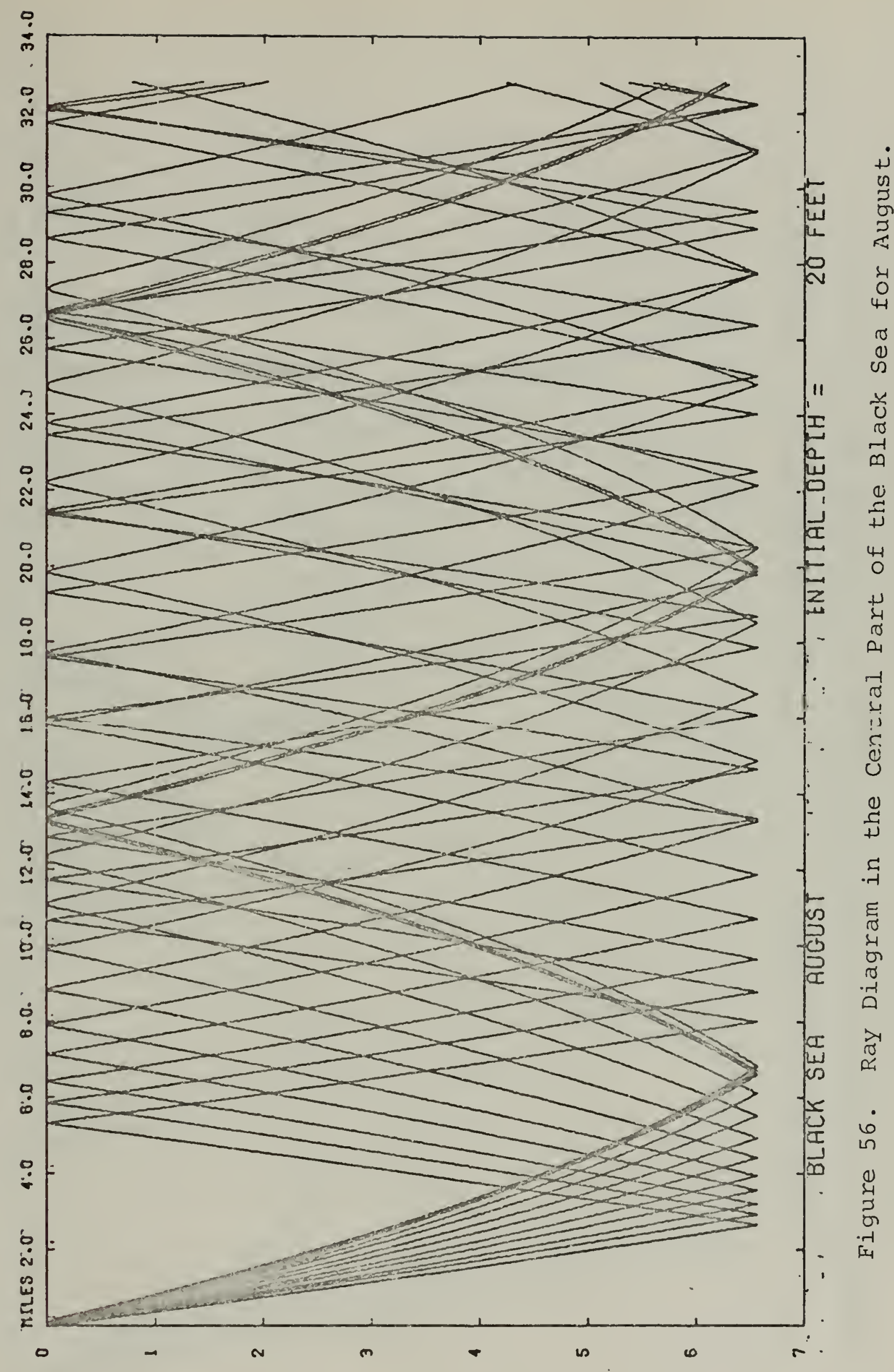

(122A 20 SONGSNOHI) HIdヨD 



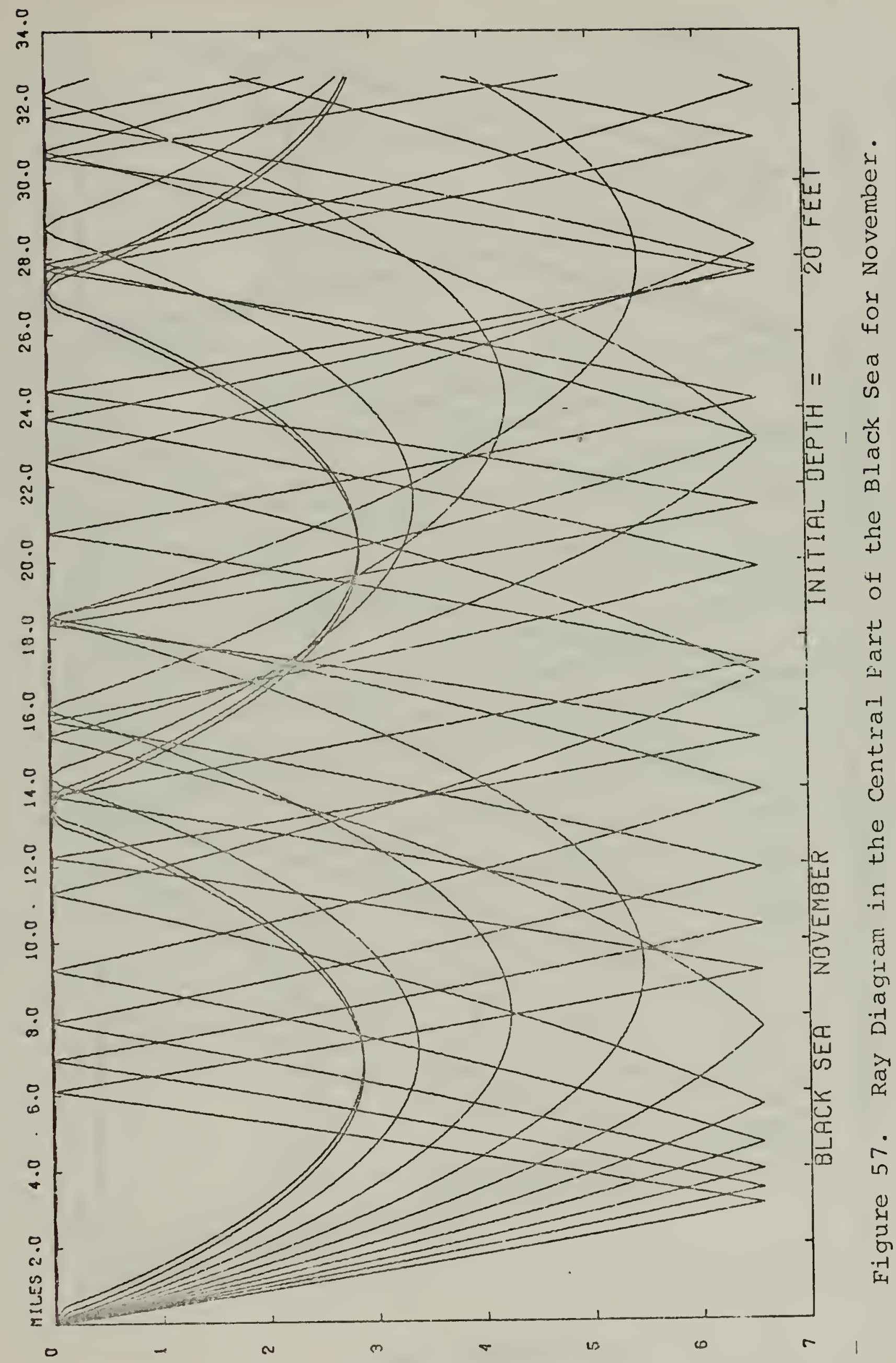

(133」 tO SONGSกOHL) H. $\$ 30$ 



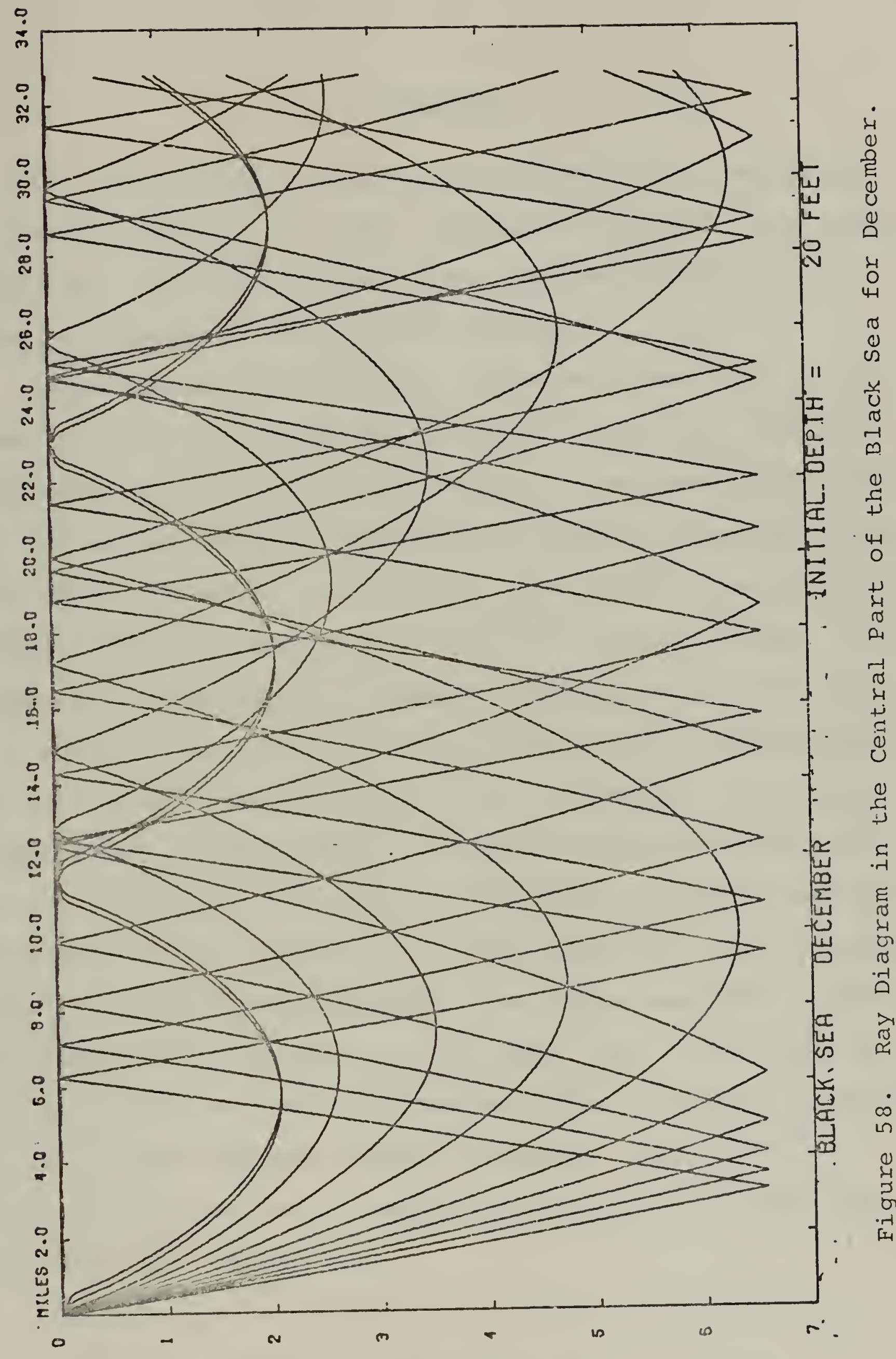

(1JZ3 JO SONUSNOHL) KLd 30 


\section{CONCLUSION}

The propogation of sound in the Black Sea is dependent on several factors, the most important of which is the sound velocity structure. Another most important factor is the characteristics of the bottom sediments.

Large seasonal temperature variations occur only in the upper layer of the Black Sea (Figures 17 and 18). Maximum variation i.s seen at the surface and it decreases with depth. At the surface; maximum and minimum temperatures occur during the months of August and February. The temperature difference between these two months is $17.07^{\circ} \mathrm{C}$ at the sea surface. But, below $125 \mathrm{~m}$ : the maximum seasonal temperature variation is not greater than $0.22^{\circ} \mathrm{C}$. The salinity variation with season in the central part of the Black Sea is not as important as temperature. Large seasonal salinity variations occur only in the vicinity of the coast. Therefore, the sound velocity structure in the central part of the Black Sea strictiy depends upon the temperature variation. So, large amplitude sound velocity variations occur in the upper layer to a depth of $125 \mathrm{~m}$. At the sea surface, maximum sound velocity variation is 56 . $1 \mathrm{~m} / \mathrm{sec}$ between summer and winter. Below $125 \mathrm{~m}$, maximum variation is not more than $1 \mathrm{~m} / \mathrm{sec}$ at the same depth for each month (Table VII).

The Black Sea exhibits a well defined sound channel at 50 - 75 meters caused by a cold intermediate linyer. Therefore, a convergence zone occurs during the months of May, 

November and December at which time sound velocity near the bottom exceeds that near the surface. The range of rays comprising the convergence zones during these three months were found from ray diagrams (Figures 53, 57 and 58). According to these diagrams, the maximum and minimum convergence zone widths are 22, 564 yd in May and 10,148 yd in November.

At very low frequencies, sound ceases to be trapped in the mixed layer or in any sound channel. This occurs when the frequency approaches the cutoff frequency. These cutoff frequencies in the Black Sea were computed and were presented in Table $\mathrm{X}$. According to these results, high cutoff frequency is seen during the month of July when the surface duct is thin and the surface roughness is smail due to jow mean wind speeds. Therefore, the minimum useful sonar frequency must be higher than $5,558.92 \mathrm{~Hz}$ to cover all seasons.

Iittle is known about the bathymetry and the distribution of bottom sediments, and the physical properties of bottom sediments are not known for the Black Sea. Eor this reason, the bottom reflectivity and critical angles were calculated using several assumptions. These assumptions were given in Chapter IV. According to Arkhangel'skiy, the central part of the Black sea is mostly covered with gray clay and mud. Therefore very poor bottom reflective conditions exist. From earlier calculation, the bottom critical angles range from $69^{\circ} 40^{\prime}$ to $73^{\circ} 19^{\prime}$ (Table IX). So, any sound ray striking the bottom with an angle less than critical will be partly 

reflected. These reflection coefficients were given in Table IX.

Finally, monthly ray diagrams were given in Figures 51 through 58. It can be seen from these figures, that very unique sound propagation occurs in the central part of the Black Sea during the summer (July-August). The reason is a strong surface negative velocity gradient. No refracted surface reflected sound propagation is seen for the -2 to $+20^{\circ}$ rays and all rays that leave the source between these angles are reflected from the bottom, resulting in a large shadow zone formation in the summer (Figures 55 and 56). 

Appendix A

\section{COMPUTATION OF SOUND VELOCITY}

The computation of sound velocity in the sea depends on the physical properties of sea water (temperature, salinity, and pressure).

In some cases, the sound velocity profile for a particular area of the sea is determined from the temperature and salinity versus depth measurement through the use of existing tables such as those of Matthews. However for this thesis, Wilson's equation is used to compute the sound velocities [19]. The component equations are shown below:

$$
\begin{aligned}
& \mathrm{V}=1449.14+\mathrm{V}_{\mathrm{T}}+\mathrm{V}_{\mathrm{P}}+\mathrm{V}_{\mathrm{S}}+\mathrm{V}_{\mathrm{STP}} \\
& V_{T}=4.5721 \mathrm{~T}-4.4532 \times 10^{-2} \mathrm{~T}^{2}-2.6045 \times 10^{-4} \mathrm{~T}^{3} \\
& +7.9851 \times 10^{-6} \mathrm{~T}^{4} \\
& \mathrm{~V}_{\mathrm{P}}=1.60272 \times 10^{-1} \mathrm{P}+1.0268 \times 10^{-5} \mathrm{P}^{2} \\
& +3.5216 \times 10^{-9} \mathrm{P}^{3}-3.3603 \times 10^{-12} \mathrm{P}^{4} \\
& V_{S}=1.39799(S-35)+1.69202 \times 10^{-3}(S-35)^{2}
\end{aligned}
$$





$$
\begin{aligned}
\mathrm{V}_{\mathrm{STP}}= & (\mathrm{S}-35)\left(-1.1244 \times 10^{-2} \mathrm{~T}+7.711 \times 10^{-7} \mathrm{~T}^{2}+7.7016 \times 10^{-5} \mathrm{P}\right) \\
& \left.-1.2943 \times 10^{-7} \mathrm{P}^{2}+3.1580 \times 10^{-8} \mathrm{PT}+1.5790 \times 10^{-9} \mathrm{PT}^{2}\right) \\
& +\mathrm{P}\left(-1.8607 \times 10^{-4} \mathrm{~T}+7.4812 \times 10^{-6} \mathrm{~T}^{2}+4.5283 \times 10^{-8} \mathrm{~T}^{3}\right) \\
& +\mathrm{P}^{2}\left(-2.5294 \times 10^{-7} \mathrm{~T}+1.8563 \times 10^{-9} \mathrm{~T}^{2}\right)+\mathrm{P}^{3}\left(-1.9646 \times 10^{-10} \mathrm{~T}\right)
\end{aligned}
$$

Where,

$$
\begin{aligned}
\mathrm{V}= & \text { Velocity of sound in meters per second } \\
\mathrm{V}_{\mathrm{T}}= & \text { Velocity for temperature influence } \\
\mathrm{V}_{\mathrm{P}}= & \text { Velocity for pressure influence } \\
\mathrm{V}_{\mathrm{S}}= & \text { Velocity for salinity influence } \\
\mathrm{V}_{\mathrm{STP}}= & \text { Velocity for interaction of temperature, } \\
& \text { salinity and pressure influence }
\end{aligned}
$$

The entering arguments and their units and ranges are shown be iow:

$\begin{array}{lll}\text { Temperature } & \text { Degrees centigrade } & -4<\mathrm{T}<30 \\ \text { Salinity } & \text { Parts per mille } & 0<\mathrm{S}<37 \\ \text { Pressure } & \begin{array}{l}\text { Kilogram per square } \\ \text { centimeter }\end{array} & 1<\mathrm{P}<1000\end{array}$

The computer program was used to compute sound velocity profiles for given station. And the profiles of sound velocity versus depth are drawn by means of a subroutine (CALL DRAW). The main program listing is shown in Appendix B . 



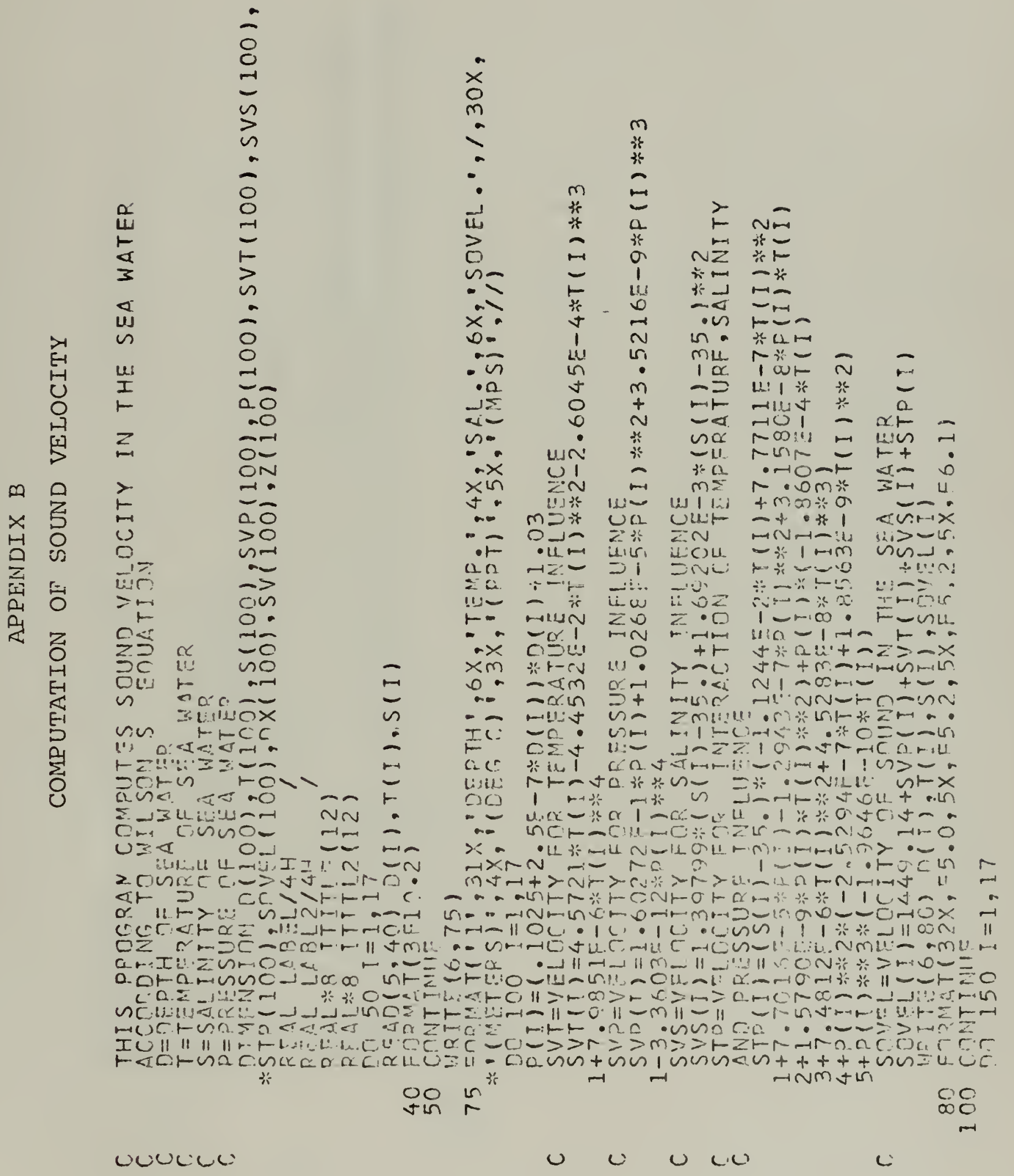





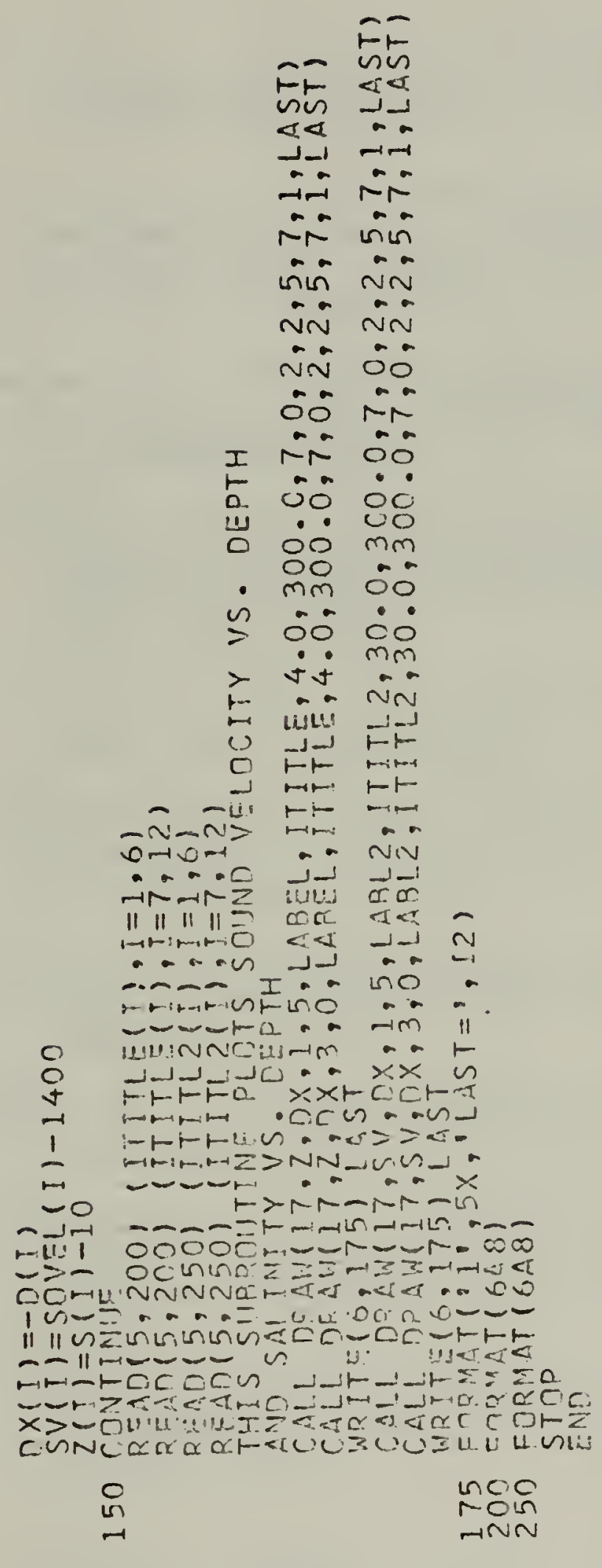

w 
G० $651 . \geqslant 9$

sibilises 


\section{LIST OF REFERENCES}

1. Caspers, H., "Black Sea and Sea of Azov," In Treatise on Marine Ecology and Paleoecology, V. $\overline{1}, \mathrm{p} .801-$ 802,30 December 1957.

2. Goncharov, V. P., Yemel'yanova, L. P., Mikhaylov, O. V., and Tsyplev, Yu. I., "Areas and Vol.umes of the Mediterranean and the Black Sea," Oceanology, V. 5, No. $6, p .38-43,1965$.

3. Caspers, H., "Black Sea and Sea of Azov," In Treatise on Marine Ecology and Paleoecology, V. $1, \mathrm{p} .808,827-829$ 30 December 1957.

4. Novitsky, V. P., Vertical Structure of Water and Gereral Features of water Circulation in the Black Sea, paper presented at U.S. Naval Oceanographic Office, Trans. 405, 1968.

5. Filippov, D. M., "The Cold Intermediate Layer in the Black Sea," Oceanology, V. 5, No. 4, p. 47-51: 1965.

6 . Vladimirtscy, Yu. $\lambda .$, " $\lambda$ n Investigation of Mixing Processes in the Black Sea," Okeanologiya, V. 1, No. 6, p. 976-982, 1961 .

7. Neumann, G., The Black Sea on Oceanographic Summary, paper presented at U.S. Naval Oceanographic Office, Trans. 139, 1961.

8. "Weyl, P. K., Oceanography on Introduction to the Marine Environment, p. 206, Wiley, 1970 .

9. Liebermann, L. N., "Reflection of Sound from Coastal Sea Bottom," The Journal of the Acoustical Society of America, v. 20, No. 3, p. 305-309, May 2948.

10. Nafe, J. E., and Drake, C. I., Physical Properties of Marine Sediments, paper presented at Lamont Geological observatory (Columbia University) Contribution No. 598, 1961 .

11. Kinsler, L. E., and Frey, A. R., Fundamentals of Acoustics, 2nd Ed., p. Kis 45, Wiley, 1962.

12. Kinsler, I. E. and Frey, A. R., Fundamentals of Acoustics, 2nd Ed., p. 144, Wiley, 1962. 

13. Urick, R. J., Principles of Underwater Sound for Engireers, p. 187-189, MCGraw-Hill, 1967.

14. Urick, R. J., Principles of Underwater Sound for Engineers, p. 216, McGraw-Hill, 1967 .

15. Urick, R. J., Principles of Underwater Sound for Engineers, p. 125, McGraw-Hill, 1967.

16. The Chief of Naval Operations Specification NAVAIR 50-1C-5I, Components of the 1000-Mb. Winds of the Northern Hemisphere, I September 1966.

17. Zenkovich, V. P., Morphology and Dynamics of the Soviet Coast of the Black Sea, paper presented at U.S. Naval Oceanographic Ofice, Trans. 141, 1962.

18. Barkovskaya, M. G., Reglularities in the Distribution of Bottom Sediments on the shelf of the soviet coast of the Elack Sea, paper presented at U.S. Naval Oceanographic Office, Trans, 250, 1965.

19. Wilson, W. D., "Equation for the speed of Sound in sea Water," The Journal of the Acoustical Society of Amexica, V. 32, No. 10, p. 1357, October 1960.

20. Urick, R. J., Principles of Underwater Sound for Engineers; Q. 195, Mcgrawiin, 1967 . 

1. Library, Code 0212

Naval Postgraduate School

Monterey, California 93940

2. Department of Oceanography, Code 58

Naval Postgraduate School

Monterey, California 93940

3. Dr. W. W. Denner

Department of Oceanography

Naval Postgraduate School

Monterey, California 93940

4. Dr. R. S. Andrews

Department of Oceanography

Naval Postgraduate School

Monterey, California 93940

5. Deniz Kurvettori Komutanligi

PersoneI Égtim Sb. Muduriugu

Ankara, Turkey

6. Dz. Kuv. Seyir ve Hidrografi Dairesi Bsk.

Cubuklu, Istanbul

Turkey

7. Istanbul Teknik Universitesi

Taskisla, Istanbul

Turkey

8. Orta-Dogu Teknik Universitesi

Ankara, Turkey

9. Dz. Yzb. Yavuz Ergengil

Muhtesip Iskender Mah.

Akseki Cad. No. 24

Fatih, Istanbul - Turkey

10. Defense Documentation Center

Cameron Station

Alexandria, Virginia 22314 

Unclassified

Secumity Classificatior.

DOCUMENT CONTROL DATA.R\& D

(Securtly classification of tille, body of abstract and indexing amnotation nust be entered when the overall report is classilied)

ORIGINATING ACTIVITY (Corporace author)

Naval Postgraduate School

Monterey, California 93940

2a. REFORT SECURITY CLASSIFICATION

2b. GROUP

Unclassified

3 REPORT TITLE

THE SOUND PROPAGATION CONDITIONS IN THE BLACK SEA

4. OESCRIPTIVE NOTES (TYPe of report and, inclusive dates)

Master's Thesis; September 1971

5. AUTHORISI (FIrst name, middle inilial, last name)

Yavuz Ergengil

Lieutenant, Turkish Navy

\begin{tabular}{|c|c|c|}
\hline $\begin{array}{l}\text { O. REPCRT DATE } \\
\text { September } 1971\end{array}$ & $\begin{array}{r}\text { 70. TOTAL NO CF DAGES } \\
120\end{array}$ & $\begin{array}{c}\text { 7b. NO. DF REFS } \\
20\end{array}$ \\
\hline $\begin{array}{l}\text { B. CONTEACT OR GRANT NO. } \\
\text { b. PROJECT NO. }\end{array}$ & 9a. ORIGINATOR'SREPOR & ER(S) \\
\hline c. & $\begin{array}{l}\text { Ob. OTHEA REPORT NO(S) } \\
\text { (his ropost) }\end{array}$ & her numbore tha: may bo asslened \\
\hline
\end{tabular}

10. DISTRIBUTION STATEMENT

Approved for public release; distribution unlimited.

11. SUPPLEMENTARY NOTES

12. SPONSOFING MILITARY ACTIVITY

Naval Postgraduate School

Monterey, California 93940

The sound propagation conditions in the central part of the Black Sea were investigated. Profiles of temperature and saliniᄃy were generated by averaging data from the U.S. National Oceanographic Data Center over monthly periods. Wilson's equation was used to compute sound velocities and a digital computer program provided plots of sound velocity versus depth and selected ray trace diagrams.

Seasonal temperature, salinity and sound velocity variations are found only in the upper layer of the Black Sea. Below $125 \mathrm{~m}$, seasonal variations are insignificant.

A well defined sound channel exists in the Black sea that is caused by a cold intermediate layer. Therefore, a seasonal convergence zone is observed during the months of May, November and December.

Finally, bottom reflectivity was calculated by Rayleigh's formula and surface backscattering strength was calculated according to Schulkin and Shaffer. 

Temperature

Salinity

Sound velocity

Ray diagrams

Black Sea sound propagation conditions 







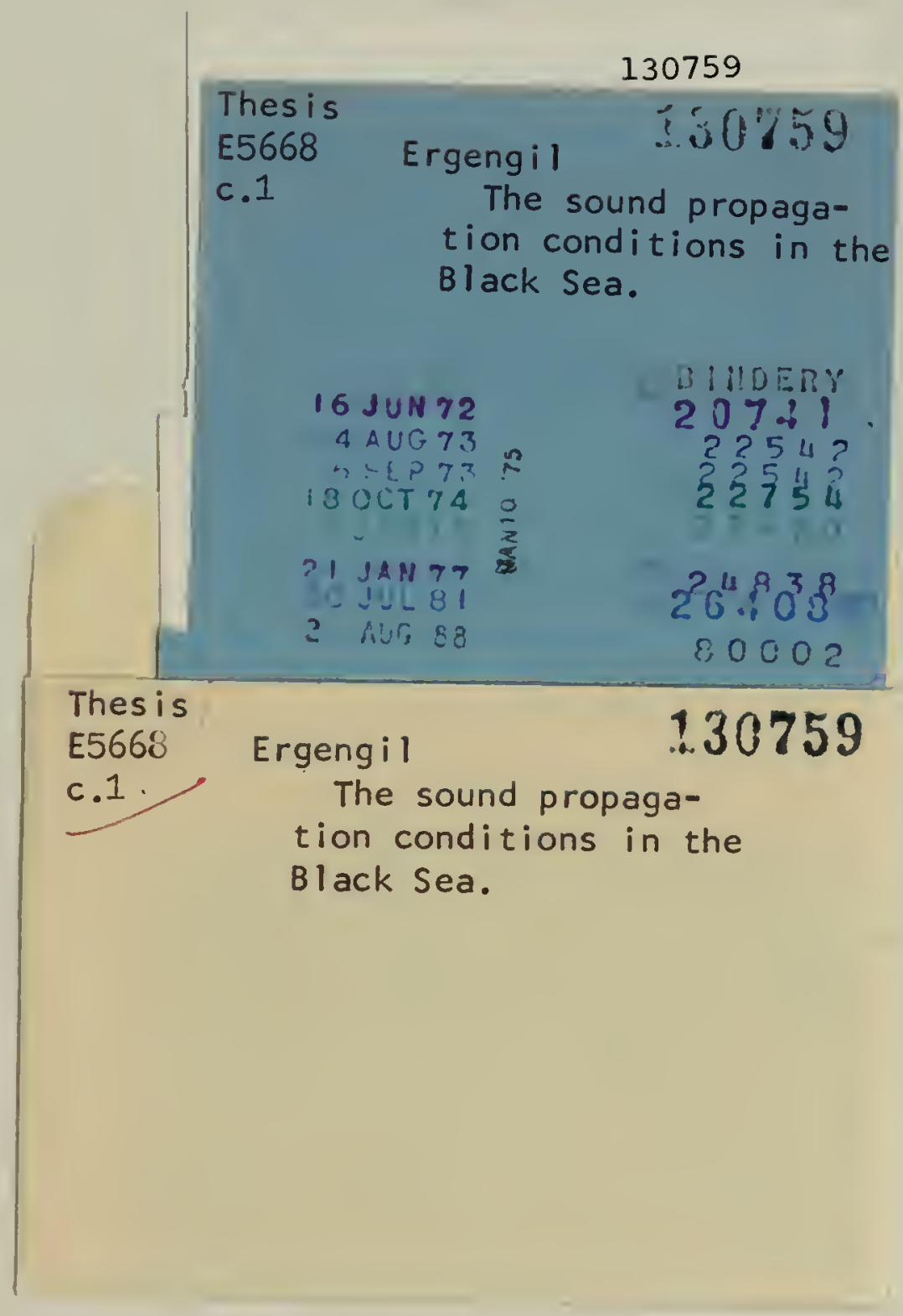


